UNIVERSIDADE DE SÃO PAULO

INSTITUTO DE FÍSICA DE SÃO CARLOS

FERNANDO MASSAYUKI TSUTAE

\title{
Processos ópticos e interação entre nanopartículas e sistemas moleculares
}





\title{
Processos ópticos e interação entre nanopartículas e sistemas moleculares
}

Dissertação apresentada ao Programa de Pós Graduação em Física do Instituto de Física de São Carlos da Universidade de São Paulo, para obtenção do título de Mestre em Ciências.

Área de Concentração: Física Aplicada

Orientador: Prof. Dr. Francisco E. G. Guimarães

\begin{abstract}
Versão corrigida
(versão original disponível na Unidade que aloja o Programa)
\end{abstract}

São Carlos

2011 


\section{AUTORIZO A REPRODUÇÃO E DIVULGAÇÃO TOTAL OU PARCIAL DESTE TRABALHO, POR QUALQUER MEIO CONVENCIONAL OU ELETRÔNICO, PARA FINS DE ESTUDO E PESQUISA, DESDE QUE CITADA A FONTE.}

Tsutae, Fernando Massayuki

Processos ópticos e interação entre nanopartículas e sistemas moleculares /Fernando Massayuki Tsutae; orientador Francisco Eduardo Gontijo Guimarães.-- versão corrigida --São Carlos, 2011.

$87 \mathrm{p}$.

Dissertação (Mestrado em Ciências - Área de concentração: Física Aplicada) - Instituto de Física de São Carlos da Universidade de São Paulo.

1. Porfirinas. 2. Dióxido de titânio. 3. Fotodegradação. 4. Adsorção. I. Título. 




\section{AGRADECIMENTOS}

Aos meus pais, que sempre acreditaram em mim. Obrigado pelo amor, pela paciência, pela educação que me deram e pelos inúmeros sacrifícios que fizeram para que nada me faltasse. Sou muito grato pelos seus esforços e prometo que todos eles serão recompensados. Vocês sempre estiveram e estarão presentes no meu coração.

Aos meus avós e ancestrais pela coragem de vir do outro lado do mundo e encarar uma terra desconhecida em busca de uma vida melhor aos meus familiares. Um sincero obrigado à vocês.

A minha namorada Michelle pelo amor, paciência, compreensão e pela alegria que trouxe à minha vida.

Aos meus amigos, Sebastião, Anderson, Netto, Jeison, Douglas, Fernando Bambozzi e Gustavo Vilaça. Obrigado pelos bons momentos, pelo apoio e amizade.

Aos meus amigos de grupo Regina, Danilo, Luís, Aroldo, Angelo, Nirton, Mike, Fernando e Gustavo. Obrigado pela companhia, ajuda e amizade.

Ao grupo de polímeros pela estrutura laboratorial e boas condições de trabalho Aos técnicos, Débora, Bruno, Níbio e Aroldo pela assistência e suporte.

Ao grupo de Biofotônica do IFSC pela parceria e colaboração.

Ao professor Ernesto Pereira e aos doutores Adriano Rebello e Adriane Rosário por fornecer parte do meu material de trabalho e pelas críticas construtivas.

Ao professor Francisco Guimarães pela orientação, dedicação e boas idéias.

Ao $C N P q$ pela ajuda financeira. 



\section{RESUMO}

TSUTAE, F. M. Processos ópticos e interação entre nanopartículas e sistemas moleculares. 2011. 87 p. Dissertação (Mestrado) - Instituto de Física de São Carlos, Universidade de São Paulo, São Carlos, 2011.

A transferência de carga entre adsorbatos moleculares doadores e nanopartículas (NPs) semicondutoras aceitadoras têm encontrado extensivas aplicações recentes em células fotovoltaicas e de combustíveis, em fotocatálise e em eletrônica molecular. Além disso, NPs têm sido usadas como suporte para reagentes moleculares, fotosintetizadores e fármacos para variados fins. A eficiência destes dispositivos moleculares depende do estudo detalhado da dinâmica de transferência de carga na interface entre uma NP e moléculas adsorvidas e, em particular, da transferência lateral de energia entre moléculas adsorvidas. Além disso, é necessário otimizar de um lado a atração Coulombiana entre doadores oxidados e aceitadores reduzidos e por outro lado as reações de ancoramento de modo que elas não fiquem limitadas ao encontro estocástico e difuso em solução. Em especial, tem-se observado uma crescente demanda por dispositivos fotovoltaicos híbridos construídos a partir de NPs de dióxido de titânio $\left(\mathrm{TiO}_{2}\right)$. Estudos de estabilidade à longo prazo e modificações na interface de tais dispositivos são essenciais para se obter uma melhor eficiência. Também já é bem conhecida na literatura o uso de NPs de $\mathrm{TiO}_{2}$ como uma alternativa na degradação de corantes e tratamento de efluentes. Outra classe de estudos igualmente importante consiste na aplicação de porfirinas e seus derivados na geração de oxigênio singleto e no tratamento de câncer. Portanto, é de grande interesse o estudo de sistemas baseados nas propriedades das porfirinas e $\mathrm{TiO}_{2}$. O presente trabalho de mestrado teve como objetivo o estudo por técnicas espectroscópicas a) da adsorção de moléculas de porfirina emissora de luz na superfície de NPs semicondutoras de $\mathrm{TiO}_{2}$, b) dos processos ópticos envolvidos na transferência de carga e de energia na interface entre NP aceitadora e as porfirinas doadoras adsorvidas e do efeito da NP na fotoestabilidade e fotodegradação da porfirina. Em nosso estudo, escolhemos uma porfirina (Photogem ${ }^{\circledR}$ ou PG) como padrão de sistema molecular, pois apresenta bandas de absorção e emissão bem definidos. Foram utilizadas séries distintas de NPs de $\mathrm{TiO}_{2}$ com diferentes razões de área superficial por volume e porcentagens das fases predominantes rutilo e anatase preparadas sob diversas condições pelo método dos precursores poliméricos. Desenvolvemos um método que consiste na centrifugação das NPs juntamente com as 
moléculas adsorvidas e posterior analise óptica da solução sobrenadante para estudar a adsorção das porfirinas na superfície do $\mathrm{TiO}_{2}$. Observamos que NPs de $\mathrm{TiO}_{2}$ com predominância da fase anatase em sua estrutura possui maior interação e, consequentemente, maior adsorção molecular. A fase rutilo possui baixa adsorção molecular por ser extremamente estável. A afinidade e interação entre porfirina e partículas de $\mathrm{TiO}_{2}$ em solução foram analisadas para diferentes valores de $\mathrm{pH}$. Também foram estudados efeitos da agregação e cobertura molecular nos processos de fotodegradação e de transferência lateral de energia entre moléculas adsorvidas.

Palavras-chave: Porfirinas. Dióxido de Titânio. Fotodegradação. Adsorção. 


\begin{abstract}
TSUTAE, F. M. Optical processes and interactions between nanoparticles and molecular systems. 2011. 87 p. Dissertação (Mestrado) - Instituto de Física de São Carlos, Universidade de São Paulo, São Carlos, 2011.
\end{abstract}

Actually, charge transfer processes between molecular adsorbate donors and semiconductor nanoparticles (NPs) acceptors have found extensive applications in photocatalysis, photovoltaics cells and molecular electronics. Moreover, NPs have been used as carrier by molecular reagents, photosynthesizing and drugs for various purposes. The efficiency of these molecular devices depends on the detailed study of the dynamics of charge transfer at the interface between NPs and adsorbed molecules and, in particular, the lateral energy transfer between adsorbed molecules. Furthermore, it is necessary to optimize the Coulomb attraction between oxidized donors and reduced acceptors as well as anchoring reactions so that they are not limited by stochastic and diffuse interaction in solution. In particular, there has been a growing demand for hybrid photovoltaic devices based on nanoparticles of titanium dioxide $\left(\mathrm{TiO}_{2}\right.$-NPs). Studies of long-term stability and interface modification are essential to obtain devices with better efficiency. Also well known in literature it is the employ of $\mathrm{TiO}_{2}-\mathrm{NPs}$ as an alternative in dye degradation and wastewater treatment. Another class of important study is based on the application of porphyrins and their derivatives in the generation of singlet oxygen and treatment of cancer. Thus, it is of great interest the study of systems based on porphyrin and $\mathrm{TiO}_{2}$ properties. The present work had as objective the study by spectroscopic technics: a) the adsorption of a light-emitting porphyrin on the $\mathrm{TiO}_{2}-\mathrm{NPs}_{\text {surfaces, }}$ ) optical processes involved in charge and energy transfer in the interface between NP acceptor and porphyrins donors and the effect of NP on the photostability and photodegradation of porphyrins. In our study, we chose a porphyrin (or PG Photogem $®$ ) as standard molecular system, because it shows well defined absorption and emission bands. We used $\mathrm{TiO}_{2}-\mathrm{NPs}$ which differ in area/volume ratios and in the percentage of rutile and anatase phases that predominates under different conditions of preparation by polymeric precursor method. We developed a method based on the centrifugation of the NPs with adsorbed molecules and subsequent optical analysis of the supernatant solution to study the adsorption of porphyrins on $\mathrm{TiO}_{2}$-NPs surfaces. We observed that $\mathrm{TiO}_{2}-\mathrm{NPs}$ with predominantly anatase phase in its structure has greater interaction and, consequently, higher molecular adsorption. The rutile phase has low molecular adsorption due to your great stability. The affinity and interaction 
between porphyrin and $\mathrm{TiO}_{2}$-NPs in solution were analyzed for different $\mathrm{pH}$ values. Other subjects discussed in this work include molecular aggregation effects and coverage during photodegradation and lateral energy transfer between adsorbed molecules.

Keywords: Porphyrins. Titanium Dioxide. Photodegradation. Adsorption. 


\section{LISTA DE FIGURAS}

Figura 1 - a) Estrutura da porfina; b) Estrutura básica das porfirinas

Figura 2 - Estrutura monomérica do $\mathrm{PG}^{5}$

Figura 3 - Diagrama de Jablonski referente aos principais processos óticos 24 envolvidos na excitação do PG

Figura 4 - Diagrama ilustrativo referente aos principais processos envolvidos nas reações do tipo I

Figura 5 - Diagrama ilustrativo referente aos principais processos envolvidos nas reações do tipo II

Figura 6 - Diagrama ilustrativo referente à absorção luminosa segundo a lei 26 de Lambert-Beer

Figura 7 - Figura ilustrativa do fenômeno de fluorescência (direita) e sua 28 supressão (esquerda)

Figura 8 - Representação esquemática de bandas de energia em materiais

Figura 9 - Diagrama esquemático dos principais processos e produtos da 31 fotocatálise em semicondutores

Figura 10 - Previsão do efeito de arraste variando a quantidade de PG. A 38 ordem e espaçamento entre as retas é apenas ilustrativo

Figura 11 - Previsão do efeito de arraste variando a quantidade de $\mathrm{TiO}_{2}$. A 40 ordem e espaçamento entre as retas é apenas ilustrativo. Os círculos em preto correspondem aos pontos críticos de cada partícula

Figura 12 - Exemplo de determinação da concentração ótima através da PL do 42 PG para diversas concentrações de NPs de $\mathrm{TiO}_{2}$ da série A. O círculo em azul corresponde ao ponto de concentração ótima para a partícula do tipo A2

Figura 13 - Curva característica do processo de degradação do PG

Figura 14 - a) Espectro de absorção do PG para várias concentrações; b) 46 Espectro de PL do PG para várias concentrações 
Figura 15 - a) Ajuste Linear para obtenção do coeficiente de extinção molar 46 do PG; b) Ajuste linear no espectro de PL

Figura 16 - Dependência a) do valor do máximo da absorbância da banda de Soret e b) da intensidade da luminescência $\mathrm{I}_{\mathrm{PL}}$ em $613 \mathrm{~nm}$ das amostras da série A em função da concentração de PG

Figura 17 - a) Dependência do valor do máximo da absorbância da banda de Soret e b) da intensidade da luminescência $\mathrm{I}_{\mathrm{PL}}$ em $613 \mathrm{~nm}$ das amostras da série D em função da concentração de PG

Figura 18 - Dependência do valor máximo da banda de Soret da solução 52 sobrenadante em função da concentração das NPs de $\mathrm{TiO}_{2}$ (gráficos à esquerda) e da área efetiva (gráficos à direita) para as séries $\mathrm{A}, \mathrm{B}, \mathrm{C}$ e $\mathrm{D}$ em solução contendo concentração de PG de $4 \times 10^{-6} \mathrm{M}$ antes da centrifugação

Figura 19 - Resultados medidos através de espectroscopia de 53 fotoluminescência (PL) para o efeito de arraste ao se variar a quantidade de $\mathrm{TiO}_{2}$

Figura 20 - Resultados medidos através de a) espectroscopia de absorção e b) 54 PL para o efeito de arraste ao se variar a quantidade de $\mathrm{TiO}_{2}$ para as partículas do tipo A3, B2, C1 e D1. As linhas pontilhadas correspondem ao ajuste (fitting) de cada curva experimental

Figura 21 - Constantes $y_{0}$ e k obtidas do ajuste exponencial para cada tipo de 55 partícula mostrado na figura 19

Figura 22 - a) Espectros de excitação (detectados em $613 \mathrm{~nm}$ ) na região do ultra-violeta e espectros de emissão correspondentes (excitados em $395 \mathrm{~nm})$ na região do vermelho $(600-700 \mathrm{~nm})$ do PG e b) intensidade da PL com e sem centrifugação em função da concentração das NPs SIGMA ALDRICH ${ }^{\circledR}$ em solução com pH=7

Figura 23 - Possíveis orientações da porfirina e modos de ligação (A até F) 58 para o ácido carboxílico sobre $\mathrm{TiO}_{2}{ }^{41}$

Figura 24 - Esquema representativo dos processos ópticos de uma porfirina 60 adsorvida na superfície de uma NP de $\mathrm{TiO}_{2}$ e diagrama de energia da porfirina e do $\mathrm{TiO}_{2}{ }^{35}$, bem como da cinética dos processos mais importantes depois da excitação. As energias estimadas para o fundo da banda de condução do $\mathrm{TiO}_{2}$ e para o orbital LUMO são aproximadamente $-0,5 \mathrm{eV}$ e $-1 \mathrm{eV}$, respectivamente 
Figura 25 - Adsorção do PG sobre as $\mathrm{NPs}$ de $\mathrm{TiO}_{2}$ em $\mathrm{pH}=4$. A figura 61 compara espectros de excitação e PL em função da concentração de $\mathrm{TiO}_{2}$ como foi feito na Figura 22 para $\mathrm{pH}=7$, concentração de $\mathrm{PG}=2 \times 10^{-6} \mathrm{M}$ e sem centrifugação

Figura 26 - Efeito do pH na adsorção do PG sobre as $\mathrm{NPs}$ de $\mathrm{TiO}_{2}$. a) Razão das intensidades do PG com o pH em solução com $\left(\mathrm{I}_{\mathrm{TiO}_{2}}\right)$ e sem $\left(\mathrm{I}_{\mathrm{PG}}\right) \mathrm{TiO}_{2}$. b) Espectro de absorção das soluções PG-TiO 2 e PG

Figura 27 - a) Dependência da absorbância com o pH na região da banda de 65 Soret. b) Dependência da PL com o pH (excitação em 395 nm)

Figura 28 - Esquema dos experimentos de PL e absorbância observando as 65 condições de concentração especificadas para a) arraste variando $\left[\mathrm{TiO}_{2}\right]$ e b) arraste variando $[\mathrm{PG}]$

Figura 29 - Comparação da razão entre os máximos dos espectros do sistema 66 PG- $\mathrm{TiO}_{2}\left(\mathrm{NPs}\right.$ de $\mathrm{TiO}_{2}$ A3) e os máximos dos espectros do PG (tomado como referência) em função do $\mathrm{pH}$ após a centrifugação. Eixo vertical à esquerda: razão correspondente aos máximos da absorbância em $395 \mathrm{~nm}$. Eixo vertical à direita: razão correspondente aos máximos da PL em 613 nm

Figura 30 - Dependência com o $\mathrm{pH}$ da razão $\mathrm{I}_{\mathrm{PL}, \mathrm{TiO}_{2}} / \mathrm{I}_{\mathrm{PL}, \mathrm{PG}}$ para o segundo caso $\mathrm{C}_{\mathrm{M}}^{1}>\mathrm{C}_{\mathrm{M}}$ para NPs de $\mathrm{TiO}_{2}$ representantes da séria $\mathrm{A}(\mathrm{A} 2)$ e da série D (D4)

Figura 31 - a) Espectros de absorção referentes à degradação do PG em pH 4.69

b) Espectros de PL para o mesmo caso da figura a)

Figura 32 - a) Espectros de absorção e PL referentes à degradação do PG em pH 7. b) Espectros de PL para o mesmo caso da figura a)

Figura 33 - a) Espectros de absorção e PL referentes à degradação do PG em 70 pH 10. b) Espectros de PL para o mesmo caso da figura a)

Figura 34 - a) Taxas dos espectros de absorção para a degradação do PG em $\mathrm{pH} 4,7,10$. b) Taxas dos espectros de PL para a degradação do PG em pH 4, 7, 10

Figura 35 - a) Decaimento da PL no experimento de fotodegradação das 74 moléculas de PG adsorvidas na superfície de diferentes partículas de $\mathrm{TiO}_{2}$

Figura 36 - Decaimento da absorbância do PG em função do tempo de 76 excitação para $\mathrm{PG}$ adsorvido em A3 para $\mathrm{pH}$ 4, 7 e 10 



\section{LISTA DE TABELAS}

Tabela 1 - Caracterização física das NPs de $\mathrm{TiO}_{2}$ (LIEC): Razão molar entre os precursores poliméricos (isopropóxido de titânio (TI), ácido cítrico (AC) e etileno glicol (EC)), Composição, temperatura de calcinação, área superficial especifica $(\mathrm{S})$, diâmetro médio de partícula (D), bandgap óptico $\mathrm{E}_{\mathrm{g}}$

Tabela 2 - Estimativa do número médio de moléculas de PG adsorvidas na 56 superfície das partículas de $\mathrm{TiO}_{2}$

Tabela 3 - Valores das constantes de velocidade de degradação $\mathrm{k}\left(\min ^{-1}\right)$ para os espectros da figura 34

Tabela 4 - Constantes de velocidade de degradação referentes à figura 35 



\section{LISTA DE ABREVIATURAS}

PG - PHOTOGEM ${ }^{\circledR}$

NP - Nanopartícula

Ti - Titânio

$\mathrm{TiO}_{2}-$ Dióxido de Titânio

TFD - Terapia Fotodinâmica, do inglês Photodynamic Therapy (PDT)

UV-VIS - Região do espetro eletromagnético entre o ultra-violeta e o visível

POA - Processos oxidativos avançados

EROs - Espécies reativas de oxigênio

- OH - Radical hidroxila

$\mathrm{O}_{2}^{--}$- Radical superóxido

${ }^{1} \mathrm{O}_{2}$ - Oxigênio singleto

PG-TiO - Sistema contendo moléculas de PG e NPs de $\mathrm{TiO}_{2}$

S/V - Razão entre a área da partícula S e seu volume V

M - Molaridade (mol/L)

[PG] - Concentração de PHOTOGEM ${ }^{\circledR}(\mathrm{M})$

$\left[\mathrm{TiO}_{2}\right]$ - Concentração de $\mathrm{TiO}_{2}(\mathrm{M})$

TE - Transferência de energia

TC - Transferência de carga

PZZP - Potencial zeta de ponto zero 



\section{SUMÁRIO}

1 INTRODUÇÃ

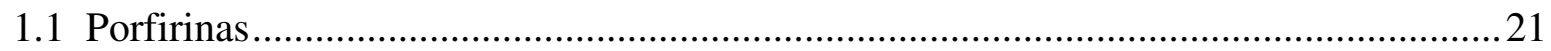

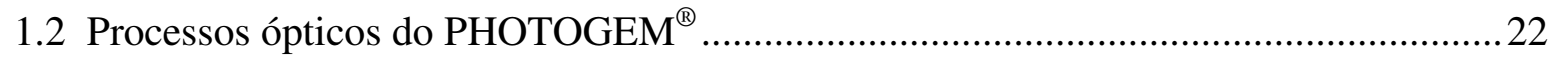

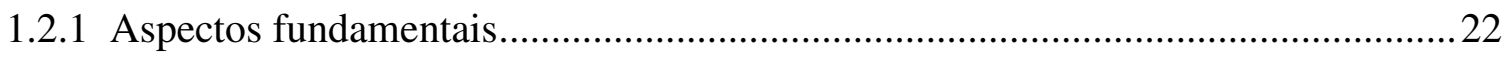

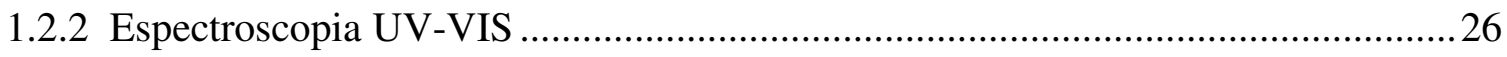

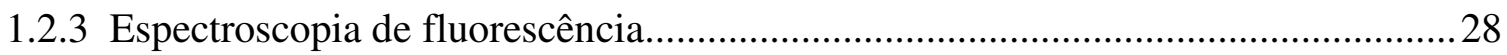

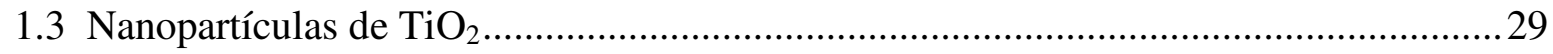

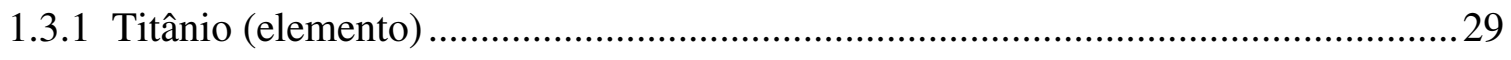

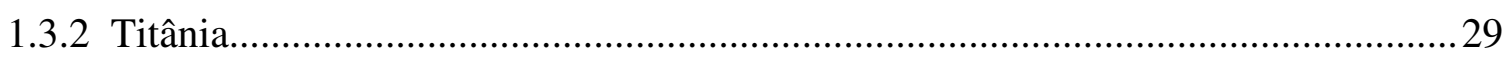

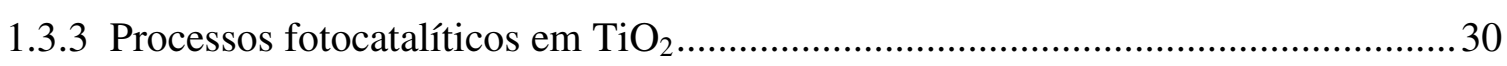

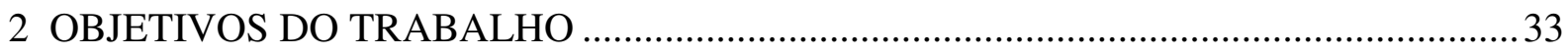

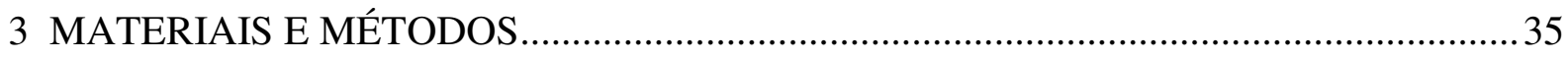

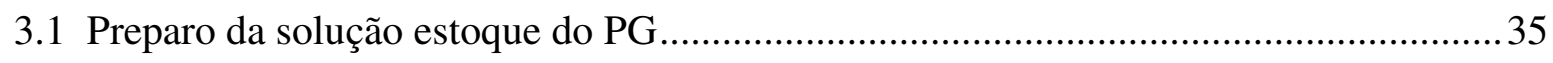

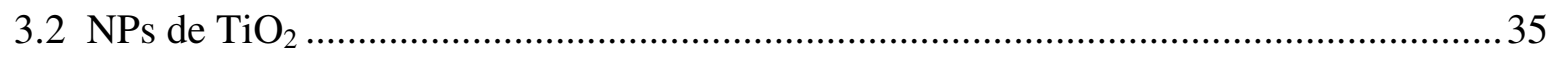

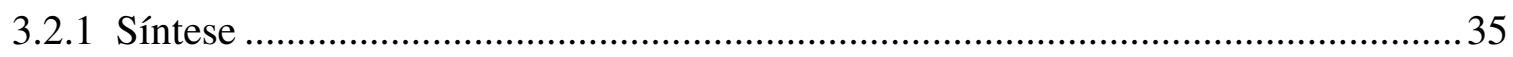

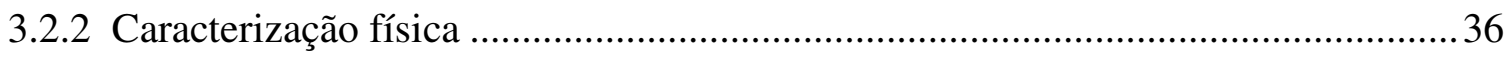

3.3 Experimentos de arraste de moléculas .................................................................. 37

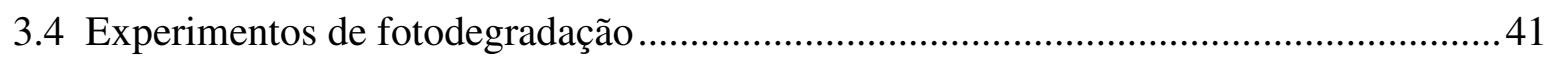

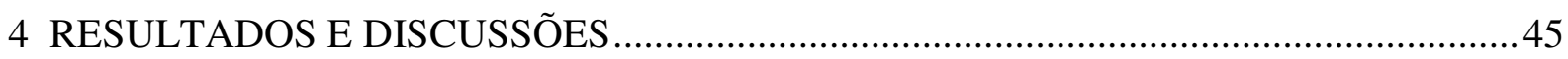

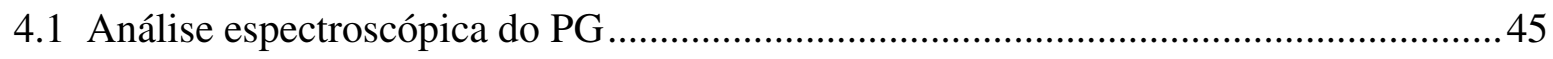

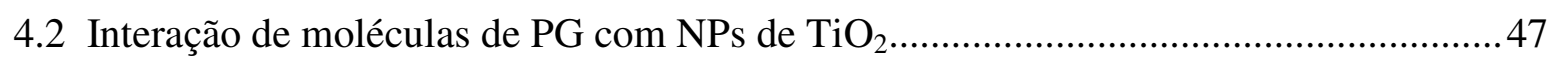

4.2.1 Arraste pela variação da quantidade de PG................................................................ 47

4.2.2 Arraste através da variação da quantidade de $\mathrm{TiO}_{2}$.............................................50

4.2.3 A adsorção molecular sobre o $\mathrm{TiO}_{2}$..................................................................56

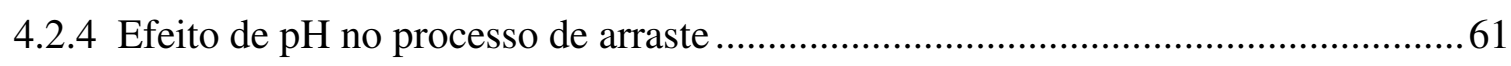

4.3 Análise espectroscópica da fotodegradação do PG .................................................. 68

4.4 Fotodegradação do PG adsorvido na superfície das partículas de $\mathrm{TiO}_{2}$.......................73

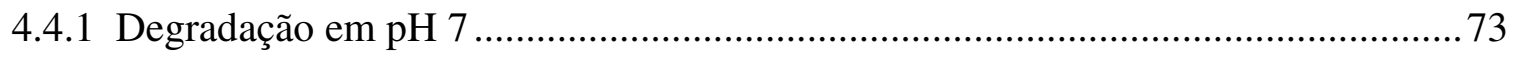

4.4.2 Degradação do PG sobre $\mathrm{TiO}_{2}$ : efeito de $\mathrm{pH}$....................................................... 75 
5 CONCLUSÕES

6 TRABALHOS FUTUROS

79

REFERÊNCIAS. 


\section{INTRODUÇÃO}

\subsection{Porfirinas}

As porfirinas constituem um grupo muito importante de moléculas orgânicas, presentes nos mais variados sistemas biológicos. Como exemplo, podemos citar a Fe-porfirina que constitui o sítio ativo de hemoproteínas. Tais proteínas estão presentes na hemoglobina e mioglobina sanguínea, responsáveis pelo transporte e armazenamento de oxigênio no sistema circulatório de muitos animais. Outro exemplo de grande importância é dado pela clorofila que é uma Mg-porfirina reduzida, responsável pelo processo de fotossíntese nos vegetais. Em nível fisiológico, elas são as principais responsáveis pela manutenção da vida, pois estão presentes nos principais processos bioquímicos relacionados à vida como a conhecemos.

As porfirinas são compostos derivados da porfina, que possui uma estrutura mais simples formada por quatro anéis pirrólicos ligados entre si por átomos de carbono, resultando em um sistema altamente conjugado, com transições eletrônicas no visível e UV próximo.
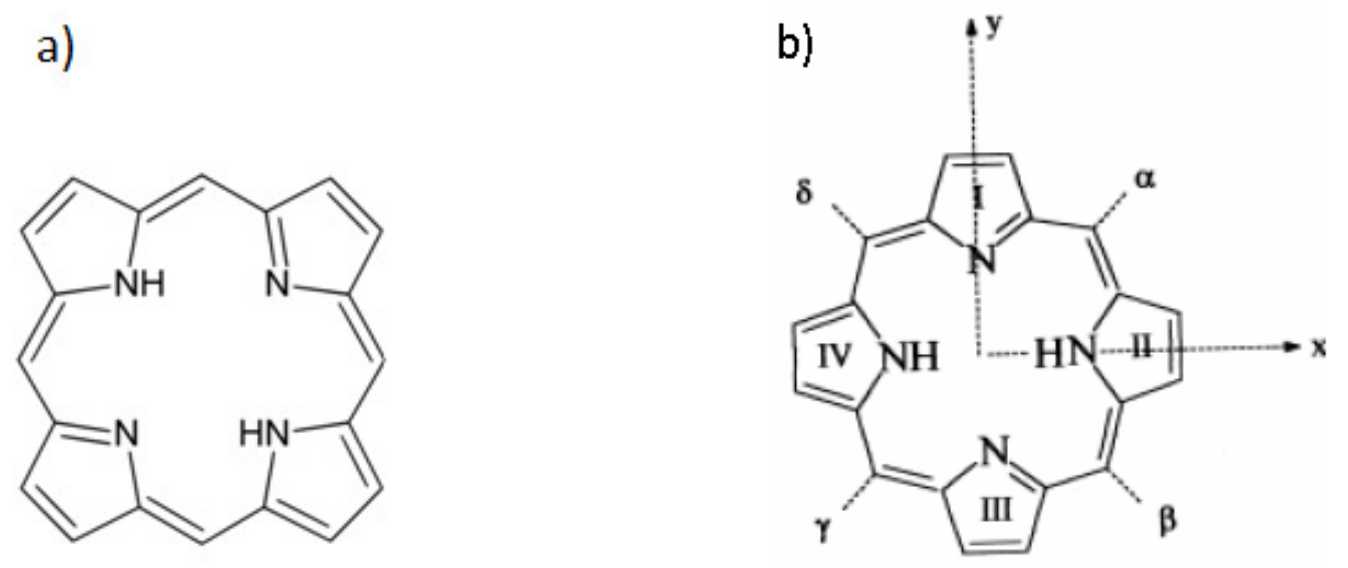

Figura 1-a) Estrutura da porfina; b) Estrutura básica das porfirinas 
A figura 1 b) mostra a numeração usual ${ }^{1}$ para os quatro anéis pirrólicos (I, II, III e IV) e os quatro carbonos das metinas, também chamados de posições meso $(\alpha, \beta . \gamma, \delta)$. Toda porfirina que apresenta esta estrutura é chamada de porfirina de base livre.

Nota-se também que no macrociclo da porfirina há dois átomos de nitrogênio e dois grupos NH. Sabe-se da literatura ${ }^{2}$ que os dois átomos de nitrogênio são capazes de aceitar prótons, enquanto os dois grupos NH são capazes de perder prótons. Quando os átomos de nitrogênio dos anéis II e IV perdem prótons e ocorre coordenação de um íon metálico com os quatro átomos de nitrogênio, temos como resultado final uma estrutura chamada metaloporfirina.

Uma das principais aplicações das porfirinas está centrada no tratamento de câncer através da terapia fotodinâmica (TFD). Até o momento, o fotossensibilizador mais empregado na TFD é um tipo especial de porfirina chamada derivado de hematoporfirina (HpD). $O$ princípio básico da TFD consiste na fotossensibilização sistêmica ou localizada e induzida por um fotossensibilizador (HpD). O diferencial da técnica de TFD em relação a outras modalidades de tratamento está em sua maior seletividade e afinidade do fotossensibilizador por células cancerosas. Geralmente injeta-se o fotossensibilizador por via intravenosa e sua atividade fotodinâmica inicia-se quando o tecido tumoral é irradiado com luz em um comprimento de onda e dose adequados. A destruição do tecido ocorre principalmente devido à geração de espécies reativas de oxigênio (EROS) e transferência de energia via oxigênio singleto. Tais processos são induzidos pelo estado excitado das moléculas dos fotossensibilizadores após irradiação com luz. Na próxima sessão será feita uma discussão mais refinada sobre a fotofísica envolvida nestes processos.

\subsection{Processos ópticos do PHOTOGEM ${ }^{\circledR}$}

\subsubsection{Aspectos fundamentais}


Em nosso trabalho utilizamos um tipo de porfirina que é muito empregada na área de PDT e conhecida comercialmente como PHOTOGEM ${ }^{\circledR}$ (MOSCOU, RÚSSIA). Sua composição consiste numa mistura de monômeros, dímeros e oligômeros unidas por ligações éter ou éster ${ }^{3,4}$. A molécula de PG apresenta uma banda de absorção intensa quando em solução aquosa em torno de $370 \mathrm{~nm}$ conhecida como banda de Soret e outras quatro de menor intensidade denominadas bandas-Q que ocorrem em comprimentos de onda maiores (500 a $700 \mathrm{~nm})$. Sua estrutura monomérica é representada através da fórmula $\left[\mathrm{C}_{34} \mathrm{H}_{38} \mathrm{~N}_{4} \mathrm{O}_{6}\right]_{\mathrm{n}}$ para $\mathrm{n}=1$.

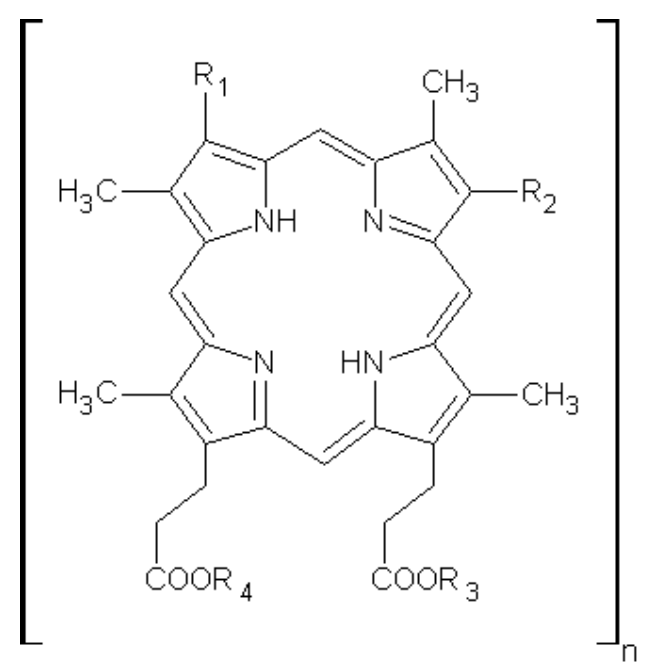

Figura 2 - Estrutura do $P G^{5}$

Na figura 2 podemos notar que há quatro radicais ligantes: R1, R2, R3 e R4. Os radicais R1 e R2 podem se ligar a estruturas do tipo $\mathrm{CH}(\mathrm{OH}) \mathrm{CH}_{3}$ e $\mathrm{CH}_{2} \equiv \mathrm{CH}_{2}$ enquanto os radicais $\mathrm{R} 3$ e $\mathrm{R} 4$ se ligam ao $\mathrm{H}$. Todos os radicais também podem se ligar à estrutura monomérica de outras moléculas de PG formando dímeros, trímeros ou oligômeros ${ }^{6,5}$.

O principio básico da ação fotodinâmica do PG consiste na excitação da molécula (inicialmente no estado fundamental) para um estado excitado. Isto é conseguido irradiando as moléculas de PG com luz de comprimento de onda adequado para cobrir a diferença de energia entre os dois estados. O diagrama a seguir ilustra os principais processos ligados à ação fotodinâmica do PG. 


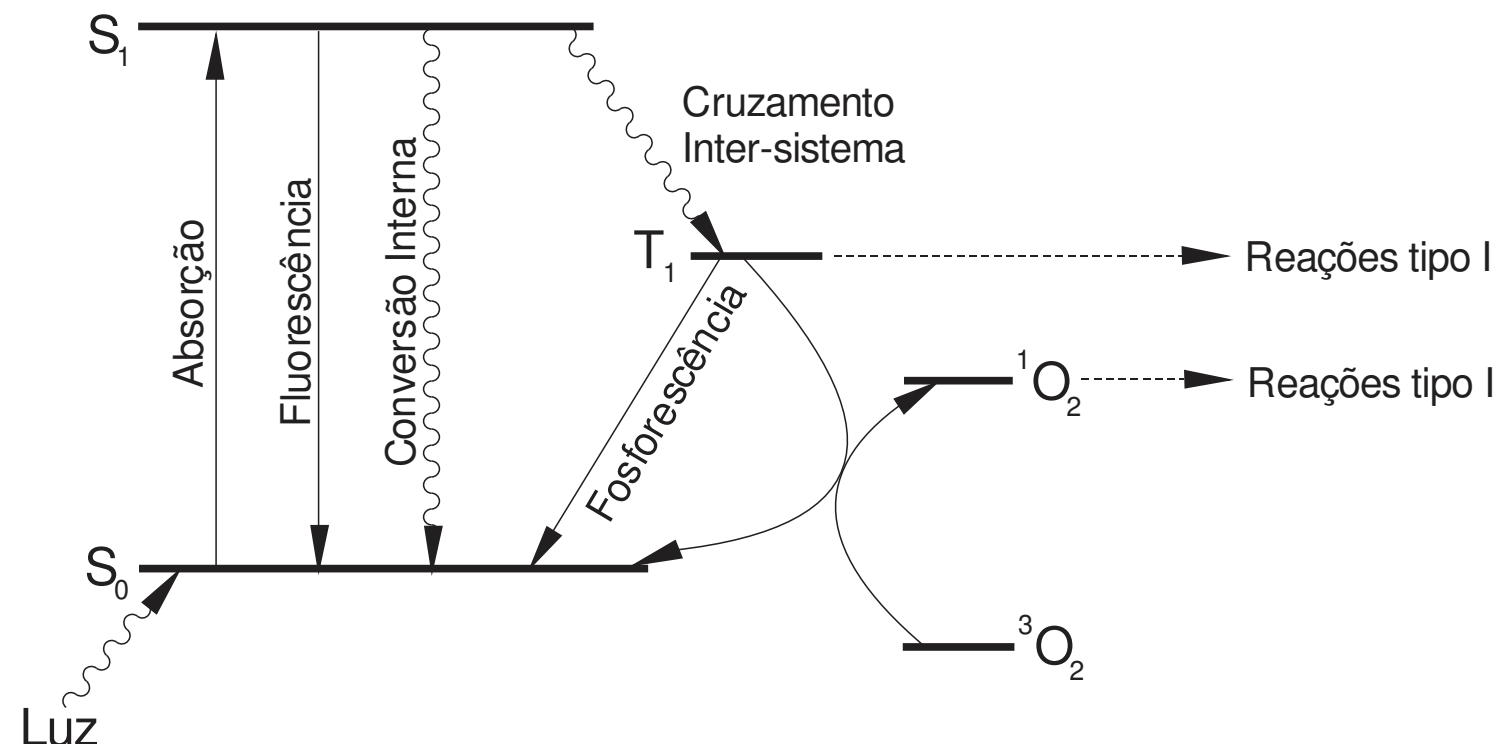

Figura 3 - Diagrama de Jablonski referente aos principais processos óticos envolvidos na excitação do PG

Como mostra a figura 3, temos inicialmente um elétron de uma molécula de PG no estado singleto fundamental. Através do processo de absorção luminosa o elétron é promovido para um estado excitado $\mathrm{S}_{1}$. A partir deste estado o elétron pode retornar ao estado $\mathrm{S}_{0}$ através de três processos distintos.

Os dois primeiros processos são chamados de fluorescência e conversão interna e ocorrem devido à transição entre estados de mesma multiplicidade de spin. Vemos na figura 3 que tais transições ocorrem entre estados singleto que possuem elétrons emparelhados $(\uparrow \downarrow)$. A principal diferença entre os dois processos está no fato da fluorescência ser um processo radiativo na qual ocorre emissão de fótons enquanto na conversão interna temos liberação de calor de forma não radiativa.

O terceiro processo é chamado de cruzamento inter-sistema. Este processo ocorre entre estados de diferente multiplicidade de spin de forma não radiativa. Na figura 3 esta transição ocorre entre os estados $\mathrm{S}_{1}$ e $\mathrm{T}_{1}$.

A transição radiativa entre o estado $T_{1}$ e $S_{0}$ é chamada de fosforescência. Tal transição é proibida por spin resultando em um maior tempo de vida do estado $\mathrm{T}_{1}$. O prolongamento do tempo de vida deste estado é fundamental, pois desta forma a molécula de PG terá mais tempo para interagir com outras moléculas vizinhas. Esta interação pode ocorrer através de dois processos distintos, representados na figura 3 pelas reações do tipo $\mathrm{I}^{\mathrm{e}} \mathrm{II}^{7,8}$. Tais reações levam à formação de espécies reativas de oxigênio (EROs) $)^{9}$ como o radical hidroxila $(\cdot \mathrm{OH}), \mathrm{o}$ 
radical superóxido $\left(\mathrm{O}_{2}^{--}\right)$e o oxigênio singleto $\left({ }^{1} \mathrm{O}_{2}\right)$, responsáveis pelo efeito de degradação característico do PG.

Nas reações do tipo I ocorre transferência de elétrons ou hidrogênios do tipo redox entre o estado $T_{1}$ do PG e outras moléculas presentes no meio ${ }^{10}$. Em consequiência desta interação são gerados íons radicais que tendem a reagir com o oxigênio molecular no estado fundamental, de modo a produzir radicais $\cdot \mathrm{OH}$ e $\mathrm{O}_{2}^{--}$.

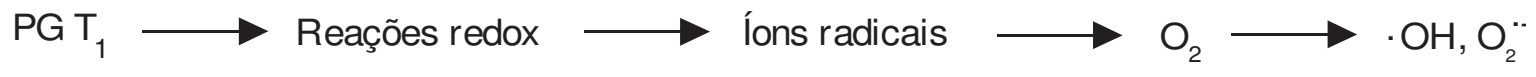

Figura 4 - Diagrama ilustrativo referente aos principais processos envolvidos nas reações do tipo I

As reações do tipo II são caracterizadas por processos de transferência de energia entre o PG no estado $\mathrm{T}_{1}$ e o oxigênio molecular $\left({ }^{3} \mathrm{O}_{2}\right)$. Após a transferência de energia, o oxigênio é promovido para o estado singleto $\left({ }^{1} \mathrm{O}_{2}\right)$ e o PG volta para o estado fundamental. O oxigênio singleto é o único das EROs que é um estado excitado e em ambientes aquosos possui tempo de vida ${ }^{11}$ de $2 \mu$ s. Este tempo de vida é consideravelmente longo se comparado com outros radicais como o $\cdot \mathrm{OH}$ que possui um tempo médio de vida de 10 ns. Então, aumenta-se a possibilidade de interação do ${ }^{1} \mathrm{O}_{2}$ com outras estruturas presentes na solução resultando na degradação destas estruturas.

$\mathrm{PGT}_{1} \longrightarrow$ Transferência de energia $\longrightarrow$ Oxigênio molecular $\left({ }^{3} \mathrm{O}_{2}\right) \longrightarrow$ Oxigênio singleto $\left({ }^{1} \mathrm{O}_{2}\right)$

Figura 5 - Diagrama ilustrativo referente aos principais processos envolvidos nas reações do tipo II

Na literatura, é muito comum utilizar o termo photobleaching ${ }^{12}$ para se referenciar ao processo de degradação de corantes via radiação luminosa. Em fotoquímica também se usa o termo fotoclareamento quando se observa a diminuição da absorção óptica e da intensidade da PL do $\mathrm{PG}^{13}$. 


\subsubsection{Espectroscopia UV-VIS}

Uma das técnicas mais utilizadas na caracterização óptica de porfirinas é baseada na absorção eletrônica de luz e é chamada de espectroscopia UV-VIS. Através desta técnica é possível quantificar a intensidade de luz absorvida por um material assim como medir a posição das bandas de absorção em um determinado intervalo de comprimentos de onda. A intensidade de absorção também é chamada de absorbância e depende da probabilidade de interação entre a radiação incidente e as moléculas de PG assim como da diferença entre o estado fundamental e o estado excitado.

Através de medidas de absorção UV-VIS é possível relacionar características da amostra com a quantidade de luz absorvida. Para tal propósito, utiliza-se a lei de LambertBeer $^{14}$ :

$$
I=I_{0} e^{-\varepsilon l c}
$$

onde "l" é o tamanho da amostra (largura da cubeta) medido em cm, $\mathrm{I}_{0}$ e I são as intensidades da luz incidente e transmitida, respectivamente. A concentração da amostra "c" é dada em mol/litro (M). O parâmetro " $\varepsilon$ " é chamado de coeficiente de extinção molar e seu valor é especifico para cada tipo de amostra num dado solvente e também depende do comprimento de onda.

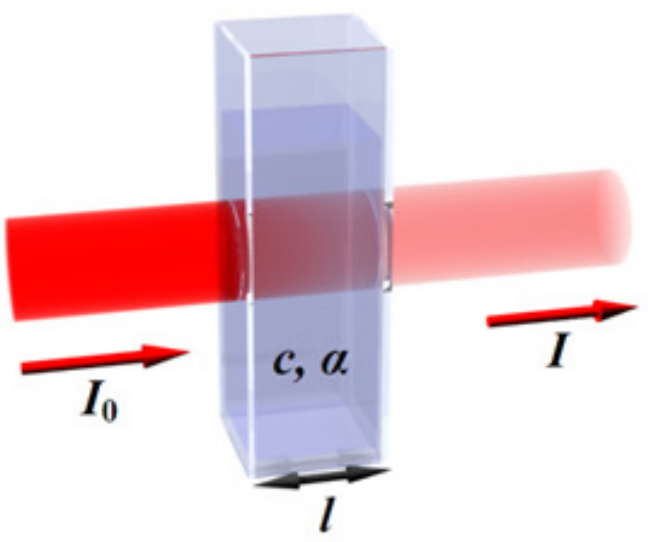

Figura 6 - Diagrama ilustrativo referente à absorção luminosa segundo a lei de Lambert-Beer 
A absorbância se relaciona com a transmitância $\mathrm{T}=\mathrm{I} / \mathrm{I}_{0}$ de um material através da equação:

$$
A=-\ln (T)
$$

Portanto:

$$
A=-\ln \left(\frac{\mathrm{I}}{\mathrm{I}_{0}}\right)=\varepsilon \operatorname{lc}
$$

Nas porfirinas, a banda de maior intensidade (banda de Soret) aparece na região de $400 \mathrm{~nm}$ e possui coeficiente de extinção $(\varepsilon)$ da ordem ${ }^{1-2}$ de $10^{4}-10^{5} \mathrm{M}^{-1} \mathrm{~cm}^{-1}$.

As transições eletrônicas observadas em moléculas orgânicas ocorrem entre orbitais moleculares específicos. No estado fundamental, estes orbitais se dividem em três categorias:

- $\quad$ Orbitais $\sigma$ : São orbitais associados às ligações simples. Nestes orbitais a distribuição eletrônica apresenta simetria cilíndrica em torno da ligação química.

- Orbitais $\pi$ : Estão relacionados às ligações múltiplas. Devido à delocalização dos elétrons tem-se uma melhor interação com a vizinhança.

- $\quad$ Orbitais n: Correspondem aos orbitais ocupados pelos pares livres de heteroátomos como o oxigênio e nitrogênio. Estes orbitais não estão envolvidos nas ligações químicas.

Para os estados excitados têm-se os seguintes orbitais moleculares:

- $\quad$ Orbitais $\sigma^{*}$ (sigma antiligante): possuem simetria cilíndrica com um plano nodal entre os átomos.

- $\quad$ Orbitais $\pi^{*}$ (Pi antiligante): orbitais delocalizados com plano nodal ao longo do eixo de ligação.

As principais bandas observadas nos espectros de absorção das porfirinas (banda de Soret e bandas Q) estão no visível e UV próximo e são devidas à transições do tipo $\pi \rightarrow \pi^{*}$. Este tipo de transição ocorre devido à presença de grupos funcionais insaturados nas moléculas de $\mathrm{PG}^{14}$. Tais grupos são capazes de absorver no UV-visível e são chamados de cromóforos. Dependo do tipo de substituinte na periferia das porfirinas pode ocorrer pertubação dos níveis eletrônicos e com isso muda-se a intensidade das bandas. 


\subsubsection{Espectroscopia de fluorescência}

O processo de fluorescência, também conhecido como fotoluminescência ou PL, possui relação direta com o processo de absorção óptica. Na fluorescência ocorre o processo inverso e as moléculas excitadas perdem energia radiativamente e retornam ao estado fundamental. Tal transição ocorre sem mudança de spin, diferentemente das transições observadas em fosforescência.

O tempo de vida de fluorescência é da ordem de $10^{-9} \mathrm{~s}$ que é suficientemente longo para que ocorra processos como transferência de carga, mudanças na conformação da molécula e reorientação dos cromóforos ${ }^{15}$. Portanto, a sensibilidade de medida é o principal atrativo da espectroscopia de luminescência, com limites de detecção de até três ordens de magnitude melhores que aqueles encontrados nas técnicas de absorção.

Um dos principais problemas da espectroscopia de fluorescência está no fato de que muitas moléculas não apresentam fluorescência perceptível ou apresentam redução de fluorescência devido a fenômenos de desativação. Tais fenômenos não radiativos, representado pela conversão interna e cruzamento intersistema, competem com a emissão radiativa por fluorescência, resultando na diminuição de sua intensidade, processo este conhecido como supressão de fluorescência ou quenching.

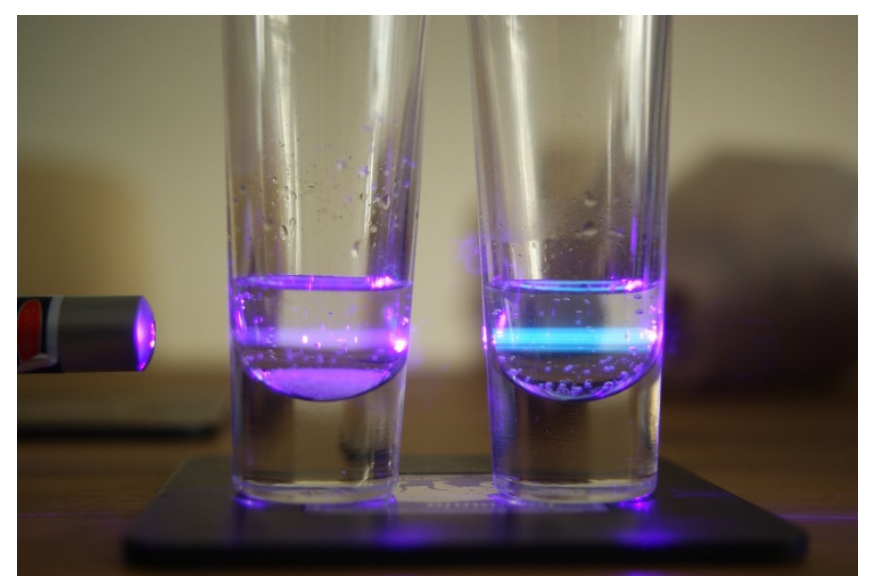

Figura 7 - Figura ilustrativa do fenômeno de fluorescência (direita) e sua supressão (esquerda) 


\subsection{Nanopartículas de $\mathrm{TiO}_{2}$}

\subsubsection{Titânio (elemento)}

Descoberto em 1791 pelo inglês Willian Gregor na forma de ilmenita $\left(\mathrm{FeTiO}_{3}\right)$ e pelo químico alemão Martin $\mathrm{H}$. Klaproth na forma rutilo, o titânio recebeu este nome em homenagem aos titãs mitológicos. É o nono elemento químico mais abundante na crosta terrestre e geralmente encontra-se associado a rochas ígneas e seus derivados. Por ser um elemento de baixa densidade e alta resistência, o titânio é utilizado com freqüência na indústria de materiais em partes estruturais de veículos, bicicletas e na fabricação de próteses.

\subsubsection{Titânia}

A maior parte do titânio comercializado no mundo é utilizado na forma de óxidos, como a titânia (dióxido de titânio ou $\mathrm{TiO}_{2}$ ). De baixo custo, foto-estável e atóxico, a titânia tem atraído muita atenção nas ultimas décadas ${ }^{16,17}$ devido as suas propriedades singulares. Possui três diferentes formas cristalinas: anatase, brookita e rutilo (mais estável e comum). $\mathrm{Na}$ indústria de pigmentos, a titânia é amplamente utilizada em tintas brancas, pois é o mais branco e brilhante pigmento produzido industrialmente ${ }^{18}$. Devido a sua estabilidade química e mecânica, também se utiliza a titânia como revestimento anticorrosivo ${ }^{19}$. Nas áreas de pesquisa, a titânia encontra aplicações em fotocatálise ${ }^{20}$ e dispositivos fotovoltaicos ${ }^{21}$. 


\subsubsection{Processos fotocatalíticos em $\mathrm{TiO}_{2}$}

Atualmente, com o crescimento industrial e populacional, tem-se observado um grande aumento de problemas ambientais. Um dos principais problemas é a contaminação de água doce por pesticidas, agrotóxicos e corantes industriais. Embora muitos governos tenham adotado medidas regulamentadoras com a finalidade de diminuir a poluição ambiental, tornase também necessário desenvolver técnicas de descontaminação e despoluição para assim garantir um crescimento sustentável e minimizar a agressão ao meio ambiente. Inserido neste contexto, destacam-se os processos oxidativos avançados (POAs) como alternativa para tratamento de água através da geração de espécies altamente reativas.

Entre as principais técnicas baseadas em POAs destaca-se o método de fotocatálise heterogênea, no qual o catalisador e o material a ser degradado se encontram em fases distintas. Os fotocatalisadores são materiais conhecidos por acelerar processos de transformações moleculares quando sensibilizados com luz. Na fotocatálise heterogênea, através da excitação eletrônica de materiais semicondutores como o $\mathrm{TiO}_{2}$, ocorre geração superficial de sítios oxidativos e redutivos.

Os materiais semicondutores recebem este nome por apresentar condutividade intermediaria em relação aos materiais condutores e isolantes. No estado fundamental, suas estruturas eletrônicas são caracterizadas pela presença de uma banda de menor energia e ocupada eletronicamente chamada de banda de valência (BV) e por uma banda mais enérgica e desocupada chamada de banda de condução (BC). A diferença de energia entre estas duas bandas é chamada de energia de bandgap $\left(\mathrm{E}_{\mathrm{g}}\right)$. Para o $\mathrm{TiO}_{2}$, o valor de $\mathrm{E}_{\mathrm{g}}$ está entre 3,2 eV (anatase) e 3,0 eV (rutilo) ${ }^{22}$. 


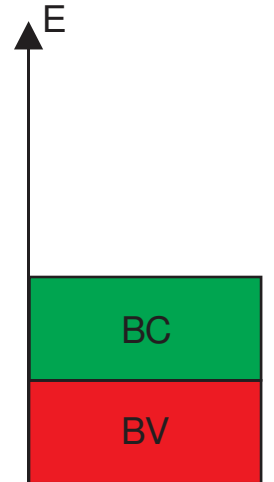

Condutores

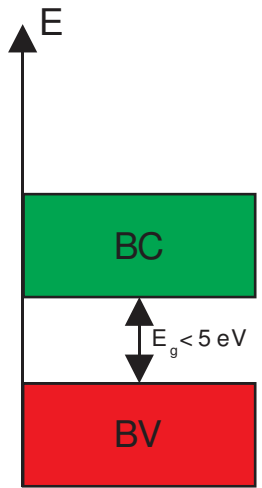

Semicondutores

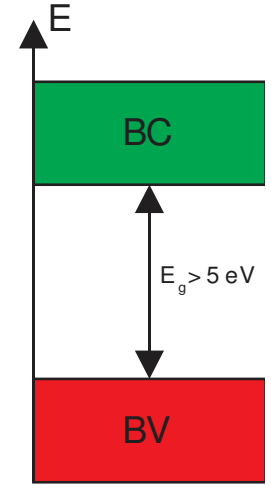

Isolantes

Figura 8 - Representação esquemática das bandas de energia em materiais

Através da absorção de fótons de energia $E \geq E_{g}$ na superfície das partículas de $\mathrm{TiO}_{2}$ ocorrerá promoção de elétrons $\left(\mathrm{e}^{-}\right)$da $\mathrm{BV}$ para a $\mathrm{BC}$ e geração de buracos $\left(\mathrm{h}^{+}\right)$na $\mathrm{BV}$. Eventualmente, os elétrons e os buracos podem se recombinar resultando em liberação de energia na forma de calor ou também podem reagir com aceptores ou doadores de elétrons adsorvidos sobre a superfície das partículas ${ }^{23}$. Na figura 9 são mostrados os princípios básicos da fotocatálise em semicondutores.

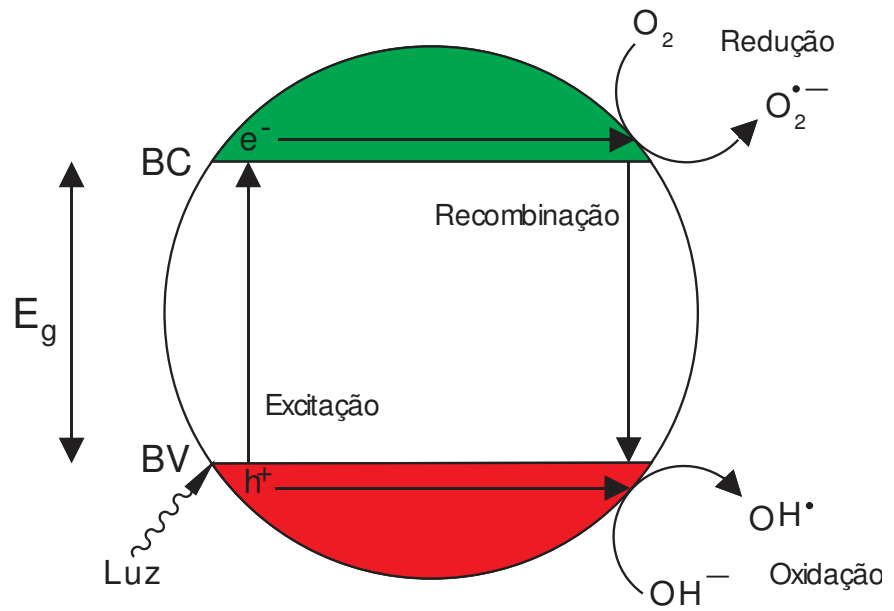

Figura 9 - Diagrama esquemático dos principais processos e produtos da fotocatálise em semicondutores

Vemos na figura 9 que as cargas criadas na superfície das partículas podem interagir com espécies químicas presentes na solução. Através de uma reação de redução sobre o $\mathrm{O}_{2}$ 
gera-se o radical superóxido $\mathrm{O}_{2}^{--}$. O radical hidroxila é gerado pela oxidação de íons hidroxila $\left(\mathrm{OH}^{-}\right)$. Estes radicais apresentam um alto poder oxidante ${ }^{24}$ e quando entram em contato com moléculas orgânicas presentes na solução são capazes de levá-las à degradação ou mineralização (transformação em espécies inorgânicas). 


\section{OBJETIVOS DO TRABALHO}

- Analisar a interação entre PG e NPs de $\mathrm{TiO}_{2}$ por arraste (adsorção molecular)

- Estudo da influência do pH na adsorção do PG nas NPs de $\mathrm{TiO}_{2}$

- Realizar experimentos de degradação do PG e do complexo PG-TiO 2 


\section{MATERIAIS E MÉTODOS}

\subsection{Preparo da solução estoque do PG}

Em nossos experimentos de fotodegradação e arraste utilizamos como molécula padrão o PHOTOGEM ${ }^{\circledR}$, um derivado de hematoporfirina. A partir de sua forma em pó, foi preparada uma solução estoque na concentração de $0,5 \mathrm{~g} / \mathrm{L}$ usando água ultrapura (Milli-Q). Partindo desta solução estoque foram preparadas outras soluções, diluídas de forma a obter a concentração exigida em cada tipo de experimento.

\subsection{NPs de $\mathrm{TiO}_{2}$}

\subsubsection{Síntese}

As NPs de $\mathrm{TiO}_{2}$ utilizadas neste trabalho foram sintetizadas no Laboratório Interdisciplinar de Eletroquímica e Cerâmica (LIEC) da UFScar pela pós-doutoranda Adriane V. Rosário sob supervisão do professor doutor Ernesto C. Pereira de Souza. Para a síntese das NPs foi utilizado o método dos precursores poliméricos.

O método acima descrito ${ }^{25}$ consiste na formação de uma rede polimérica em conjunto com íons metálicos. Na primeira etapa deste processo ocorre a complexação de cátions na presença de ácido cítrico e em seguida adiciona-se etileno glicol. Inicia-se então a formação 
da cadeia polimérica através de uma reação de esterificação entre o complexo e o glicol. Após tratamento térmico adequado elimina-se a parte orgânica, resultando na formação do óxido de titânio. Na etapa final, através de moagem, tem-se óxido de titânio na forma de pó.

Através da manipulação de variáveis de preparação como temperatura de calcinação e razão molar entre o precursor de titânio, ácido cítrico e etileno glicol (Ti/AC/EG) obteve-se diferentes propriedades estruturais do material final como tamanho de partícula e composição (anatase, rutilo). A manipulação destas propriedades estruturais é de grande importância, pois resulta em propriedades físicas e fotocatalíticas diferenciadas.

\subsubsection{Caracterização física}

A caracterização física das NPs também foi feita no LIEC através de técnicas de difração de raios-X (DRX), microscopia eletrônica de varredura de campo (FEG, MEV) e adsorção por isoterma de BET. Através de medidas de refletância difusa, foi possível estimar o bandgap óptico das NPs. 
Tabela 1 - Caracterização física das NPs de $\mathrm{TiO}_{2}$ (LIEC): Razão molar entre os precursores poliméricos (isopropóxido de titânio (TI), ácido cítrico (AC) e etileno glicol (EC)), Composição, temperatura de calcinação, área superficial especifica $(S)$, diâmetro médio de partícula $(D)$, bandgap óptico $E_{g}$

\begin{tabular}{cccccccc}
\hline Razão & $\begin{array}{c}\text { Temperatura } \\
\text { de calcinação }\end{array}$ & \% de fase & $\mathbf{S}$ & $\mathbf{D}$ & $\begin{array}{c}\text { band } \\
\text { gap }\end{array}$ \\
& TI/AC/EC & $\left({ }^{\circ} \mathbf{C}\right)$ & Anatase & Rutilo & $\mathbf{~ m}^{\mathbf{2}} / \mathbf{g}$ & $\mathbf{n m}$ & $\mathbf{E}_{\mathbf{g}}(\mathbf{e V})$ \\
\hline A1 & & 400 & 100 & - & 100 & 15 & 3,2 \\
A2 & $01: 16: 64$ & 500 & 100 & - & 96 & 16 & 3,23 \\
A3 & & 600 & 98,5 & 1,5 & 67 & 23 & 3,2 \\
A4 & & 700 & 95,4 & 4,6 & 58 & 26 & 3,18 \\
B1 & & 400 & 100 & - & 83 & 18 & 3,15 \\
B2 & $01: 08: 32$ & 500 & 98,5 & 1,5 & 67 & 22 & 3,13 \\
B3 & & 600 & 83,4 & 16,6 & 36 & 41 & 3,06 \\
B4 & & 700 & 25,7 & 74,3 & 16 & 96 & 3,02 \\
C1 & & 400 & 97 & 3 & 64 & 23 & 3,13 \\
C2 & $1: 4: 16$ & 500 & 94,6 & 5,4 & 41 & 37 & 3,1 \\
C3 & & 600 & 69,2 & 30,8 & 32 & 47 & 3,04 \\
C4 & & 700 & 12 & 88 & 22 & 69 & 3,02 \\
D1 & & 400 & 94 & 6 & 63 & 24 & 3,11 \\
D2 & $01: 02: 08$ & 500 & 65,2 & 34,8 & 33 & 46 & 3,02 \\
D3 & & 600 & 12,4 & 87,6 & 11 & 141 & 3 \\
D4 & & 700 & 0,8 & 99,2 & 10 & 156 & 2,99 \\
\hline
\end{tabular}

Analisando a tabela 1 vemos que com o método dos precursores poliméricos é possível controlar precisamente a composição (de 100\% anatase até 100\% rutilo) e área superficial (de 10 a $100 \mathrm{~m}^{2} / \mathrm{g}$ ). Através deste controle da composição temos um controle do bandgap, que tende ao valor de 3,2 eV (anatase pura) para amostras com percentual maior de anatase e 3,02 eV (rutilo puro) para amostras com maior percentual de rutilo.

\subsection{Experimentos de arraste de moléculas}

O experimento de arraste consiste na adsorção de moléculas na superfície de um material. A substância adsorvida é chamada de adsorbato e o material sobre o qual ocorre a adsorção é chamado adsorvente. Neste trabalho utilizamos o PG como adsorbato e as 
partículas de $\mathrm{TiO}_{2}$ da tabela 1 como adsorvente. Em todos os experimentos de arraste utilizamos água ultrapura como solvente e as soluções foram mantidas sob constante agitação. Alíquotas das soluções foram recolhidas somente depois de dez minutos de agitação após a adição do PG ou de $\mathrm{TiO}_{2}$ e centrifugadas em uma ultracentrífuga da marca EPPENDORF ${ }^{\circledR}$ a $14680 \mathrm{rpm}$. Após a centrifugação, uma alíquota do sobrenadante foi retirada e colocada numa cubeta de quartzo de $1 \mathrm{~cm}$ de caminho óptico. Em seguida foram feitas medidas de absorção óptica UV-VIS com o espectrofotômetro HITACHI U-2900 ${ }^{\circledR}$ e medidas de fotoluminescência (PL) com o espectrofluorímetro SHIMADZU RF-5301PC ${ }^{\circledR}$. Os resultados das medidas foram plotados no ORIGIN ${ }^{\circledR}$. Utilizamos os máximos de absorção e PL de cada medida como parâmetro de referência.

Em nossos experimentos, o processo de adsorção foi quantificado através de dois métodos. No primeiro método mantivemos fixa a quantidade de adsorvente $\left(\mathrm{TiO}_{2}\right)$ e variamos a quantidade de adsorbato (solução estoque de PG). A previsão de arraste, para este tipo de experimento, no qual se varia a quantidade de moléculas de PG presente em solução, pode ser explicada através da figura seguinte.

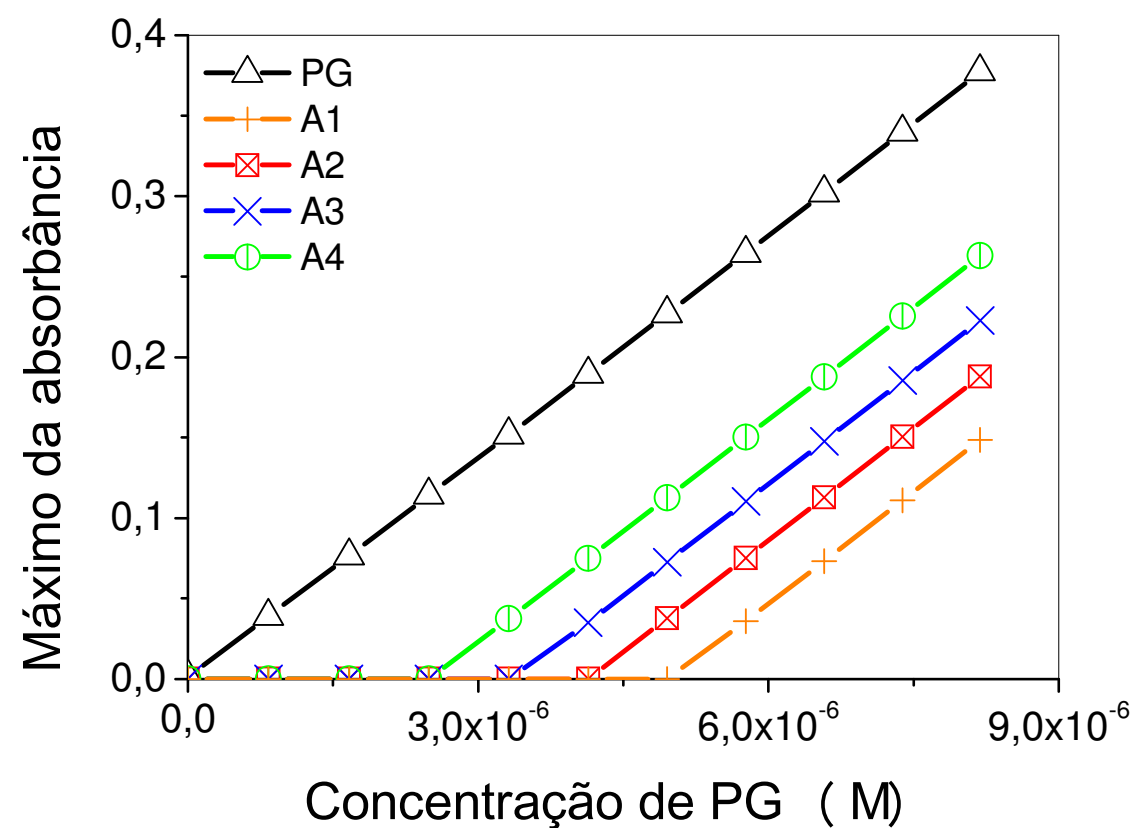

Figura 10 - Previsão do efeito de arraste variando a quantidade de PG. A ordem e espaçamento entre as retas é apenas ilustrativo

Como mostra a figura 10, prevemos um crescimento linear para os máximos dos espectros de absorção com o aumento da quantidade de PG. Vemos através das retas verde, 
azul, vermelho e laranja que as partículas de $\mathrm{TiO}_{2}$ possuem inicialmente valores nulos de absorção até atingirem uma determinada concentração crítica de PG, característica de cada tipo de partícula de $\mathrm{TiO}_{2}$. Isto pode ser explicado da seguinte maneira: Inicialmente tem-se poucas moléculas de PG de modo que a quantidade de partículas de $\mathrm{TiO}_{2}$ presente na solução é suficiente para arrastar todas as moléculas. O arraste total prossegue até atingir uma concentração critica de moléculas. Neste ponto, específico para cada tipo de $\mathrm{TiO}_{2}$, ocorre uma saturação da capacidade de arraste do $\mathrm{TiO}_{2}$ : as partículas estão com todos os seus sítios ativos superficiais ligados a moléculas de PG. A partir deste ponto não há mais efeito de arraste e inicia-se então um crescimento linear dos pontos de máxima absorção com o aumento da concentração de PG. As retas em verde, azul, vermelho e laranja que evidenciam este crescimento devem possuir a mesma inclinação da reta preta, que corresponde ao aumento da concentração de uma solução referência, ou seja, somente PG $\left(\operatorname{sem~} \mathrm{TiO}_{2}\right)$.

No segundo método foi feito o contrário: mantivemos fixa a quantidade de adsorbato e variamos a quantidade de adsorvente. A previsão de arraste para este tipo de experimento pode ser explicada através de uma equação cuja taxa de variação da concentração do PG seja proporcional à sua própria concentração, ou seja:

$$
\frac{d y}{d x}=-k y+C
$$

onde:

$y \equiv[P G] \rightarrow$ Concentração de $P G$

$x \equiv\left[\mathrm{TiO}_{2}\right] \rightarrow$ Concentração de $\mathrm{TiO}_{2}$

$k \equiv$ Constante de proporcionalidade

$C \equiv$ Constante de saturação ou background

Integrando a equação (4) teremos o seguinte resultado:

$$
y=A+B \cdot e^{-k \cdot x}
$$




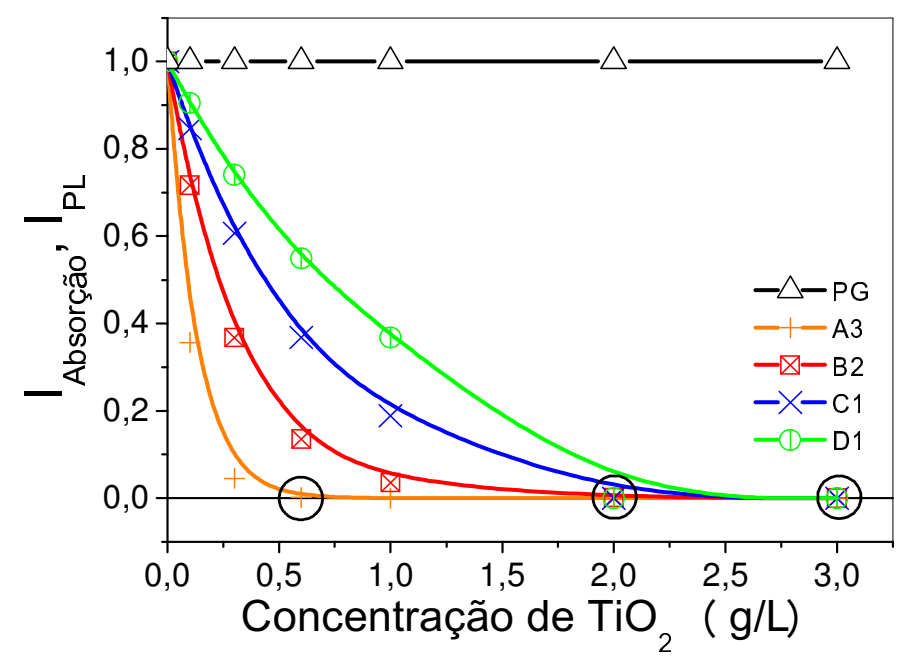

Figura 11 - Previsão do efeito de arraste variando a quantidade de $\mathrm{TiO}_{2}$. A ordem e espaçamento entre as retas é apenas ilustrativo. Os círculos em preto correspondem aos pontos críticos de cada partícula

Para cada tipo de partícula tem-se distintos valores das constantes A, B e k da equação (5). Na figura 11 as curvas verde, azul vermelho e laranja possuem inicialmente valores unitários de absorção, pois as medidas foram normalizadas. Em seguida, observa-se uma queda exponencial da PL ou absorção com o aumento da quantidade de $\mathrm{TiO}_{2}$. Pode-se ver que para cada curva representando um tipo de NP temos distintos pontos críticos. Tais pontos correspondem à capacidade máxima de adsorção de moléculas de PG para cada tipo de partícula. Para os pontos anteriores ao ponto crítico tem-se poucas partículas de $\mathrm{TiO}_{2}$ para que ocorra arraste total das moléculas. Todos os sítios ativos superficiais das partículas de $\mathrm{TiO}_{2}$ estão ligados a moléculas de PG. A queda prossegue até chegar ao ponto crítico, onde ocorre total arraste das moléculas. Este ponto, também específico para cada tipo de partícula, determina a concentração mínima de $\mathrm{TiO}_{2}$ necessário para se ter o máximo de arraste. A partir dele, todo aumento de concentração de $\mathrm{TiO}_{2}$ resulta em arraste total (ou quase total) das moléculas ou seja, tem-se valores de absorção ou PL próximos a zero. Consta também na figura uma previsão para a amostra de referência, simbolizada por uma reta preta de valor constante, pois em uma solução contendo apenas a referência (PG) não ocorre arraste das moléculas.

Sabe-se também que propriedades superficiais do $\mathrm{TiO}_{2}$ como densidade de estados superficiais e posição das bandas de valência e condução são fortemente influencias pelo pH do meio. Portanto, com a finalidade de estudar o efeito de $\mathrm{pH}$ na solução, foram feitas medidas de absorção e PL para soluções com diversos valores de $\mathrm{pH}$. Para medir o pH das 
soluções utilizamos o pHmetro CORNING SCHOLAR $425^{\circledR}$. Para acidificar a solução utilizamos soluções aquosas de $\mathrm{HCl}$ de 1 a $10^{-3} \mathrm{M}$. Para deixar o meio mais alcalino utilizamos soluções aquosas de $\mathrm{NaOH}$ de $10^{-1}$ a $10^{-3} \mathrm{M}$.

Através destes experimentos foi possível determinar para quais concentrações ocorre a máxima adsorção de moléculas de PG na superfície das partículas de $\mathrm{TiO}_{2}$ e então, quantificar o processo de arraste.

\subsection{Experimentos de fotodegradação}

Nas últimas décadas, o $\mathrm{TiO}_{2}$ tem atraído muita atenção em diversas áreas. Uma característica interessante do $\mathrm{TiO}_{2}$, principalmente para aplicações biológicas, é a sua baixa toxicidade, assim como seu baixo custo de obtenção. Áreas como a fotocatálise heterogênea tem demonstrado grande interesse no uso de $\mathrm{TiO}_{2}$ na destruição de contaminantes químicos e biológicos. Nesta seção descreveremos a metodologia utilizada na fotodegradação do PG, catalisada pelas NPs de $\mathrm{TiO}_{2}$.

Como passo inicial para as medidas de fotodegradação foi necessário determinar as concentrações do PG e das NPs de $\mathrm{TiO}_{2}$ que otimizem o processo de degradação ou seja, as concentrações nas quais se tem uma máxima adsorção das moléculas do PG na superfície das partículas de $\mathrm{TiO}_{2}$. Tais pontos foram determinados através dos experimentos de arraste descritos na seção anterior, correspondendo aos pontos onde ocorre uma saturação do arraste. Como exemplo, temos na próxima figura um ponto circulado em azul, correspondendo à concentração de 0,6 g/L de NP de $\mathrm{TiO}_{2}$ do tipo A2 para $100 \mathrm{uL}$ de PG. 


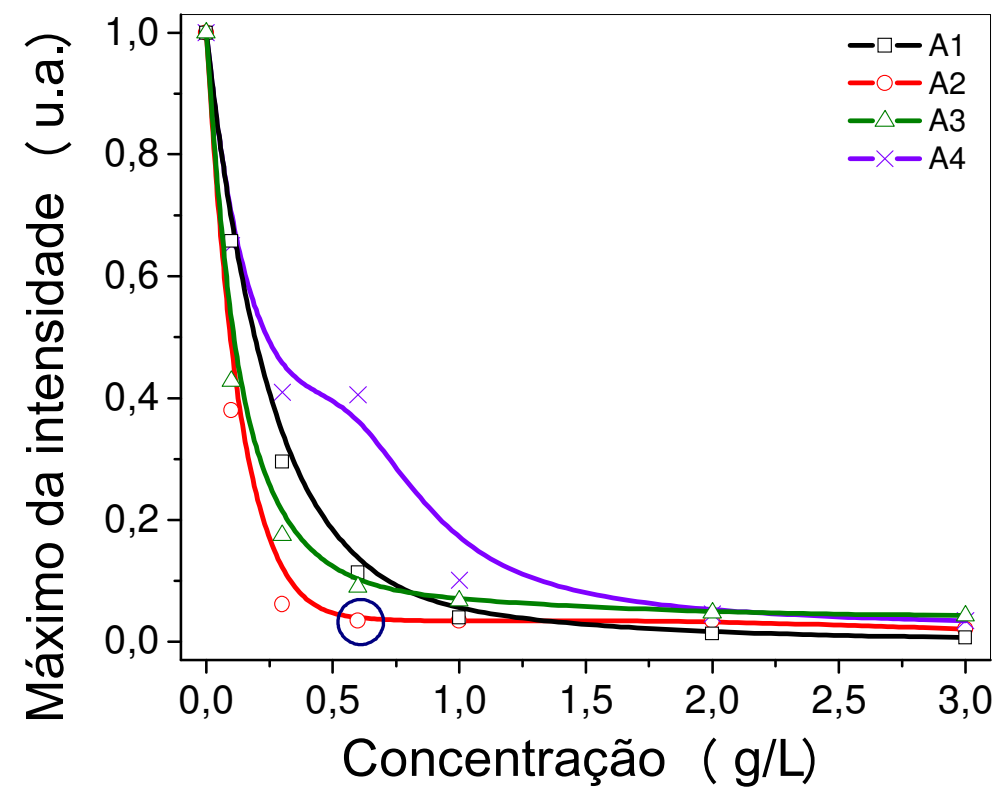

Figura 12 - Exemplo de determinação da concentração ótima através da PL do PG para diversas concentrações de $\mathrm{NPs}$ de $\mathrm{TiO}_{2}$ da série A. O círculo em azul corresponde ao ponto de concentração ótima para a partícula do tipo $A 2$

Depois de encontrado o ponto ótimo, podemos preparar a solução contendo a quantidade adequada de PG e o tipo específico de $\mathrm{TiO}_{2}$. Assim, como nos experimentos de arraste, mantivemos a solução sob agitação durante 10 minutos antes de retirar uma alíquota e então colocar em uma cubeta de $1 \mathrm{~cm}$. Esta alíquota corresponde a uma quantidade de solução necessária para cobrir a altura do feixe de luz utilizado para a degradação. A solução na cubeta também era mantida sob constante agitação durante todo o processo de degradação através de um agitador construído especialmente para se adaptar no interior do compartimento de medida do espectrofluorímetro. A fotodegradação da solução foi então feita no interior do espectrofluorímetro através de um feixe de luz de $395 \mathrm{~nm}$ que corresponde ao máximo da absorbância do PG. A potência do feixe utilizado foi de $18 \mathrm{~mW}$ e a área frontal no qual o feixe era incidido tinha $60 \mathrm{~mm}^{2}$. Portanto, o feixe tinha intensidade de $30 \mathrm{~m} \mathrm{~W} / \mathrm{cm}^{2}$. Espectros de absorção e PL da solução foram periodicamente medidos no próprio espectrofluorímetro. Também foi necessário fazer uma fotodegradação somente do PG para se ter um parâmetro de referência de degradação.

O processo de fotodegradação do PG possui dependência com a concentração do próprio PG na solução em um determinado instante de tempo t. Portanto, a fotodegradação pode ser descrita por uma cinética de primeira ordem ${ }^{28}$ dada pela equação (6). 


$$
\frac{[P G]_{t}}{[P G]_{0}}=e^{-k \cdot t}
$$

Onde:

$[P G]_{t} \rightarrow$ Concentração de PG em um instante $t$

$[P G]_{0} \rightarrow$ Concentração de PG no instante inicial (sem degradar)

$k \rightarrow$ Constante de velocidade da reação

$t \rightarrow$ Tempo de degradação

Como $[P G]_{t}$ é proporcional aos máximos dos espectros de absorção e PL podemos escrever a equação (6) na seguinte forma:

$$
\frac{I_{t}^{a b s, P L}}{I_{0}^{a b s, P L}}=e^{-k \cdot t}
$$

Onde:

$I_{t}^{a b s, P L} \rightarrow$ Máximo da absorção ou PL do PG no instante $t$

$I_{0}^{a b s, P L} \rightarrow$ Máximo da absorção ou PL do PG no instante inicial

Na figura 13 logo abaixo temos um exemplo de aplicação da equação (7) em escala logarítmica (eixo vertical).

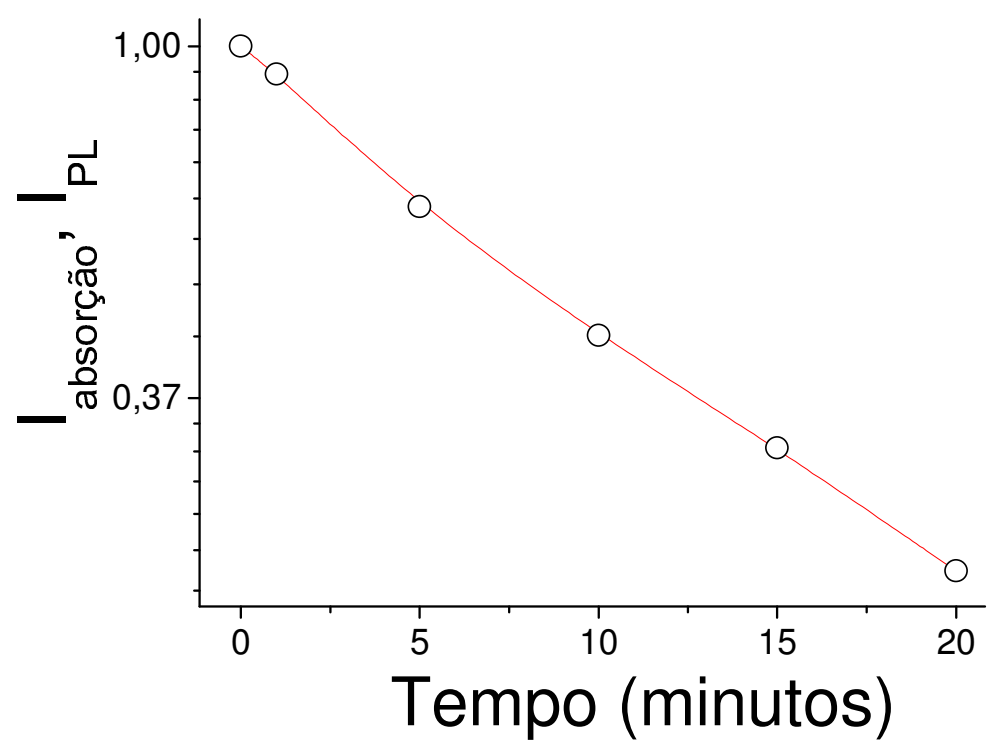

Figura 13 - Curva característica do processo de degradação do PG 


\section{RESULTADOS E DISCUSSÕES}

\subsection{Análise espectroscópica do PG}

As propriedades químicas e eletrônicas de porfirinas e ftalocianinas tem sido estudadas intensivamente por mais de $75 \operatorname{anos}^{33}$. Uma considerável fração dos trabalhos publicados dedicou-se à interpretação das regiões distintas no espectro óptico de absorção e emissão indo desde a região do infravermelho próximo até o UV-Visível. As porfirinas são pigmentos de cor púrpura e pode ser de origem natural. A estrutura em anel conjugado da porfirina é a razão pela qual todos os derivados porfírínicos absorvem luz mais eficientemente a um comprimento de onda próximo dos $410 \mathrm{~nm}$, dando-lhes a sua cor avermelhada característica. A presença adicional de um íon metálico pode afetar esta propriedade devido ao fenômeno de transferência de carga dos átomos de nitrogênio para o metal, que possui uma energia na faixa da radiação visível.

O PG, assim como outras moléculas que possuem uma estrutura de porfirina, possui bandas características de absorção no UV-Visível. A banda principal e de maior intensidade chama-se banda de Soret ou banda B e pode ser observada na figura 14 a) com pico em torno de 370nm. A banda de menor intensidade é chamada de banda Q. O espectro de PL mostra que há duas bandas principais. Uma de maior intensidade em $613 \mathrm{~nm}$ e outra de menor intensidade em $675 \mathrm{~nm}$. 

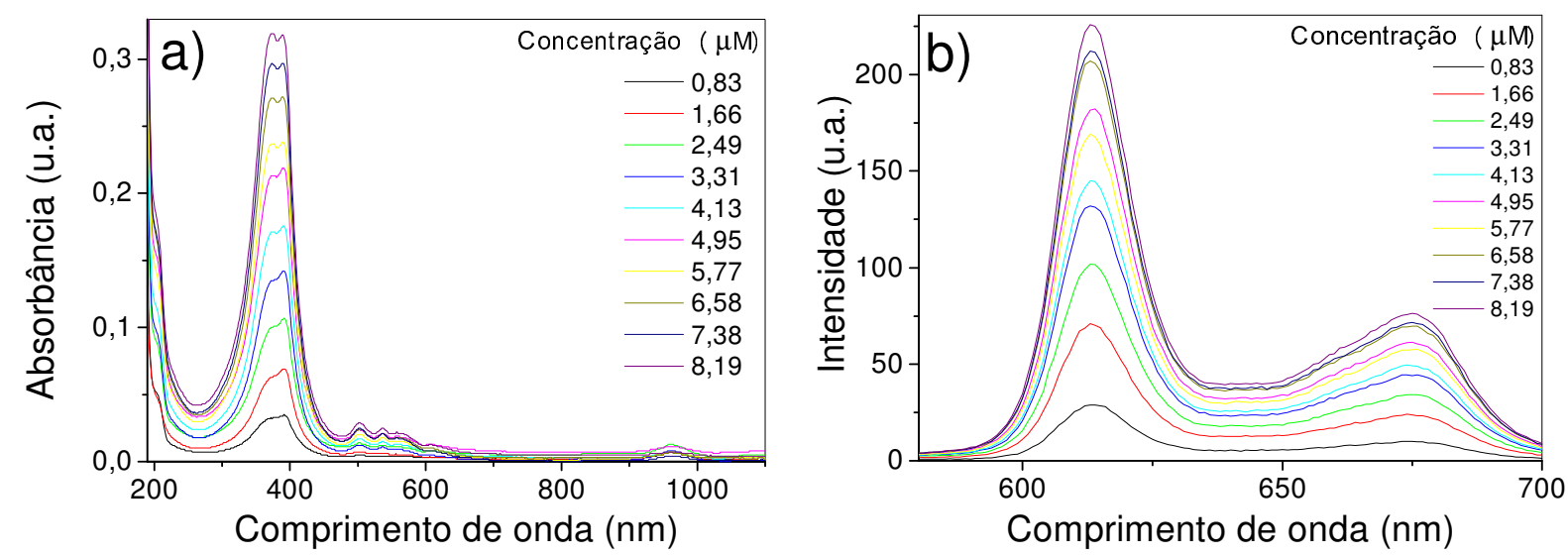

Figura 14 - a) Espectro de absorção do PG para várias concentrações; b) Espectro de PL do PG para várias concentrações

As concentrações de PG nas figuras 14 a) e b) correspondem a acréscimos de $20 \mu \mathrm{L}$ de PG da solução estoque em $10 \mathrm{~mL}$ de água Milli- $\mathrm{Q}^{\circledR}$. Este intervalo de concentrações inicia-se com a adição $20 \mu \mathrm{L}(0,83 \mu \mathrm{L})$ e termina com $200 \mathrm{uL}(8,19 \mu \mathrm{L})$. Podemos ver na figura 14 que a banda de Soret possui pico em torno de $370 \mathrm{~nm}$. A banda Q é caracterizada por quatro picos de menor intensidade em 503, 537, 568 e $606 \mathrm{~nm}$.
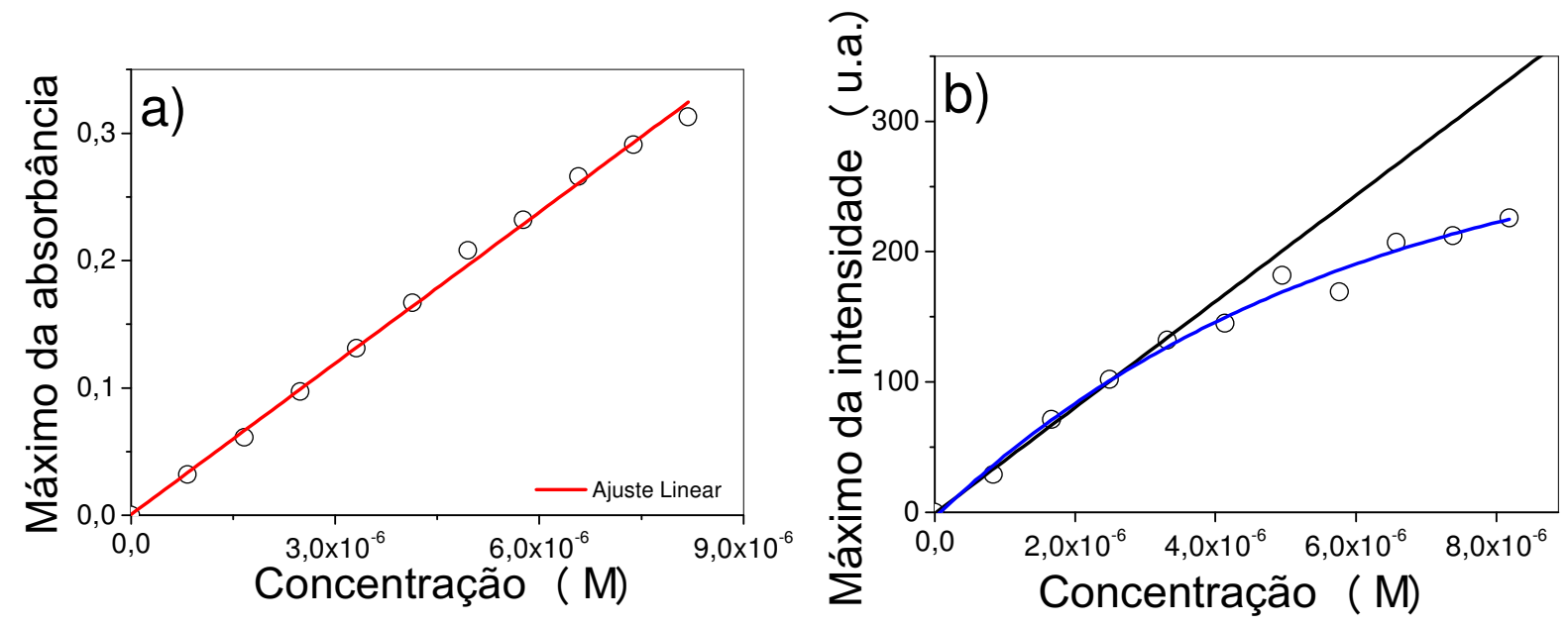

Figura 15 - a) Ajuste Linear para obtenção do coeficiente de extinção molar do PG; b) Ajuste linear no espectro de PL

Podemos estimar o coeficiente de extinção molar $\varepsilon$ do PG para o espectro de absorção em função da concentração C de PG através da variação do pico da banda de Soret e da lei de Lambert-Beer $(A=\varepsilon \cdot l \cdot C)^{14}$. Como é esperado por essa lei, a absorbância varia linearmente na faixa de concentração de PG estudada. A figura 15 a) mostra o ajuste linear resultando no 
valor de $\varepsilon=4 \times 10^{4} \mathrm{M}^{-1} \cdot \mathrm{cm}^{-1}$, valor este de acordo com o usualmente encontrado para porfirinas $^{1,2}$. Já a PL não segue a mesma tendência da absorbância (figura 15 b). A dependência da intensidade da PL é linear até concentrações de PG em torno de $4 \times 10^{-6} \mathrm{M}$ e apresenta um desvio da linearidade a partir de concentrações maiores, tendendo a uma saturação. Esta saturação é uma indicação da presença de processos não radiativos que se originam pela formação de agregados de PG. A literatura mostra que porfirinas podem formar dímeros e agregados do tipo $\mathrm{H}_{\text {e }} \mathrm{J}^{5,29}$. Levando em consideração as complicações produzidas pela formação de agregados, os experimentos a seguir foram realizados em sua maioria para concentrações menores que $4 \times 10^{-6} \mathrm{M}$.

\subsection{Interação de moléculas de PG com NPs de $\mathrm{TiO}_{2}$}

Os experimentos de arraste de moléculas de PG foram executadas com 16 diferentes tipos de NPs de $\mathrm{TiO}_{2}$, (tabela 1). Estas NPs foram divididas em quatro séries (A, B, C e D). Cada série difere da outra pela razão entre os precursores poliméricos (TI/AC/EG). Dentro de cada série, a diferença entre um tipo de partícula e outra se dá através da temperatura de calcinação. Descreveremos, a seguir, os resultados obtidos.

\subsubsection{Arraste pela variação da quantidade de PG}

Neste experimento, foram feitas medidas de adsorção de moléculas de PG sobre a superfície de NPs de $\mathrm{TiO}_{2}$. Com o intuito de observar uma maior diferença na adsorção das moléculas, escolhemos as NPs das séries A e D (tabela 1) por apresentarem maiores diferenças estruturais como tamanho de partícula, área superficial, composição, assim como a razão dos precursores utilizados na síntese. A concentração de $\mathrm{TiO}_{2}$ nas soluções foi mantida constante. 
As figuras 16 a) e b) mostram a dependência do valor do máximo da absorbância da banda de Soret e do máximo da intensidade da luminescência $\mathrm{I}_{\mathrm{PL}}$ em $613 \mathrm{~nm}$ das amostras da série A em função da concentração de PG, respectivamente. Os pontos pretos na figura são referentes às medidas executadas sobre a solução contendo apenas PG. Tais medidas foram realizadas com o intuito de se ter uma referência para fins de comparação. Também se vê na figura que a curva sobre os pontos pretos apresenta o mesmo coeficiente angular das curvas sobre outros pontos do gráfico. Neste experimento, a concentração da $\mathrm{NP}$ de $\mathrm{TiO}_{2}$ foi fixada em 0,3 g/L e as medidas de absorbância e PL foram feitas em alíquotas da solução sobrenadante após a centrifugação da solução contendo a NP e o PG.

Nos experimentos de arraste para NPs da série A podemos ver que há concordância entre os resultados experimentais e previstos na seção 2.3. Para concentrações dessa molécula abaixo de $4 \times 10^{-6} \mathrm{M}$, o valor da absorbância para o sobrenadante do sistema $\mathrm{PG}-\mathrm{TiO}_{2}$ é muito menor que a intensidade para o PG tomado como referência, o que demonstra a interação do PG com a partícula de $\mathrm{TiO}_{2}$. Nessa região, a intensidade aumenta lentamente com o aumento da concentração de PG o que pode estar associado à contribuição de NPs que não foram arrastadas na centrifugação. Para concentrações de PG maiores que $4 \times 10^{-6} \mathrm{M}$, a intensidade da PL do $\mathrm{PG}-\mathrm{TiO}_{2}$ aumenta a uma taxa próxima à do $\mathrm{PG}$, indicando que o PG já não pode mais se complexar sobre a superfície do $\mathrm{TiO}_{2}$ e, consequentemente, ocorre uma saturação na interação do $\mathrm{PG}$ com o $\mathrm{TiO}_{2}$, o que produz um aumento da concentração do $\mathrm{PG}$ na solução sobrenadante. Também podemos observar que o ponto de saturação é diferente para as quatro NPs (em torno de $4 \times 10^{-6} \mathrm{M}$ ) o que confere propriedades químicas (número de grupos funcionais ligantes, fase) e/ou físicas (razão área/volume (S/V)) distintas para estas partículas que podem alterar o processo de adsorção do PG na superfície das $\mathrm{NPs}$ de $\mathrm{TiO}_{2}$. Tirando o efeito da saturação da PL (figura 15 b)) para altas concentrações de PG, o mesmo efeito pode ser observado para a intensidade da PL (figura 16 b)). Este resultado demonstra que tanto a absorbância quanto a emissão podem dar informações sobre o processo de adsorção molecular sobre NPs quando se emprega a metodologia de arraste acima descrita. 

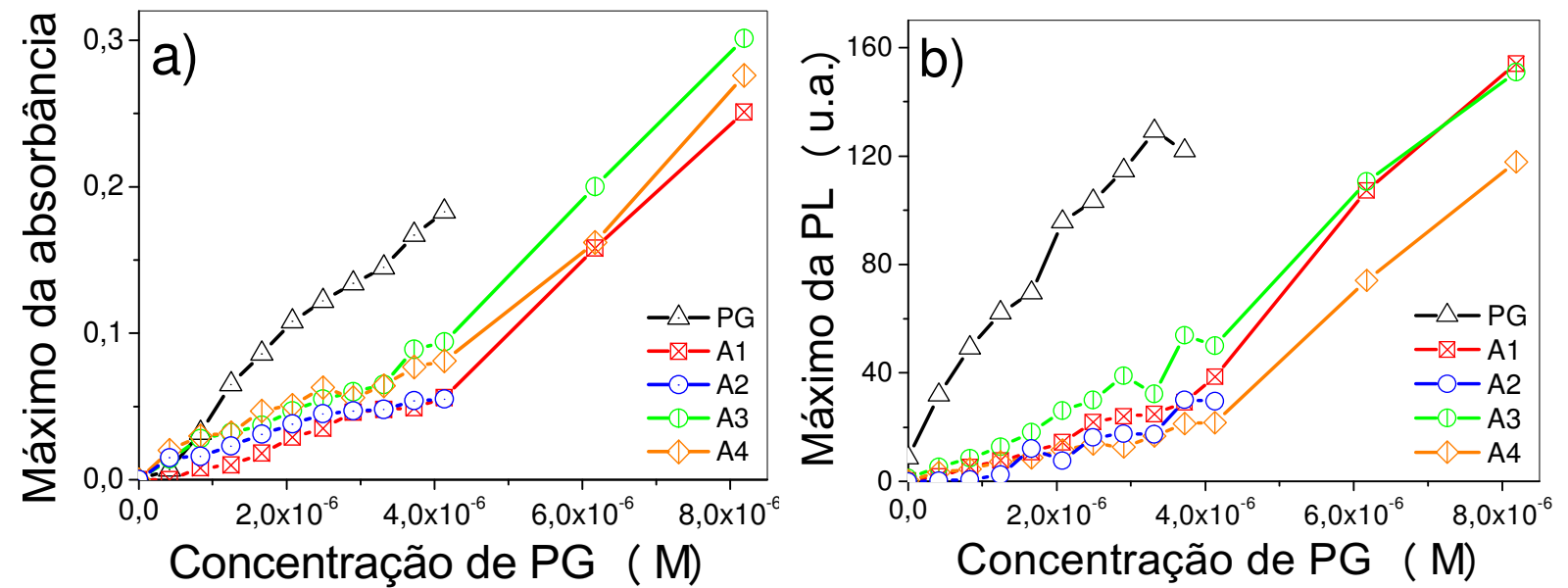

Figura 16 - a) Dependência a) do valor do máximo da absorbância da banda de Soret e b) da intensidade da luminescência $\boldsymbol{I}_{P L}$ em $613 \mathrm{~nm}$ das amostras da série A em função da concentração de $P G$

A figura 17 mostra o mesmo experimento descrito acima para as partículas da série D. Neste experimento, a concentração da $\mathrm{NP}$ de $\mathrm{TiO}_{2}$ também foi fixada em $0,3 \mathrm{mg} / \mathrm{mL}$ e as medidas de absorbância e PL foram feitas em alíquotas da solução sobrenadante após a centrifugação da solução contendo a NP e o PG.
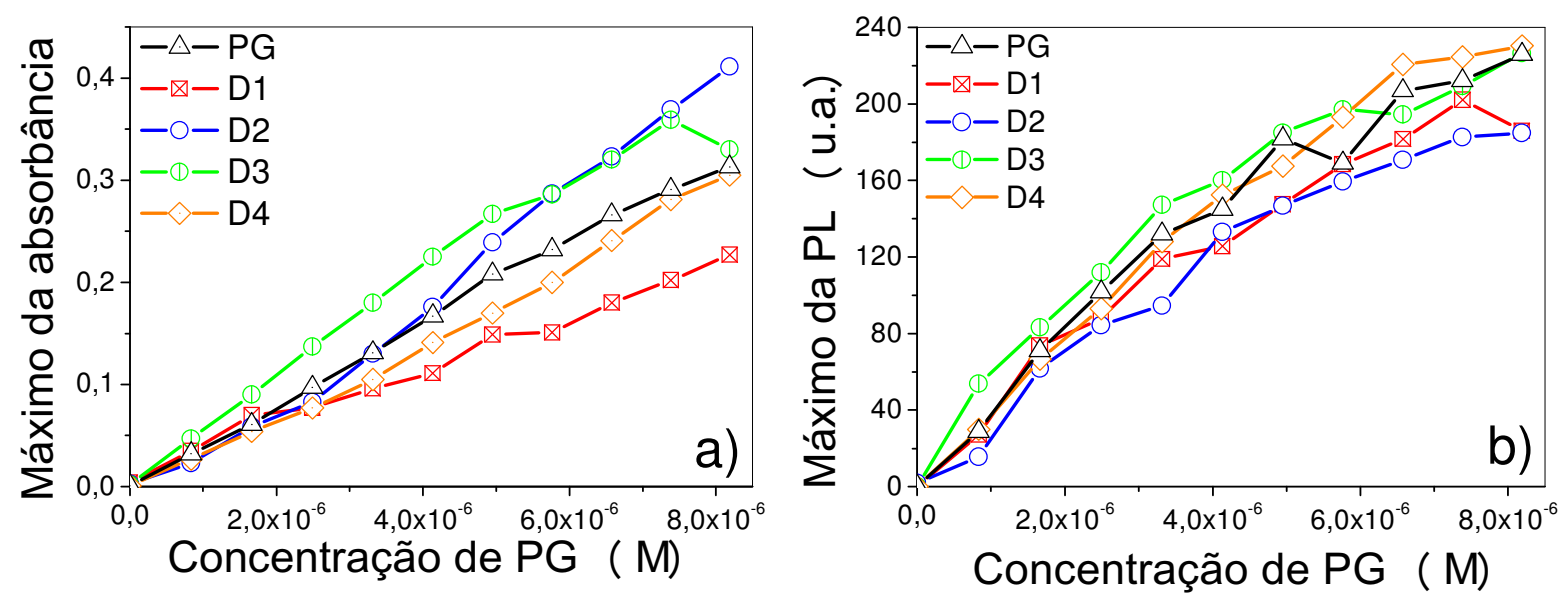

Figura 17 - a) Dependência do valor do máximo da absorbância da banda de Soret e b) da intensidade da luminescência $I_{P L}$ em $613 \mathrm{~nm}$ das amostras da série $D$ em função da concentração de PG

Analisando as figuras 17 a) e b), pode-se ver que elas possuem comportamento e taxas semelhantes àqueles medidos para a solução contendo apenas PG tomada como referência (triângulos pretos). $\mathrm{O}$ experimento não possui a forma característica de um processo de arraste típico observado para as partículas da série A, mas certamente está refletindo as suas 
propriedades e interações moleculares. Uma possível hipótese para a ausência de arraste seria o fato das partículas da série D serem maiores se comparadas com as partículas da série A (conforme a tabela 1) e em decorrência disto, possuírem menores áreas superficiais, o que resultaria numa menor capacidade de adsorção de moléculas. Tal hipótese não se verifica muito consistente, pois não observamos efeito de arraste para partículas do tipo D1 que possui tamanho e área superficial comparável às partículas do tipo A3, mesmo para pequenas concentrações de PG. Outra possível explicação que se mostra mais consistente pode estar na diferença entre as razões TI/AC/EG dos precursores poliméricos das séries A e D. Retornando à tabela 1 , vemos que a série $\mathrm{D}(1: 2: 8)$ possui concentração do precursor de Ti (isopropóxido de titânio) oito vezes maior que a da série $\mathrm{A}(1: 16: 64)$. Também vemos na tabela 1 que para as partículas da série $\mathrm{D}$ há uma maior presença de $\mathrm{TiO}_{2}$ na forma rutilo conforme se aumenta a temperatura de calcinação. Para NPs da série A, a fase anatase é predominante, mesmo para altas temperaturas. Assim, podemos atribuir à fase rutilo à baixa adsorção do $\mathrm{PG}$, pois este possui uma estrutura menos reativa que a anatase ${ }^{34}$, resultando em um menor número de sítios ativos para arraste. Esta pode ser a razão para a preferência no uso de camadas aceitadoras de elétrons de $\mathrm{TiO}_{2}$ cristalino na fase anatase em células fotovoltaicas de corante ${ }^{35-40}$.

Os experimentos acima demonstram que o método de arraste desenvolvido no presente trabalho é bastante sensível à interação molecular com NPs em solução. Os parâmetros utilizados devem ser encontrados previamente e ajustados principalmente ao número de sítios ativos na superfície que é proporcional à razão S/V das NPs. O mesmo resultado pode ser obtido fazendo-se o arraste em função da concentração da NP e será descrito na próxima seção. Esta metodologia auxilia na determinação dos efeitos dos principais parâmetros envolvidos na interação e adsorção molecular sobre as NPs.

\subsubsection{Arraste através da variação da quantidade de $\mathrm{TiO}_{2}$}

Neste experimento, utilizamos uma metodologia oposta ao que foi empregada na seção anterior. Mantivemos fixa a concentração de moléculas de PG em um valor menor ou igual à concentração de saturação, encontrado na seção anterior. Assim, garantimos a condição de 
máximo arraste ou menor concentração de PG na solução sobrenadante após a centrifugação (ver figura 16). O valor da absorbância e da luminescência é medido variando a concentração de NPs de $\mathrm{TiO}_{2}$ nas soluções. Pela simplicidade do experimento, foi possível fazer uma comparação entre as quatro séries de $\mathrm{NPs}$ de $\mathrm{TiO}_{2}$. Para cada tipo de partícula de $\mathrm{TiO}_{2}$ foram feitas medidas de PL e absorção com a finalidade de entender e quantificar o efeito de arraste, ou seja, a interação especifica de cada tipo de partícula com as moléculas de PG.

A figura 18 compara a dependência do valor máximo da banda de Soret da solução sobrenadante em função da concentração das $\mathrm{NPs}_{\text {de }} \mathrm{TiO}_{2}$ (gráficos à esquerda) e da razão entre a concentração e a área superficial específica (gráficos à direita) para as séries A, B, C e D em solução contendo concentração de PG de $4 \times 10^{-6} \mathrm{M}$ antes da centrifugação. Espectros de absorbância mostraram baixo efeito de espalhamento de luz ou absorção das NPs de $\mathrm{TiO}_{2}$ na região espectral de absorção do PG para a faixa de concentração de $\mathrm{TiO}_{2}$ utilizada, uma vez que essas partículas estão sendo sedimentadas em sua maioria a uma centrifugação de $14680 \mathrm{rpm}$.

Vemos que a absorbância em $375 \mathrm{~nm}$ da solução sobrenadante cai para valores menores que a metade com o aumento da concentração de $\mathrm{TiO}_{2}$, que é uma indicação do arraste do PG junto com as NPs e, conseqüentemente, da adsorção do PG. Detalhes dessa adsorção serão discutidos mais abaixo. Vemos que a intensidade da interação molecular medida pela adsorção depende da série e do tipo de tratamento térmico dentro de uma mesma série (figura 18, à direita), porém fica difícil observar uma correlação com os parâmetros de preparação das amostras. Devido ao fato do fenômeno de adsorção ser um fenômeno de superfície é importante também analisar o efeito de arraste levando em conta as áreas superficiais das partículas. 

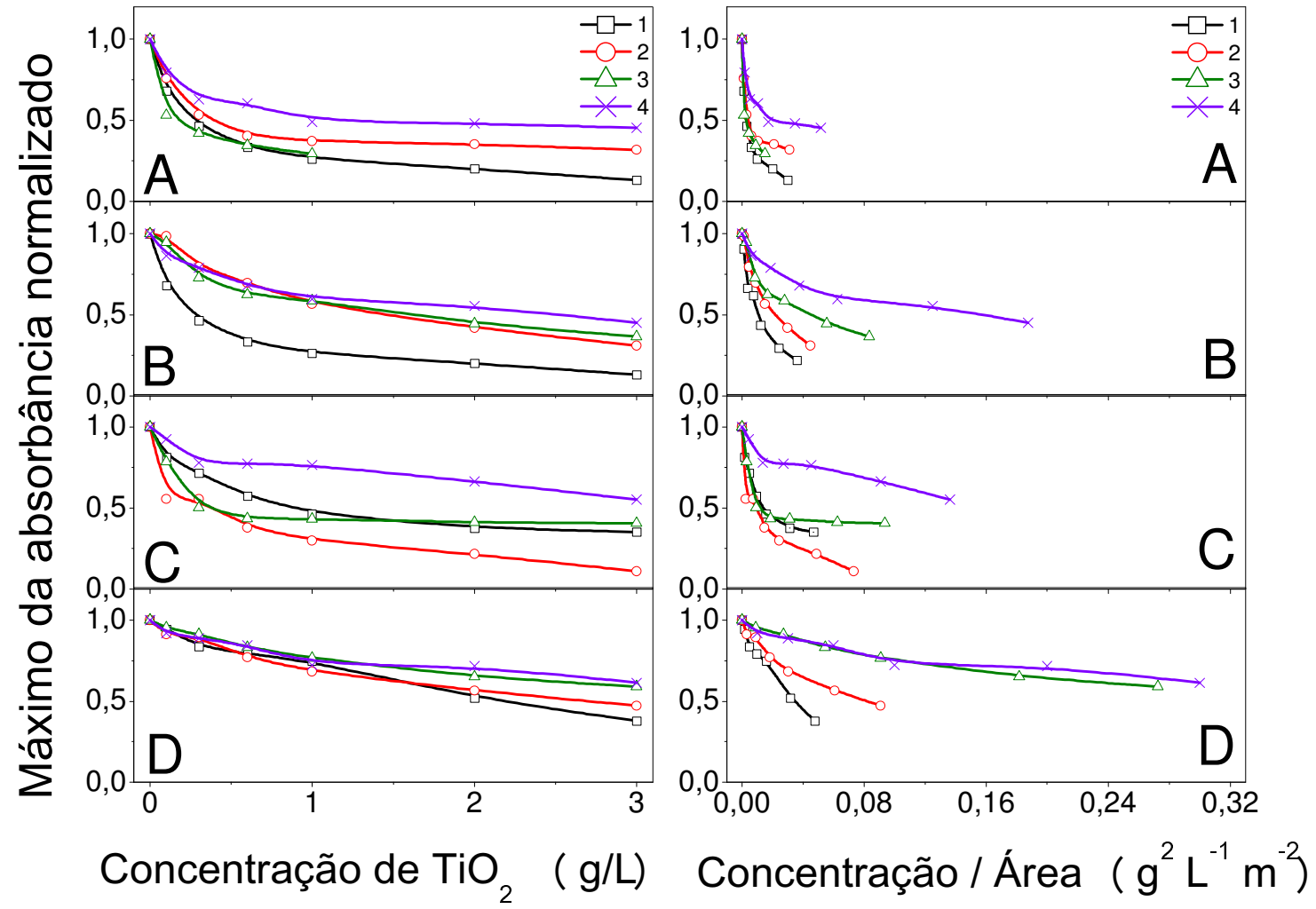

Figura 18 - Dependência do valor máximo da banda de Soret da solução sobrenadante em função da concentração das $\mathrm{NPs}$ de $\mathrm{TiO}_{2}$ (gráficos à esquerda) e da área efetiva (gráficos à direita) para as séries $A, B, C$ e $D$ em solução contendo concentração de $P G$ de $4 \times 10^{-6} M$ antes da centrifugação

Podemos eliminar o efeito da área tomando a dependência do valor da absorbância em função da razão da concentração pela área superficial efetiva $S_{\mathrm{BET}}$ (figura 18 à direita). Vemos agora uma melhor diferenciação entre as amostras. A adsorção é mais eficiente para as NPs da série A com menor porcentagem no precursor de Ti. As partículas das séries B e C possuem comportamento semelhante e as amostras da série D apresentam uma menor adsorção do PG, o que é coerente com os resultados da seção anterior de que o PG possui maior afinidade para amostras com menor concentração de Ti. Dentro de uma mesma série, a adsorção molecular aumenta com o decréscimo da temperatura de tratamento. Isto pode estar associado com a concentração de sítios na superfície responsáveis pelo ancoramento molecular e que pode estar associado à predominância de uma fase. A tabela 1 mostra que a porcentagem da fase anatase cai com o aumento da concentração do precursor de Ti, ou seja, indo na ordem de A a D. 

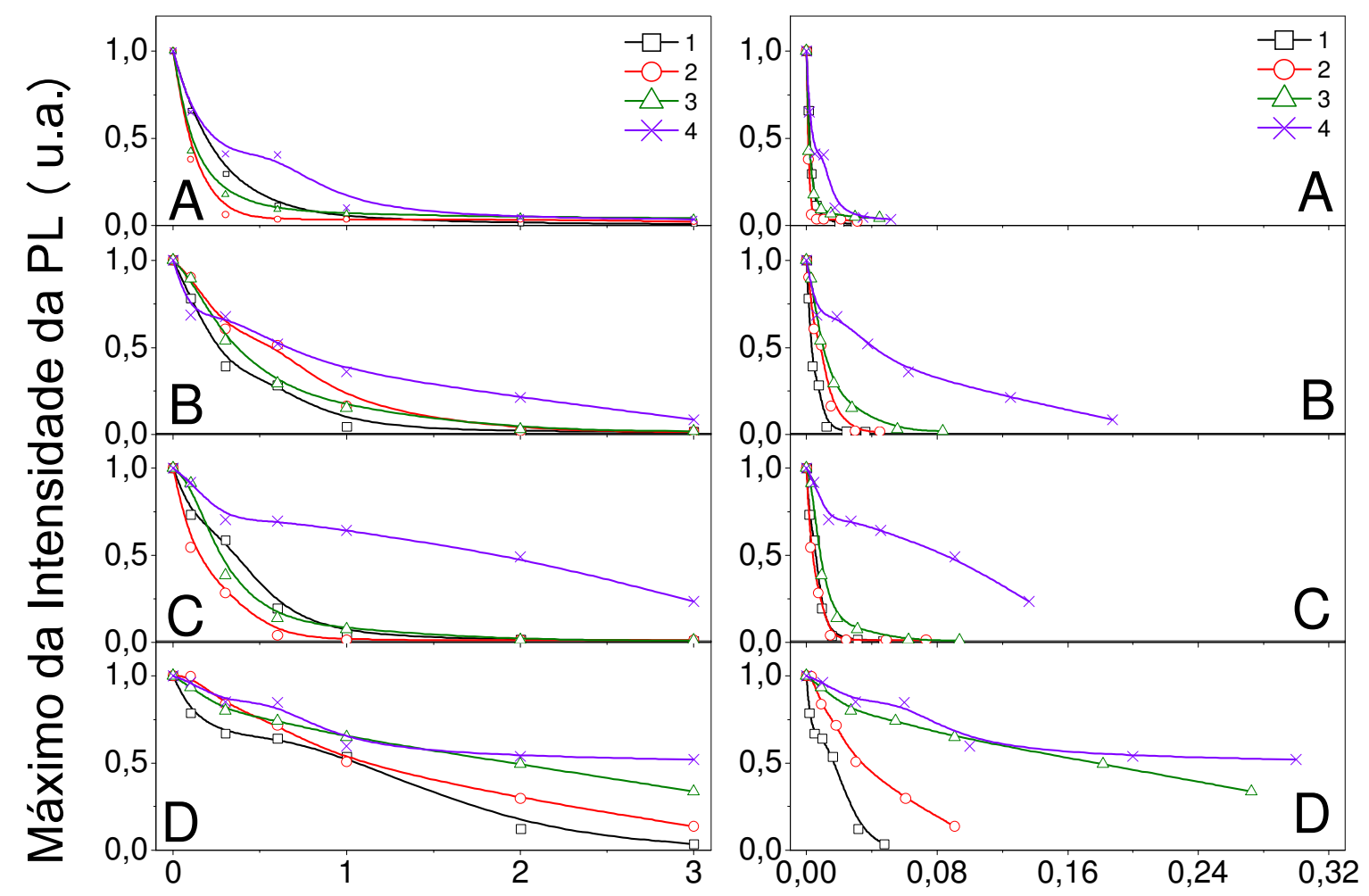

Concentração de $\mathrm{TiO}_{2}$ ( $\left.\mathrm{g} / \mathrm{L}\right)$ Concentração / Área $\left(\mathrm{g}^{2} \mathrm{~L}^{-1} \mathrm{~m}^{-2}\right)$

Figura 19 - Resultados medidos através de espectroscopia de fotoluminescência (PL) para o efeito de arraste ao se variar a quantidade de $\mathrm{TiO}_{2}$

$\mathrm{O}$ efeito de arraste ou adsorção molecular sobre NPs de $\mathrm{TiO}_{2}$ pode ser melhor observado na figura 19 pelas medidas da intensidade da PL das mesmas soluções sobrenadantes das amostras da figura 18. Diferentemente da absorbância, a intensidade da luminescência cai à zero com o aumento da concentração para a maioria das NPs. Este efeito se deve à adsorção seguida da transferência de carga do elétron excitado para o volume do $\mathrm{TiO}_{2}$. Este efeito será discutido com maiores detalhes mais a frente. A eliminação do efeito da área superficial é apresentada nos gráficos da figura 19 à direita. Com isso, podemos concluir que o processo de adsorção seguida de transferência de carga é mais eficiente para a série A com maior porcentagem da fase anatase $(\sim 100 \%)$. Este processo é menos eficiente para as NPs tratadas a temperaturas de $700{ }^{\circ} \mathrm{C}$.

Para melhor comparar partículas de séries distintas, as figuras 20 a) e b) mostram, respectivamente, as intensidades da absorbância e da PL em função da concentração das partículas A3, B2, C1 e D1. Tais partículas foram escolhidas devido ao fato de possuírem áreas superficiais semelhantes e por serem de séries distintas. Assim, podemos eliminar o 
efeito de área e utilizar os resultados das figuras 18 e 19 para as partículas mencionadas. Este procedimento garante que para cada valor de concentração no gráfico foi mantida constante a área superficial. Assim, podemos comparar partículas de séries distintas com áreas superficiais médias semelhantes (raio médio 23 nm).

Dois pontos devem ser salientados nestas figuras. Primeiramente, pode-se observar novamente que as medidas de absorbância e de luminescência fornecem resultados semelhantes, ou seja, que a adsorção do PG depende fortemente da porcentagem das fases nas NPs de $\mathrm{TiO}_{2}$. Veremos mais adiante que os espectros fornecem informações adicionais referentes à natureza da interação e fotofísica. Em segundo lugar, as medidas de absorbância na figura 20 a) deixa claro que podem existir mais de um processo de absorção dependentes da concentração das partículas. Isso pode ser visto por um decaimento inicial rápido, seguido de outro decaimento mais lento e, finalmente de uma tendência a saturação da adsorção para altas concentrações de NPs. Estes efeitos são mais complexos e podem estar associado à presença de mais de uma entidade molecular na solução de PG, como dímeros, oligômeros e agregados moleculares, como já bem reportado na literatura ${ }^{29}$ para porfirinas como o PG. Este ponto será tratado com mais detalhes em estudos futuros. A saturação da absorbância em torno de 1/3 (figura 20 a)) pode estar associada a porfirinas degradadas ou que possuem seus pontos de ancoramento comprometidos por defeitos. Estas moléculas absorvem luz através do anel conjugado, mas emitem muito pouca luminescência, como nos agregados moleculares. Vemos, portanto, que o método pode ser seletivo a espécies moleculares diferentes ou degradadas em solução. Deve-se salientar que processos de espalhamento na solução sobrenadante são minimizados pelo processo de centrifugação.
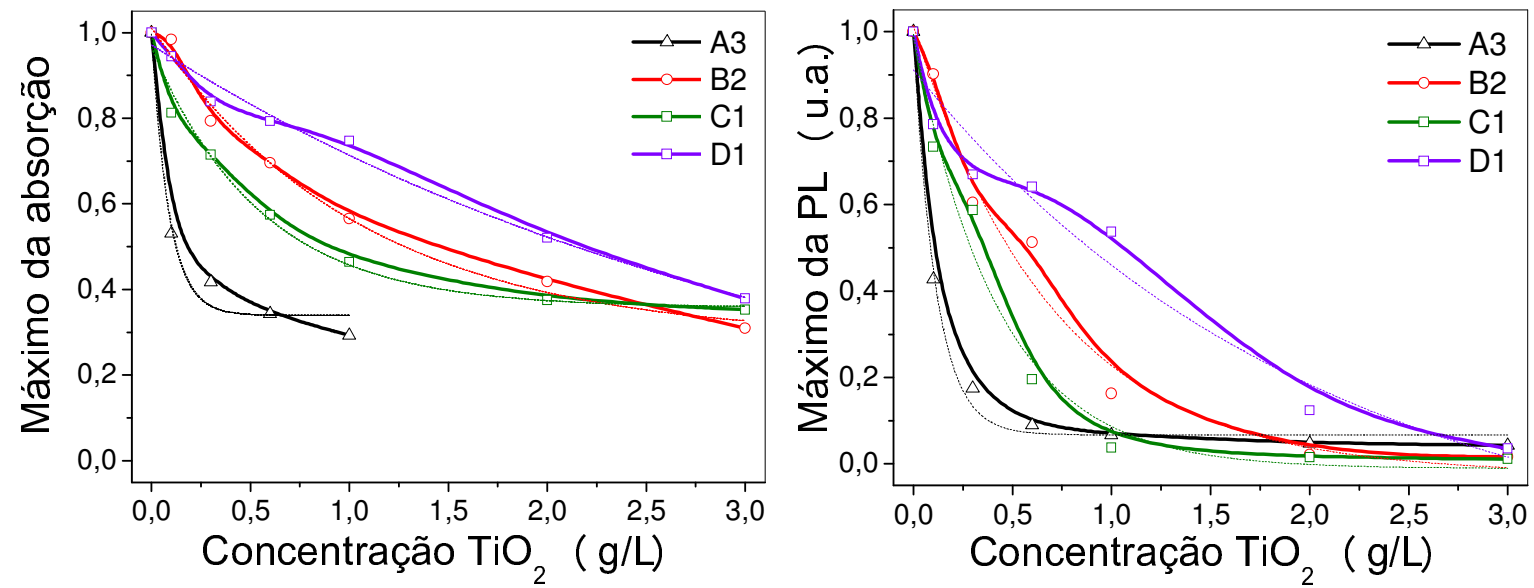

Figura 20 - Resultados medidos através de a) espectroscopia de absorção e b) PL para o efeito de arraste ao se variar a quantidade de $\mathrm{TiO}_{2}$ para as partículas do tipo A3, B2, Cl e D1. As linhas pontilhadas correspondem ao ajuste (fitting) de cada curva experimental 
Em um modelo ideal as moléculas são totalmente arrastadas desde que se tenha adsorção em uma concentração de partículas que possua sítios de ancoramento maior que o número de moléculas na solução. Como a adsorção é proporcional ao número de moléculas na solução (à concentração C), o arraste molecular pelas partículas deve ser uma exponencial simples do tipo $\mathrm{y}=\mathrm{y}_{0}+\mathrm{A} \cdot \mathrm{e}^{(-\mathrm{C} / \mathrm{k})}$, onde $\mathrm{y}_{0}$ é o termo de saturação, $\mathrm{A}=1$ e $\mathrm{k}$ é uma constante de arraste. Utilizamos esta equação para ajustar o decaimento da luminescência (ver curvas pontilhadas na figura 20 b) que possuem uma forma mais simples que a absorção e saturação praticamente nula $\left(\mathrm{y}_{0} \sim 0\right)$. $\mathrm{O}$ arraste molecular é eficiente para valores de $\mathrm{k}$ pequenos e o contrário para k grande. Segue abaixo um gráfico mostrando como as constantes $\mathrm{y}_{0}$, A e k para cada tipo de partícula mostrado na figura 19. Vemos que os valores de $\mathrm{y}_{0}$ e A correspondem aos valores esperados e que o valor de k aumenta com o aumento do precursor de $\mathrm{TiO}_{2}$ na síntese $(\mathrm{A} \rightarrow \mathrm{D})$, indicando uma piora na eficiência do arraste, apesar de uma melhora nas amostras $\mathrm{C} 1, \mathrm{C} 2$ e C3. As partículas da série D possuem um maior valor de k, evidenciando a baixa afinidade entre as partículas desta série e as moléculas de PG.

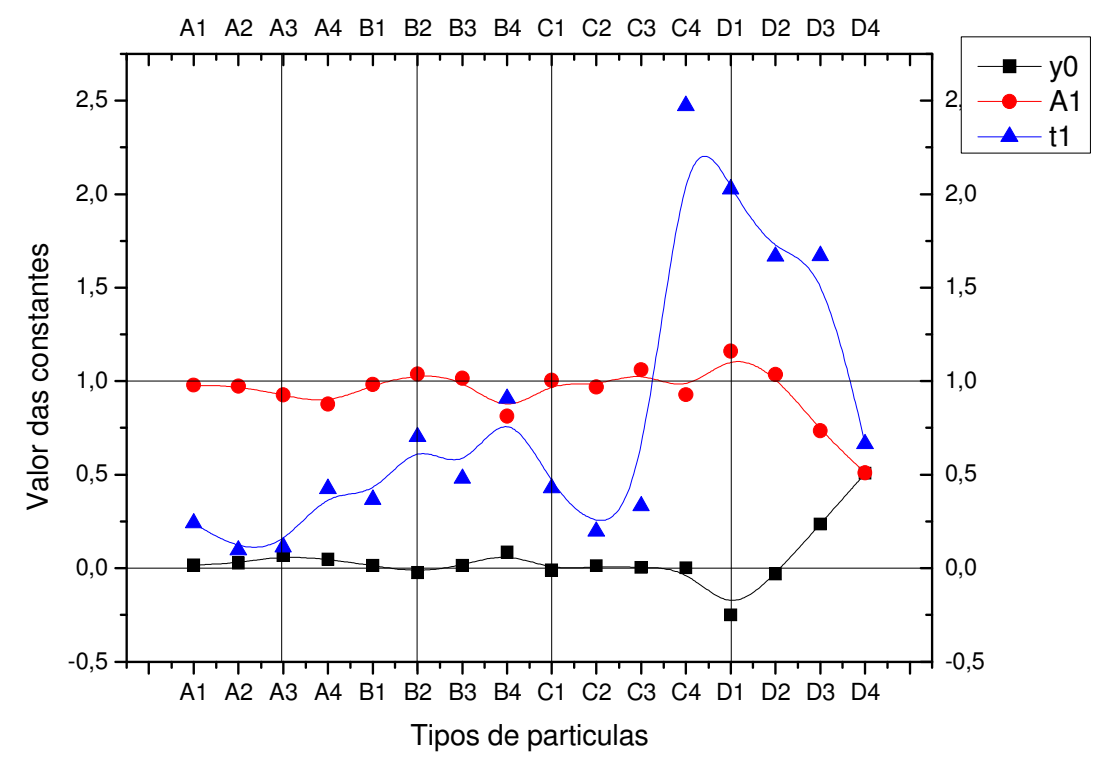

Figura 21 - Constantes $\boldsymbol{y}_{\mathbf{0}}$ e $k$ obtidas do ajuste exponencial para cada tipo de partícula mostrado na figura 19

Podemos fazer uma estimativa do número de moléculas por $\mathrm{NP}$ de $\mathrm{TiO}_{2}$, por exemplo das NPs A3, B2, C1 e D1 da figura 20 b). Suporemos na estimativa que essas partículas são esféricas e possuem mesma área (raio=23 nm). Por extrapolação, as concentrações de NPs podem ser obtidas das curvas de decaimento da luminescência para as quais o arraste das moléculas que adsorvem é total. Assim, o número médio de moléculas de PG por partícula de 
$\mathrm{TiO}_{2}$ é calculado e mostrado na tabela 2. Nesse cálculo foi considerado o fato de $30 \%$ das moléculas de PG não serem arrastadas (ver discussão acima).

Tabela 2 - Estimativa do número médio de moléculas de PG adsorvidas na superfície das partículas de $\mathrm{TiO}_{2}$

\begin{tabular}{ccc}
\hline Tipo de partícula & Pontos críticos (g/L) & № médio de PG / partículas de $\mathrm{TiO}_{2}$ \\
\hline A3 & 0,6 & 97 \\
B2 & 2 & 31 \\
C1 & 1 & 62 \\
D1 & 3 & 21 \\
\hline
\end{tabular}

Analisando a tabela 2 vemos que as partículas do tipo A3 possuem uma afinidade muito grande pelas moléculas de PG. Para as partículas da série D1 esta afinidade é quase cinco vezes menor. A obtenção destes valores referentes à cobertura molecular para cada tipo de partícula também é de fundamental importância para aplicações, bem como para o processo de fotodegradação que será descrito mais adiante, pois o processo será otimizado se todas as moléculas de PG estiverem adsorvidas na superfície das partículas de $\mathrm{TiO}_{2}$.

\subsubsection{A adsorção molecular sobre o $\mathrm{TiO}_{2}$}

$\mathrm{Na}$ seção anterior observamos que a absorção e luminescência detectam efeitos distintos da adsorção do PG sobre a superfície da NP de $\mathrm{TiO}_{2}$. Essa seção tem o objetivo de elucidar melhor estes efeitos e diferenças. Vamos apresentar o processo de adsorção sem fazer a centrifugação em termos da PL do PG (concentração fixa de $2 \times 10^{-6} \mathrm{M}$ ) e da concentração da NP de $\mathrm{TiO}_{2}$ em solução aquosa. Utilizaremos NPs produzidas pela empresa SIGMA $\mathrm{ALDRICH}^{\circledR}$ (tamanho médio=20 nm) que formam solução coloidal monodispersa, ou seja, as NPs não decantam ou alteram o estado de dispersão durante as medidas de absorbância e PL, condição que garante a confiabilidade das medidas. O espalhamento das NPs foi minimizado no intervalo de concentrações de $\mathrm{TiO}_{2}$ utilizado, de modo a não alterar as medidas de PL. 
A figura 22 a) mostra na região do ultra-violeta os espectros de excitação (detectados em $613 \mathrm{~nm}$ ) e os espectros de emissão correspondentes (excitados em $395 \mathrm{~nm}$ ) na região do vermelho $(600-700 \mathrm{~nm})$ do PG em função da concentração das NPs SIGMA ALDRICH ${ }^{\circledR}$ em solução com $\mathrm{pH}=7$. No gráfico utilizou-se escala logarítmica no eixo das ordenadas para dar evidencia às pequenas intensidades. Nesse experimento não houve centrifugação. Primeiramente, pode-se observar que a intensidade da luminescência do PG cai mais de uma ordem de grandeza para concentrações de $\mathrm{TiO}_{2}$ variando de 0 a $0,5 \mathrm{mg} / \mathrm{mL}$ o que indica uma supressão da emissão pela interação entre o $\mathrm{PG}$ e o $\mathrm{TiO}_{2}$. Além disso, a espécie emissora residual muda para altas concentrações de $\mathrm{TiO}_{2}$, o que pode ser visto pela mudança da forma espectral e predominância da linha de emissão em torno de $640 \mathrm{~nm}$. Esta emissão tem sido associada à espécie degradada de PG. Pode-se ver também que as bandas Q entre 450 e 580 nm não são detectadas para essa espécie.
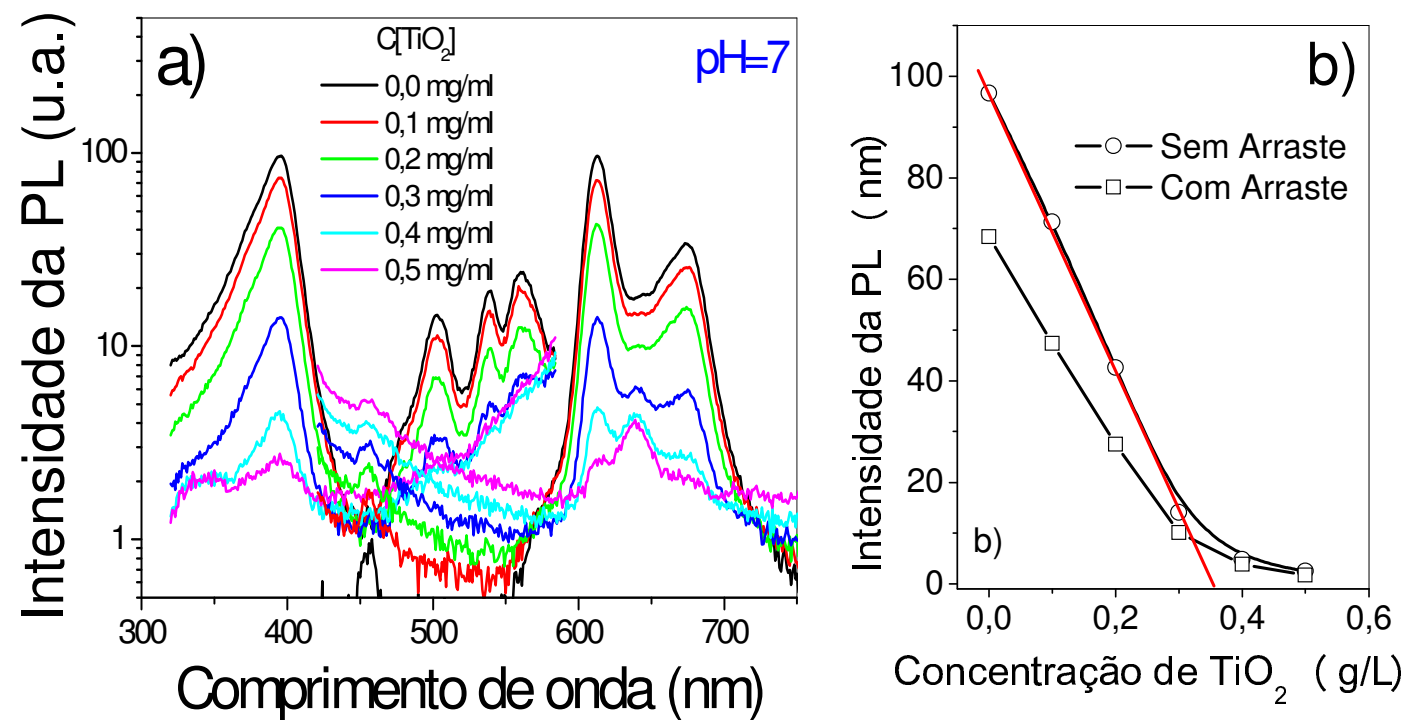

Figura 22 - a) Espectros de excitação (detectados em $613 \mathrm{~nm}$ ) na região do ultra-violeta e espectros de emissão correspondentes (excitados em $395 \mathrm{~nm}$ ) na região do vermelho (600-700 $\mathrm{nm}$ ) do PG e b) intensidade da PL com e sem centrifugação em função da concentração das NPS SIGMA ALDRICH ${ }^{\circledR}$ em solução com $\mathrm{pH}=7$

Mais detalhes desta interação entre $\mathrm{PG}$ e $\mathrm{TiO}_{2}$ pode ser visto na figura $22 \mathrm{~b}$ ). Esta figura mostra a intensidade da PL em $613 \mathrm{~nm}$ em função da concentração das NPs SIGMA $\mathrm{ALDRICH}^{\circledR}$ sem (figura 22 a)) e com centrifugação ou arraste (medindo o sobrenadante). A intensidade cai linearmente com o aumento da concentração de $\mathrm{TiO}_{2}$ até $0,3 \mathrm{mg} / \mathrm{mL}$. Isso significa que o PG se complexa com o $\mathrm{TiO}_{2}$ e ao mesmo tempo sua emissão é fortemente 
suprimida. Acima de $0,3 \mathrm{mg} / \mathrm{mL}$ existe uma saturação devido a emissão das espécies que não interagem com o $\mathrm{TiO}_{2}$. Estas espécies devem possuir baixa eficiência de emissão (degradadas ou estar na forma de pequenos agregados) ou estar em baixa concentração. É interessante observar que a intensidade da emissão cai pouco com o arraste. Como já demonstramos que as partículas são arrastadas, isto significa que as porfirinas sobre a superfície da NP de $\mathrm{TiO}_{2}$ têm a emissão fortemente suprimida. A queda da emissão com o arraste se deve a um percentual de porfirinas (aglomerados) que são arrastadas pela centrifugação de $14680 \mathrm{rpm}$. A diminuição da intensidade da PL na solução contendo somente PG (solução $0 \mathrm{mg} / \mathrm{mL}$ de $\mathrm{TiO}_{2}$ ) após a centrifugação é uma indicação da presença de partículas ou aglomerados grandes não solubilizadas de PG.
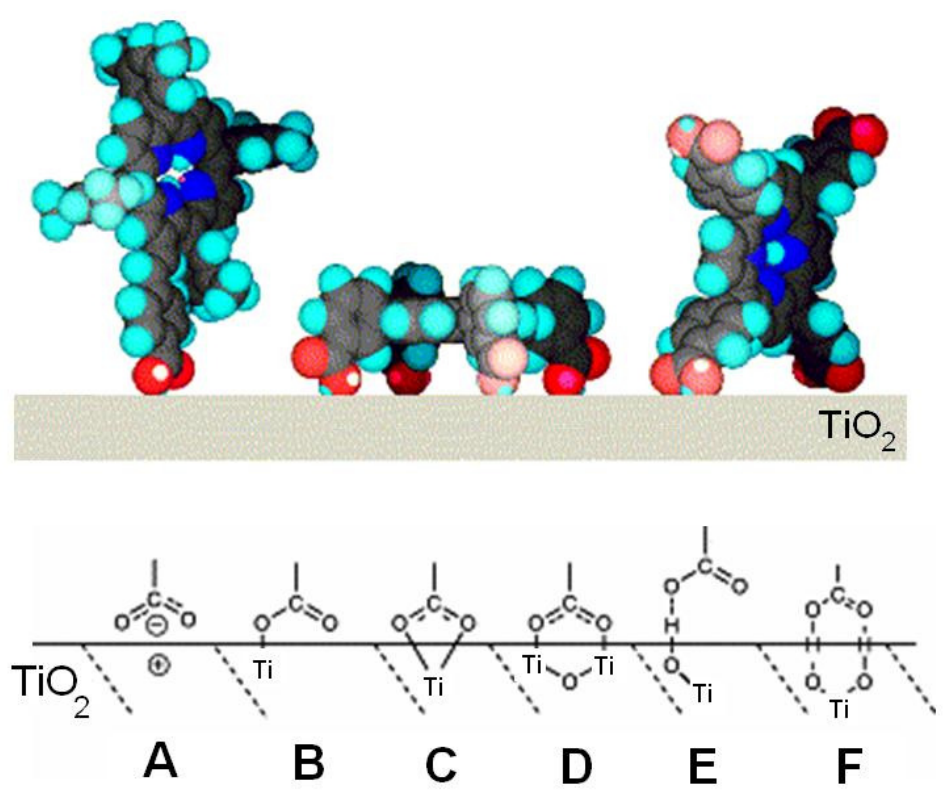

Figura 23 - Possíveis orientações da porfirina e modos de ligação (A até F) para o ácido carboxílico sobre $\mathrm{TiO}_{2}{ }^{4 l}$

Vimos acima que a fração cristalina (anatase e rutilo) desempenha um papel importante na adsorção do PG sobre o $\mathrm{TiO}_{2}{ }^{40}$. O método desenvolvido neste trabalho exige não apenas condições de propriedades ópticas ideais (minimização de agregados e resíduos, por exemplo) e o entendimento dos processos ópticos envolvidos, mas também acoplamento eletrônico interfacial estável. $\mathrm{O}$ ancoramento de corantes sobre $\mathrm{TiO}_{2}$ vem sendo realizado com sucesso através de vários grupos funcionais, como salisalato, ácido sulfônico e acido fosfórico. Grupos carboxílicos ácidos, como no PG, garantem a adsorção eficiente do corante e promove também um acoplamento eletrônico entre os níveis doadores do cromóforo 
excitado e os níveis aceitadores do nanocristal de $\mathrm{TiO}_{2}{ }^{41,42}$. A figura 23 ilustra possíveis orientações da porfirina e modos de ligação (A até F) para o ácido carboxílico sobre $\mathrm{TiO}_{2}$. Alguns modos possíveis ${ }^{41}$ indo desde ligação química até ligações de hidrogênio ( $\mathrm{A}=$ aniônica; $\mathrm{B}=$ =éster; $\mathrm{C}, \mathrm{D}=$ quelação e ponte; $\mathrm{E}, \mathrm{F}=$ ponte de hidrogênio). Hoje se sabe que pelo menos dois grupos $\mathrm{COOH}$ são necessários para formar uma ligação efetiva à superfície do $\mathrm{TiO}_{2}{ }^{42}$. Espera-se um arranjo vertical da molécula sobre essa superfície para moléculas contendo número pequeno de grupos de ancoramento ${ }^{41}$, já o arranjo deitado ocorre para número maior. Medidas de XPS (X-ray Photoelectron Spectroscopy) têm demonstrado que moléculas de corante tipo porfirinas têm preferência para o arranjo vertical ${ }^{43}$. É também sabido que o tipo coordenação no anel da porfirina (por um metal), da funcionalidade no ancoramento e do ligante alteram os estados energéticos superficiais de modo que a injeção (transferência de elétrons) seja mais rápida (taxas $>10^{13} \mathrm{~s}$ ) e, portanto, mais eficiente.

Um esquema representativo dos processos ópticos envolvidos e diagrama de energia em um sistema formado por porfirinas complexadas a superfícies de óxidos metálicos $\left(\mathrm{TiO}_{2}\right.$, $\mathrm{SnO}_{2}$ e $\left.\mathrm{ZnO}\right)^{35,37,44,45,46}$ é mostrado na figura 24. Vários processos com taxas distintas são possíveis após a excitação da porfirina através de transição óptica $\left(\pi \rightarrow \pi^{*}\right)$ do estado singleto fundamental $S^{o}$ para um estado $S^{*}$. Estes estados estão aproximadamente $0.5 \mathrm{eV}$ acima do fundo da banda de condução do $\mathrm{TiO}_{2}$ o que favorece uma transferência de elétrons da porfirina doadora para o $\mathrm{TiO}_{2}$ aceitador a uma taxa de $\mathrm{k}_{\mathrm{TR}} \sim 10^{12}-10^{13} \mathrm{~s}$. Esta transferência rápida compete de forma eficiente com a emissão $\left(\mathrm{k}_{\mathrm{r}} \sim 10^{9} \mathrm{~s}\right)$ após a relaxação vibracional interna $\left(\mathrm{k}_{\mathrm{rel}} \sim 10^{12} \mathrm{~s}\right)$. A perda do elétron para o $\mathrm{TiO}_{2}$ deixa a porfirina no estado $\mathrm{S}^{+}$com um buraco na banda $\pi$. Se a eficiência quântica do processo radiativo concorrente com a transferência de elétrons não radiativa é dada por $\eta=\frac{k_{r}}{k_{r}+k_{T R}}$ e possui valores entre 0,1 0,01\%, o que corresponde a uma forte supressão do processo emissivo da porfirina complexada na superfície do $\mathrm{TiO}_{2}$. Isto indica que a $\mathrm{PL}$ é muito mais sensível à interação do PG com a NP de $\mathrm{TiO}_{2}$ e que a queda da luminescência com a concentração dessa partícula sem a centrifugação se deve à adsorção superficial completa dessas moléculas quando em solução. A centrifugação serviria somente para retirar as NPs contendo PG inativos oticamente depositados sobre a superfície eliminando processos de espalhamento. 

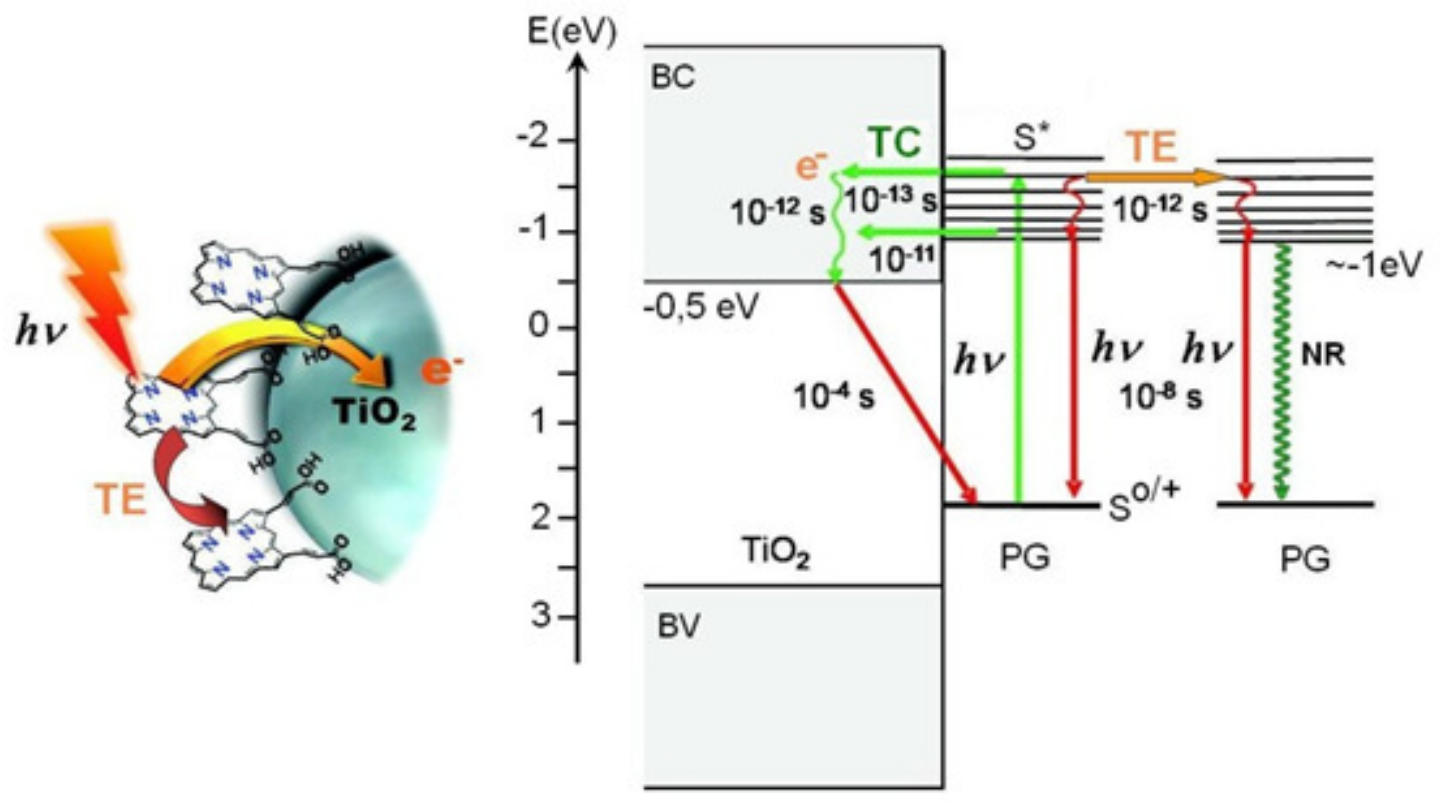

Figura 24 - Esquema representativo dos processos ópticos de uma porfirina adsorvida na superfície de uma NP de $\mathrm{TiO}_{2}$ e diagrama de energia da porfirina e do $\mathrm{TiO}_{2}{ }^{35}$, bem como da cinética dos processos mais importantes depois da excitação. As energias estimadas para o fundo da banda de condução do $\mathrm{TiO}_{2}$ e para o orbital LUMO são aproximadamente $-0,5 \mathrm{eV}$ e - $1 \mathrm{eV}$, respectivamente

Outros processos não radiativos concorrentes podem ser incorporados ao sistema estudado (figura 24). Por exemplo, a migração lateral por processo de transferência de energia (TE) entre moléculas adsorvidas na superfície do $\mathrm{TiO}_{2}^{44,47,48,49,50}$ que ocorre a uma taxa $\mathrm{k}_{\mathrm{TR}} \sim 10^{12} \mathrm{~s}$ que compete em mesmo pé de igualdade com o processo de transferência de carga (TC) para o $\mathrm{TiO}_{2}$. Este processo TE é maior com o aumento do recobrimento da superfície com moléculas de porfirina, o que aumenta a probabilidade de migração do estado excitado para um centro supressor de carga (defeitos moleculares). Outro canal não radiativo que leva à supressão do estado excitado é a transferência de energia para outras moléculas ou radicais no solvente, com a excitação de, por exemplo, oxigênio molecular singleto ${ }^{27,51,52}\left({ }^{1} \mathrm{O}_{2}\right)$. 


\subsubsection{Efeito de $\mathrm{pH}$ no processo de arraste}

A adsorção de um corante na superfície do $\mathrm{TiO}_{2}$ em suspensão coloidal depende não só da formação da ligação de ancoramento superficial, como vimos acima, mas também de forças eletrostáticas ${ }^{42}$. Estas últimas dependem sensivelmente do solvente e do $\mathrm{pH}$.

A figura 25 dá um exemplo desta forte dependência da adsorção do PG sobre as NPs de $\mathrm{TiO}_{2}$ em $\mathrm{pH}=4$. A figura compara espectros de excitação e $\mathrm{PL}$ em função da concentração de $\mathrm{TiO}_{2}$ como foi feito na figura 22 para $\mathrm{pH}=7$, com $[\mathrm{PG}]=2 \times 10^{-6} \mathrm{M}$ e sem centrifugação. Pode-se ver que as formas de linha de excitação e emissão do PG alteram em forma e em intensidade, o que será tratado em detalhe mais abaixo. Porém, a intensidade cai uma ordem de grandeza na presença de $0,1 \mathrm{mg} / \mathrm{mL}$ de $\mathrm{TiO}_{2}$ quando comparado com a solução sem a NP. $\mathrm{Na}$ figura 22 foram precisos $0,5 \mathrm{mg} / \mathrm{mL}$ para que a intensidade caísse nessa magnitude. Isto indica que a adsorção superficial é muito mais efetiva em $\mathrm{pH}$ baixo e que a área superficial equivalente a $0,1 \mathrm{mg} / \mathrm{mL}$ de $\mathrm{TiO}_{2}$ é suficiente para garantir a sua cobertura nas concentrações de PG usadas. Como na figura 22 a), a queda da intensidade se deve à transferência de carga do PG doador para a NP aceitadora de $\mathrm{TiO}_{2}$ e, provavelmente, pelo processo de supressão devido migração lateral do estado excitado $\mathrm{S}^{*}$. A mudança da forma de linha também é evidente para $\mathrm{pH}=4$, indicando que a emissão residual se deve a outras espécies emissivas na solução e que não foram adsorvidas.

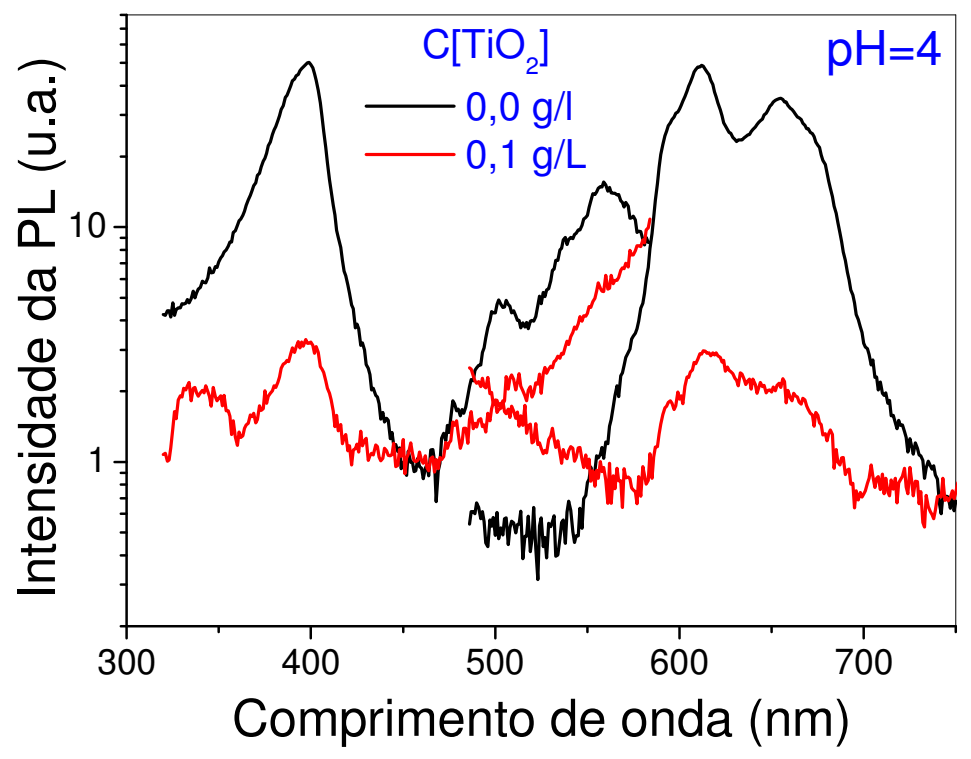

Figura 25 - Adsorção do PG sobre as $\mathrm{NPs}$ de $\mathrm{TiO}_{2}$ em pH=4. A figura compara espectros de excitação e PL em função da concentração de $\mathrm{TiO}_{2}$ como foi feito na figura 22 para $\mathrm{pH}=7$, concentração de $P G=2 \mu M$ e sem centrifugação 
A mudança da adsorção do PG sobre $\mathrm{TiO}_{2}$ com o $\mathrm{pH}$ coloidal é regido pelas forças eletrostáticas na solução. Dois parâmetros são fundamentais para o entendimento desse comportamento. O primeiro é o potencial zeta de ponto zero (PZZP ou point of zero zeta potencial) ou ponto isoelétrico que prediz a espécie (positiva e negativa) da distribuição de carga superficial de uma partícula em uma dispersão coloidal em um dado $\mathrm{pH}$, pois as partículas em sua maioria possuem cargas em meio aquoso, por exemplo. Há muitas origens para a carga superficial que depende da natureza da partícula e do meio que a envolve. Por exemplo, a dissociação de grupos ácidos $(\mathrm{COOH}-, \mathrm{COO}-)$ pode resultar no equilíbrio em uma superfície carregada negativamente. Já superfícies básicas (radicais hidroxilas terminais $\mathrm{OH}-$ ) se tornam positivas na dissociação. Nos dois casos, a quantidade de carga superficial depende da força acida e básica dos grupos superficiais e do pH da solução.

O outro parâmetro é o que dá a probabilidade de uma molécula, ou um radical na molécula, perder ou ganhar um próton $\left(\mathrm{H}^{+}\right)$quando a mesma estiver em solução aquosa. A probabilidade exata da molécula ser protonada ou desprotonada depende de seu pKa e do $\mathrm{pH}$ da solução. Por exemplo, seja AH um grupo em uma molécula. AH pode ser neutro ou carregado. $\mathrm{AH}$ se torna $\mathrm{A}^{-}$após perder um próton e a molécula se diz desprotonada. Grupos carboxílicos em porfirinas e complexos metálicos possuem pKa abaixo ou em torno de 3. Já o $\mathrm{TiO}_{2}$ (anatase) possui PZZP por volta de 6. Isso significa que o PG pode estar desprotonado $(\mathrm{COOH}-)$ para $\mathrm{pH}>3$ enquanto que as $\mathrm{NPs} \mathrm{de}^{\mathrm{TiO}_{2}}$ se encontram carregadas positivamente ${ }^{42}$ (provavelmente devido a presença de $\equiv \mathrm{Ti}-\mathrm{OH}_{2}^{+}$) para $\mathrm{pH}<6$. Assim, ocorre atração eletrostática entre as espécies desprotonadas do PG e NPs de $\mathrm{TiO}_{2}$ carregadas positivamente para valores de $\mathrm{pH}$ entre 3 e 6, favorecendo a adsorção e o ancoramento do PG. Para pH > 6, ambas as espécies estão carregadas negativamente e a repulsão eletrostática desfavorece a adsorção. Para $\mathrm{pH}<3$ as moléculas de PG estão protonadas (neutras) enquanto as NPs de $\mathrm{TiO}_{2}$ estão carregadas positivamente, resultando também em uma menor adsorção. 

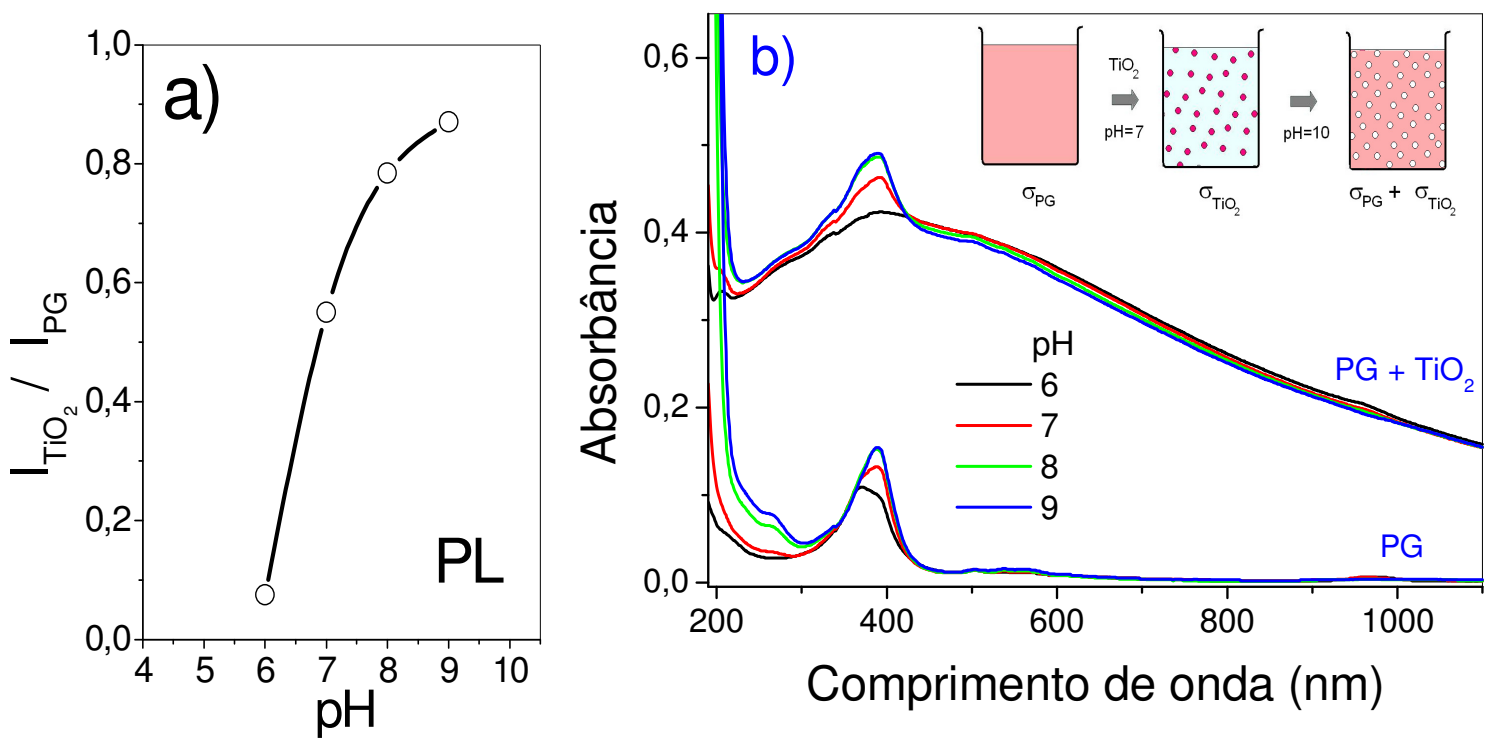

Figura 26 - Efeito do pH na adsorção do PG sobre as $\mathrm{NPs}_{\text {de }} \mathrm{TiO}_{2}$. a) Razão das intensidades do PG com o pH em solução com $\left(\boldsymbol{I}_{\mathrm{TiO}_{2}}\right)$ e sem $\left(\boldsymbol{I}_{\mathrm{PG}}\right) \mathrm{TiO}_{2}$. b) Espectro de absorção das soluções $\mathrm{PG}_{-\mathrm{TiO}}$ e PG

A figura 26 a) ilustra bem o efeito do pH na adsorção do PG sobre as $\mathrm{NPs}$ de $\mathrm{TiO}_{2}$. Nesse experimento foi medido a PL para valores de $\mathrm{pH}$ variando de 6 a 9 para o PG em solução contendo 0 e $0,5 \mathrm{mg} / \mathrm{mL}$, não centrifugado. As condições iniciais $(\mathrm{pH}=6$, concentração, etc) foram as mesmas que aquelas usadas no experimento da figura 22. A solução contendo apenas PG foi tomada como referência, pois o $\mathrm{pH}$ altera as características de emissão e absorção, como veremos abaixo. Escolhemos a solução contendo $0,5 \mathrm{mg} / \mathrm{mL}$ de $\mathrm{TiO}_{2}$ pelo fato da porfirina estar totalmente sobre as NPs, como pode ser confirmado pela supressão da luminescência naquelas condições. A figura 26 a) mostra a dependência da razão das intensidades do PG com o pH em solução com $\left(\mathrm{I}_{\mathrm{TiO}_{2}}\right)$ e sem $\left(\mathrm{I}_{\mathrm{PG}}\right) \mathrm{TiO}_{2}$. Com esse procedimento eliminamos efeitos de mudanças na forma espectral. Vemos que a intensidade aumenta 90\% quando o pH varia de 6 a 9. Este resultado demonstra a dessorção ou saída quase que total do PG da superfície do $\mathrm{TiO}_{2}$. Além disso, ele confirma a passagem pelo ponto PZZP da NP no pH=6: abaixo deste ponto ocorre a atração eletrostática e acima ocorre repulsão entre NP de $\mathrm{TiO}_{2}$ e PG.

O mesmo processo de dessorção pode ser visto através de medidas de absorbância mostrado na figura 26 b). Essa figura compara espectros na região UV-Vis-IR para as mesmas soluções da figura 26 a) contendo somente PG (referência) e PG com $\mathrm{TiO}_{2}$ a uma concentração de $0,5 \mathrm{mg} / \mathrm{mL}$ (condição de adsorção total) para valores de $\mathrm{pH}$ entre 6 e 9 . A absorbância do PG aumenta e satura para valores de $\mathrm{pH}$ maiores que 8. Na presença do $\mathrm{TiO}_{2}$, a absorbância da solução contendo PG é sobreposta às perdas da luz por espalhamento com as 
NPs de $\mathrm{TiO}_{2}$ e, por isso, apresenta-se deslocada verticalmente. É interessante notar primeiramente que essa característica de espalhamento não se altera com a variação do $\mathrm{pH}$ na faixa estudada. Isso indica que as partículas de $\mathrm{TiO}_{2}$ não sofrem agregação nessa região. Em segundo lugar, a solução contendo PG totalmente adsorvido sobre $\mathrm{TiO}_{2}$ em pH 6 não apresenta traços de absorção dessa molécula e observamos o espectro típico de espalhamento (curva preta). Isso se deve às mudanças da seção de choque e do livre caminho médio do fóton na solução (ver ilustração na figura b). Para a solução de referência a seção de choque é a do PG $\left(\sigma_{\mathrm{PG}}\right)$ que é pequena, porém o livre caminho médio do fóton é pequeno (solução homogênea), o que favorece a absorção. Quando colocamos a NP dispersa em pH 7 todas as moléculas estão adsorvidas sobre sua superfície. Esse regime favorece o espalhamento da luz e não a absorção, pois o livre caminho médio do fóton aumentou drasticamente e a luz, que propaga na solução, só espalha com a NP de $\mathrm{TiO}_{2}$ que têm seção de choque $\left(\sigma_{\mathrm{TiO}_{2}}\right)$ muito maior que a seção de choque de absorção do PG $\left(\sigma_{\mathrm{PG}}\right)$ adsorvido em sua superfície. Com a dessorção do PG com o aumento do pH, a absorção do PG pode ser observada. Nesse caso, o livre caminho médio da luz decresce novamente e passa a ser absorvida pelo PG, ao mesmo tempo que é espalhada pelas NPs. Esse experimento é outra demonstração da adsorção/dessorção do PG sobre $\mathrm{TiO}_{2}$ com a variação do estado de carga superficial com o $\mathrm{pH}$.

Vamos utilizar essas características interessantes das partículas de $\mathrm{TiO}_{2}$ de alterar o estado de carga com o pH do meio em que estão suspensas para estudar nessa seção as propriedades de adsorção do PG sobre as NPs das séries A, B, C e D. Infelizmente, não conseguimos obter valores confiáveis de PZZP para esta série. Porém, as medidas ópticas acima podem indicar alterações do estado de carga superficial nestes materiais.

Sabe-se da literatura ${ }^{23}$ que as partículas de $\mathrm{TiO}_{2}$ adquirem carga positiva em meios ácidos $(\mathrm{pH}<6)$ devido a presença de grupos $\equiv \mathrm{TiOH}_{2}^{+}$e carga negativa em meios básicos $(\mathrm{pH}$ $>7$ ) devido a presença de grupos $\equiv \mathrm{TiO}^{-}$. As moléculas de $\mathrm{PG}$ também apresentam processo de deprotonação e mudanças de suas propriedades espectroscópicas com o pH, conforme será mostrado $\operatorname{logo}$ a seguir. Portanto, é de fundamental importância estudar a adsorção de moléculas sobre partículas em soluções preparadas com diferentes valores de $\mathrm{pH}$. 

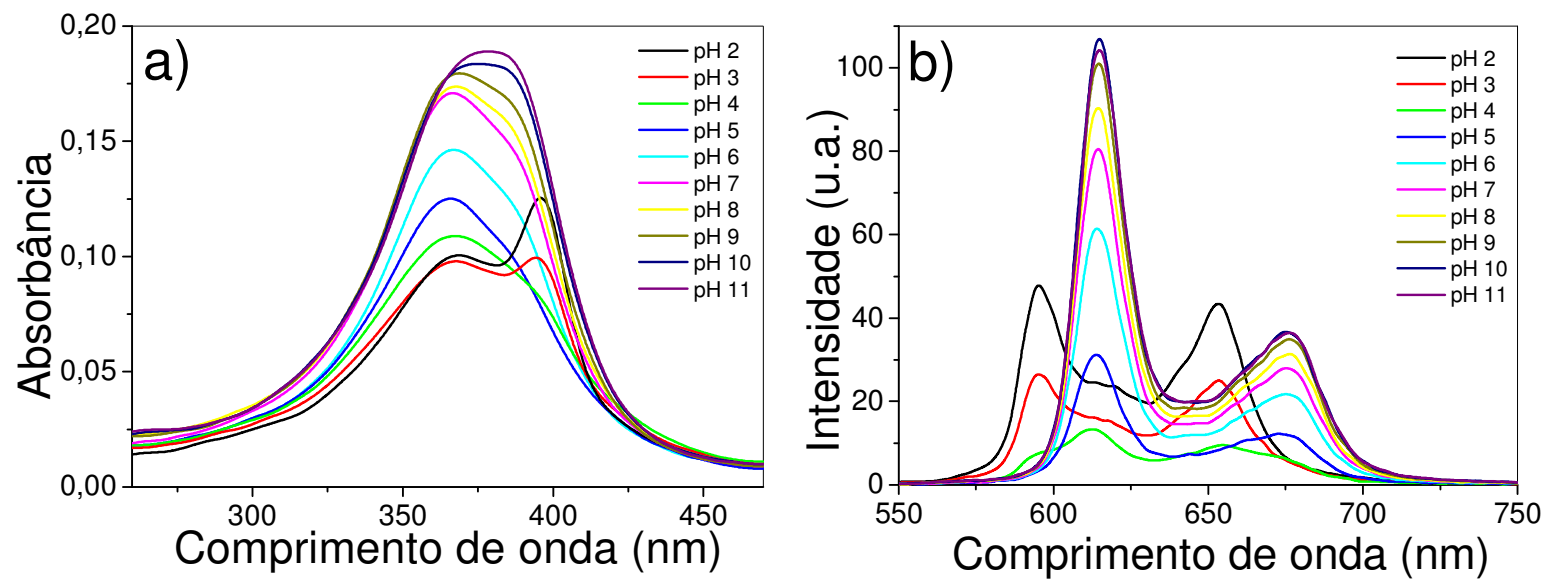

Figura 27 - a) Dependência da absorbância com o pH na região da banda de Soret. b) Dependência da PL com o pH (excitação em $395 \mathrm{~nm}$ )

As figuras 27 a) e b) mostram o quanto os espectros de absorbância na região da banda de Soret e de PL mudam suas intensidades e formas de linha conforme o pH da solução. Vemos que para soluções ácidas ocorre uma diminuição na intensidade e mudanças substanciais na forma dos espectros (para $\mathrm{pH}<5$ ). Estas mudanças na forma espectral fica mais evidente próximo ao ponto de pKa do PG (em torno de 3). A mudança de intensidade pode estar associada à formação de agregados moleculares na região de $\mathrm{pH}$ ácido e a mudança na forma de linha pode ser devido à protonação. Já para soluções básicas ocorre um aumento na intensidade dos espectros sem alterar muito suas formas uma vez que as moléculas se encontram desagregadas, prevalecendo a forma monomérica da molécula ${ }^{26}$. Portanto, as propriedades de emissão e absorção das moléculas de PG são fortemente influenciadas pela acidez ou alcalinidade da solução ${ }^{29}$. Torna-se então fundamental levar em consideração estas mudanças nos processos de adsorção dessas moléculas sobre o $\mathrm{TiO}_{2}$ com o pH do meio.

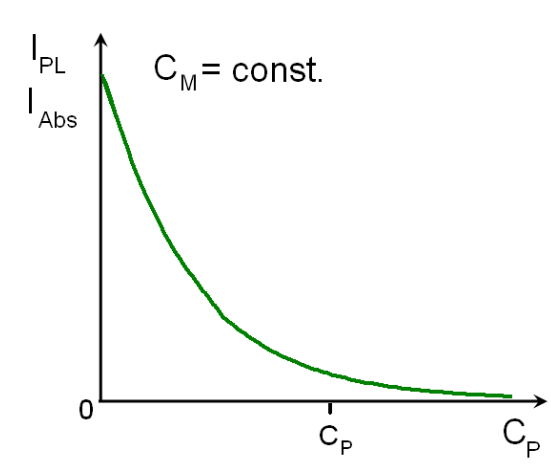

a)

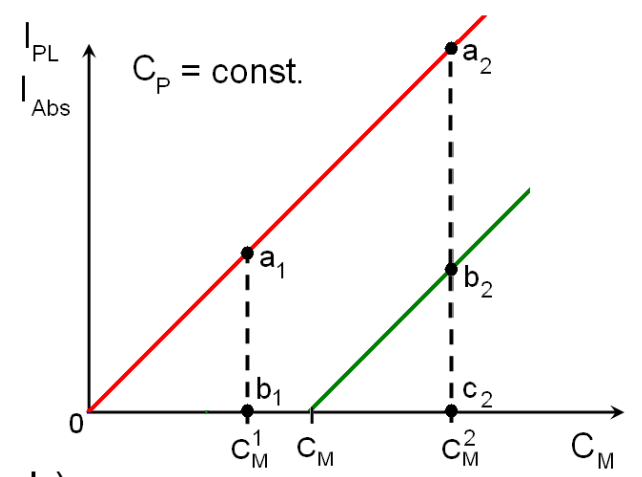

b)

Figura 28 - Esquema dos experimentos de PL e absorbância observando as condições de concentração especificadas par a) arraste variando $\left[\mathbf{T i O}_{2}\right]$ e b) arraste variando $[\mathbf{P G}]$ 
Com o intuito de se obter uma melhor compreensão do efeito de $\mathrm{pH}$ sobre a adsorção do PG sobre as NPs de $\mathrm{TiO}_{2}$ das séries A, B, C e D foram feitas medidas de PL e absorbância observando as condições apresentadas esquematicamente na figura 28. Primeiramente, determinamos a concentração $\mathrm{C}_{\mathrm{P}}$ de $\mathrm{TiO}_{2}$ que garante, a princípio, a adsorção das moléculas de PG a uma da concentração fixa $\mathrm{C}_{\mathrm{M}}$ no valor de $\mathrm{pH}$ da água MILLI-Q (pH 6) (figura 28 a)). Após a centrifugação, a intensidade da PL e o valor da absorbância na solução sobrenadante deve ser mínima nesse caso. Para essa concentração $\mathrm{C}_{\mathrm{P}}$ de $\mathrm{TiO}_{2}$, dois experimentos (figura 28 b)) serão considerados: a adsorção molecular em função do pH para concentração de $\mathrm{PG}$ menor $\left(\mathrm{C}_{\mathrm{M}}^{1}\right)$ e maior $\left(\mathrm{C}_{\mathrm{M}}^{2}\right)$ que $\mathrm{C}_{\mathrm{M}}$. No primeiro caso, não há molécula sobrenadante e será observado apenas a dessorção do PG quando o estado de carga e de protonação for alterado com a variação do $\mathrm{pH}$. Nesse caso, a intensidade da PL e da absorbância poderá alterar entre o ponto $b_{1}$ de intensidade mínima e o ponto $a_{1}$ de intensidade igual a da solução do PG sem NP. No segundo caso, o ponto de partida é $b_{2}$ que corresponde à solução que tem tanto PG adsorvido sobre as NPs quanto em excesso na solução. Nesse experimento, o aumento para valores maiores que seis induzirá a dessorção do PG adsorvido. A intensidade da PL e absorbância irá aumentar entre os pontos $b_{2}$ e $a_{2}$, nesse caso. Já o decréscimo do $\mathrm{pH}$ provocará a adsorção das moléculas em excesso na solução. Após a centrifugação, a intensidade irá cair para valores entre os pontos $b_{2}$ e $c_{2}$.

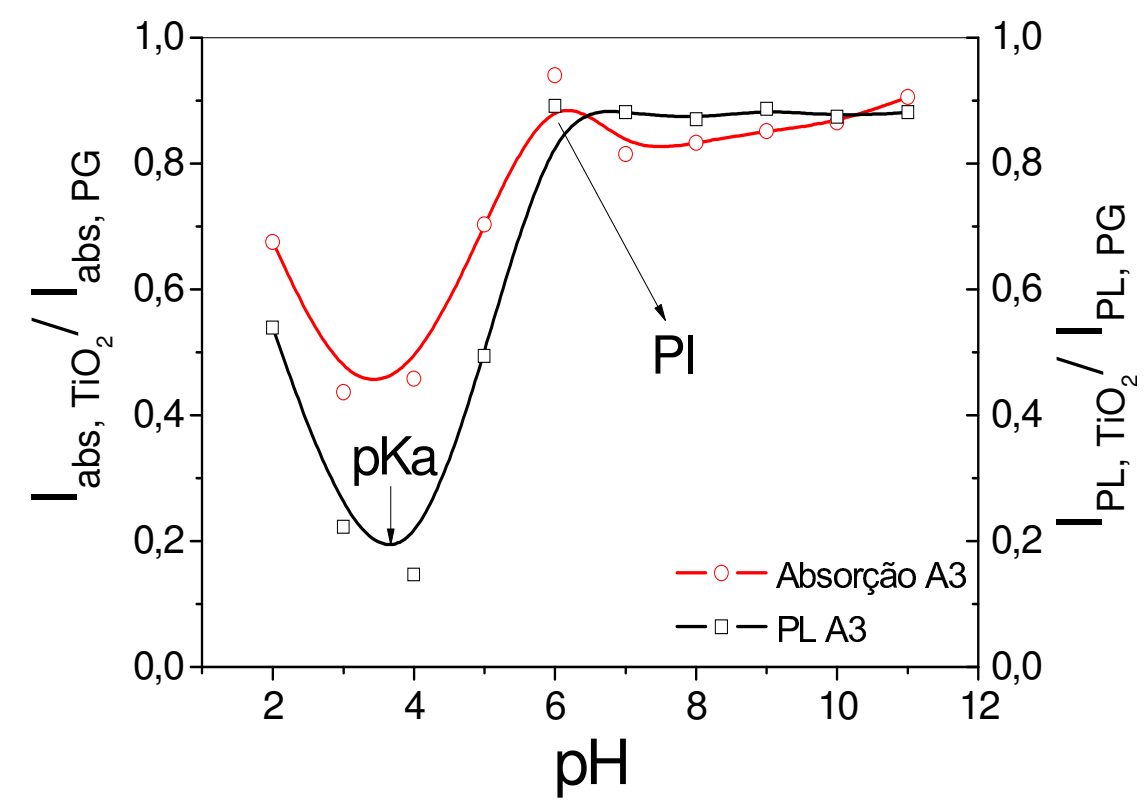

Figura 29 - Comparação da razão entre os máximos dos espectros do sistema $\mathrm{PG}_{-} \mathrm{TiO}_{2}$ (NPs de $\left.\mathrm{TiO}_{2} \mathrm{A3}\right)$ e os máximos dos espectros do PG (tomado como referência) em função do pH após a centrifugação. Eixo vertical à esquerda: razão correspondente aos máximos da absorbância em 395 nm. Eixo vertical à direita: razão correspondente aos máximos da PL em $613 \mathrm{~nm}$ 
A dependência com o $\mathrm{pH}$ para o primeiro caso $\left(\mathrm{C}_{\mathrm{M}}^{1}<\mathrm{C}_{\mathrm{M}}\right)$ é mostrado na figura 29 para NPs de $\mathrm{TiO}_{2}$ representante da série A (A3). Como vimos anteriormente, esta série de NPs possui alta afinidade pelo PG e possui predominância da fase anatase em sua estrutura. A figura 29 mostra as razões $\mathrm{I}_{\mathrm{abs}, \mathrm{TiO}_{2}} / \mathrm{I}_{\mathrm{abs}, \mathrm{PG}}$ e $\mathrm{I}_{\mathrm{PL}, \mathrm{TiO}_{2}} / \mathrm{I}_{\mathrm{PL}, \mathrm{PG}}$ em função do $\mathrm{pH}$ referente aos máximos dos espectros de absorbância (em $395 \mathrm{~nm})$ e PL em $(613 \mathrm{~nm})$ do sistema PG-TiO normalizados pelos máximos dos espectros de absorbância e PL da referência (PG), respectivamente. Podemos observar que as intensidades da PL e da absorbância para o sistema $\mathrm{PG}-\mathrm{TiO}_{2}$ são próximas na solução sobrenadante $\left(\mathrm{I}_{\mathrm{TiO}_{2}} / \mathrm{I}_{\mathrm{PG}} \sim 0.9\right)$ para $\mathrm{pH}>6$ indicando que ocorre pouca adsorção da porfirina sobre a partícula A3. Essa razão cai apreciavelmente para valores de $\mathrm{pH}$ menores que 6 , o que corresponde à adsorção molecular. Essa adsorção do $\mathrm{PG}$ sobre o $\mathrm{TiO}_{2}$ aumenta e tem um valor máximo para valores de $\mathrm{pH}$ entre 3, 5 e 4 (menor razão $\mathrm{I}_{\mathrm{TiO}_{2}} / \mathrm{I}_{\mathrm{PG}}$ ) e depois diminui para valores de $\mathrm{pH}$ menores que 3, indicando uma dessorção da porfirina $\left(\mathrm{I}_{\mathrm{TiO}_{2}} / \mathrm{I}_{\mathrm{PG}}\right.$ volta a aumentar). Esse ponto corresponde à protonação do PG levando à neutralidade de carga desta molécula e, com isso a sua dessorção. Com isso, o valor do $\mathrm{pKa}$ pode ser estimado em torno de 3,5. Além disso, este experimento permite determinar as mudanças na espécie e no valor das cargas sobre a $\mathrm{NP}$ de $\mathrm{TiO}_{2}$, ou seja, negativo para $\mathrm{pH}>6$ (produzindo repulsão com o PG) e positivo para valores de $\mathrm{pH}$ menores (gerando atração) assim como estimar o seu ponto isoelétrico (PZZP 6).

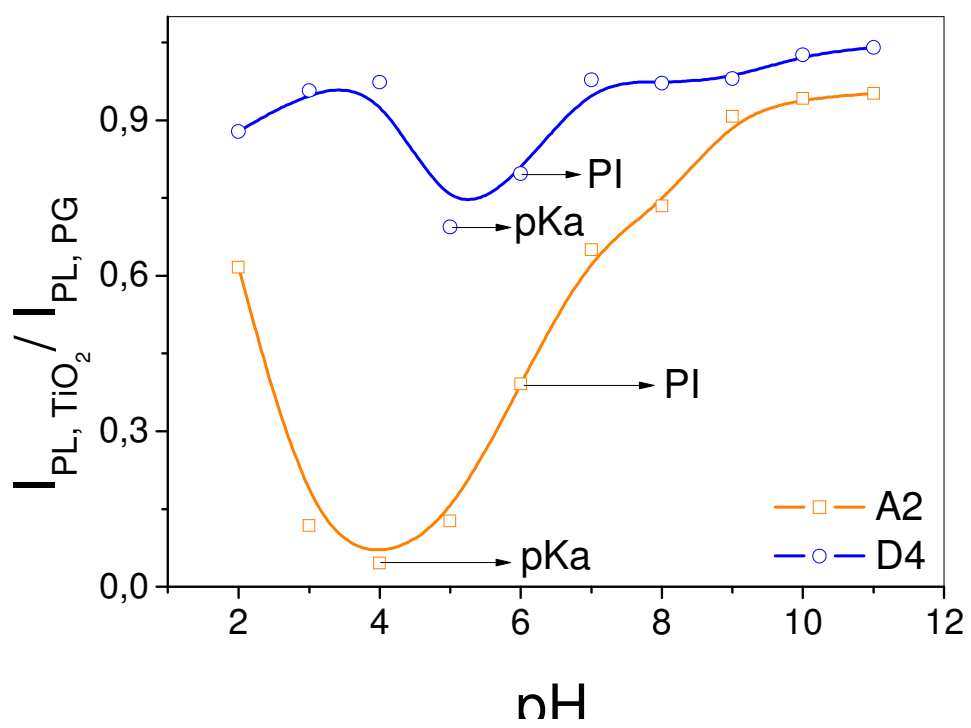

Figura 30 - Dependência com o pH da razão $\boldsymbol{I}_{\boldsymbol{P L}, \boldsymbol{T i O} \boldsymbol{O}_{2}} / \boldsymbol{I}_{\boldsymbol{P L}, \boldsymbol{P G}}$ para o segundo caso $\boldsymbol{C}_{\boldsymbol{M}}^{1}>\boldsymbol{C}_{\boldsymbol{M}}$ para NPs de TiO $\mathrm{O}_{2}$ representantes da séria $A$ (A2) e da série $D(D 4)$ 
A dependência com o $\mathrm{pH}$, agora para o segundo caso $\left(\mathrm{C}_{\mathrm{M}}^{1}>\mathrm{C}_{\mathrm{M}}\right)$ é mostrado na figura 30 para NPs de $\mathrm{TiO}_{2}$ representantes da série A (A2) que tem maior porcentagem da fase anatase e da série D (D4) que possui fase rutilo predominante. Essa figura compara a razão $\mathrm{I}_{\mathrm{TiO}_{2}} / \mathrm{I}_{\mathrm{PG}}$, como na figura 29, em função do pH após a centrifugação. Como a condição inicial já possuía PG em excesso na solução sobrenadante, a adsorção/dessorção do PG é menos abrupta próximo da região do ponto isoelétrico para $\mathrm{pH}=6$ para a partícula de $\mathrm{TiO}_{2} \mathrm{~A} 2$ contendo fase anatase predominante. É interessante notar que o PG começa a ser adsorvido já para $\mathrm{pH}$ menor que 9 e a adsorção é máxima para $\mathrm{pH}=4$. Para $\mathrm{pHs}$ menores que 4 o PG fica protonado (pKa 3.5) , o que muda o caráter da interação molecular e a consequente dessorção evidente desta porfirina. Já a adsorção é pequena para a partícula D4. Existe uma pequena adsorção para $\mathrm{pH} \sim 6$ o que pode estar associado com o traço da fase anatase presente nessa partícula. Porém a dessorção prevalece para valores de $\mathrm{pH}$ abaixo de 6. Segundo a literatura ${ }^{53}$, a superfície da fase rutilo é muito estável quimicamente e sem defeitos. Este aspecto pode estar colaborando para a baixa adsorção do PG sobre estas superfícies. No espaço de tempo deste trabalho não foi possível estudar a dependência da adsorção do PG sobre as outras partículas das séries A, B, C e D, o que será realizado futuramente.

\subsection{Análise espectroscópica da fotodegradação do PG}

Em nosso trabalho, utilizamos o PG como molécula padrão para estudarmos tanto o efeito da adsorção molecular bem como do efeito desta na fotodegradação. Tal molécula é conhecida por gerar compostos oxidantes altamente reativos como radicais do tipo oxigênio singleto quando excitadas com um determinado comprimento de onda ${ }^{5,7,13}$. Portanto, este tipo de molécula é capaz, por si só, de iniciar um processo de autodegradação quando fotoexcitadas, mesmo na ausência do $\mathrm{TiO}_{2}$. Além disso, porfirinas são usadas atualmente como material absorvedor de luz e doador de elétrons em células fotovoltaicas orgânicas de corantes contendo NPs de $\mathrm{TiO}_{2}$ como material aceitador e em células fotocatalíticas e fotoeletroquímicas à base de semicondutores para, por exemplo, geração de hidrogênio ${ }^{54}$. Fotocatálise mediada por NPs de $\mathrm{TiO}_{2}$ tem sido extensivamente estudada para a degradação de poluentes do meio ambiente ${ }^{55}$. Por isso, as propriedades superficiais do $\mathrm{TiO}_{2}$ são 
consideradas as mais promissoras no que diz respeito à melhora da cinética das reações e dos mecanismos associados à fotodegradação. Portanto, torna-se fundamental estudar o comportamento desta molécula quando adsorvida sobre NPs e submetida a uma fonte de excitação. Nesta seção, a fotodegradação do PG será descrito em termos de um modelo cinético e depois explicaremos os resultados obtidos por espectroscopia de absorção UV-VIS e por PL.

Com o intuito de se obter um melhor entendimento da cinética de degradação e a tentativa de se obter informação óptica de traços de possíveis fotoprodutos foram feitas medidas de absorção e PL do PG sob três valores distintos de $\mathrm{pH}$, pois sabe-se que o $\mathrm{pH}$ do meio pode exercer grande influência na degradação do $\mathrm{PG}^{26}$.
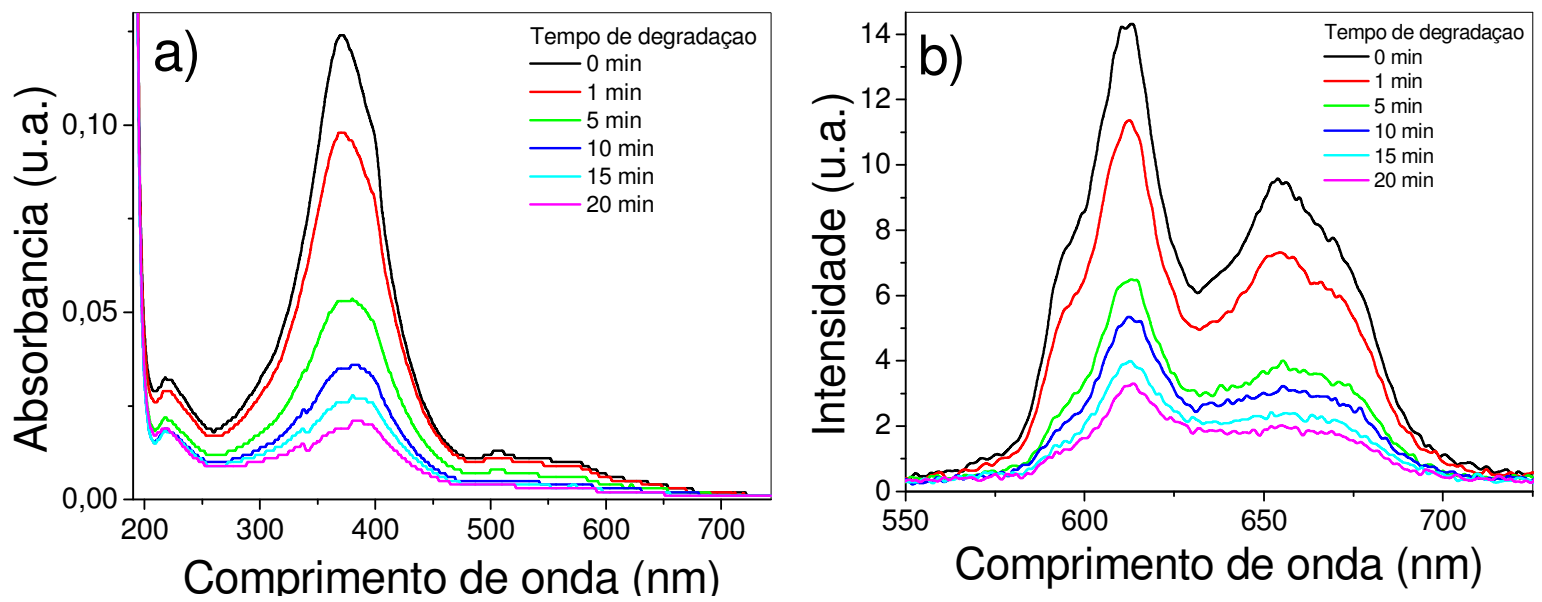

Figura 31 - a) Espectros de absorção referentes à degradação do PG em pH 4. b) Espectros de PL para o mesmo caso da figura a)
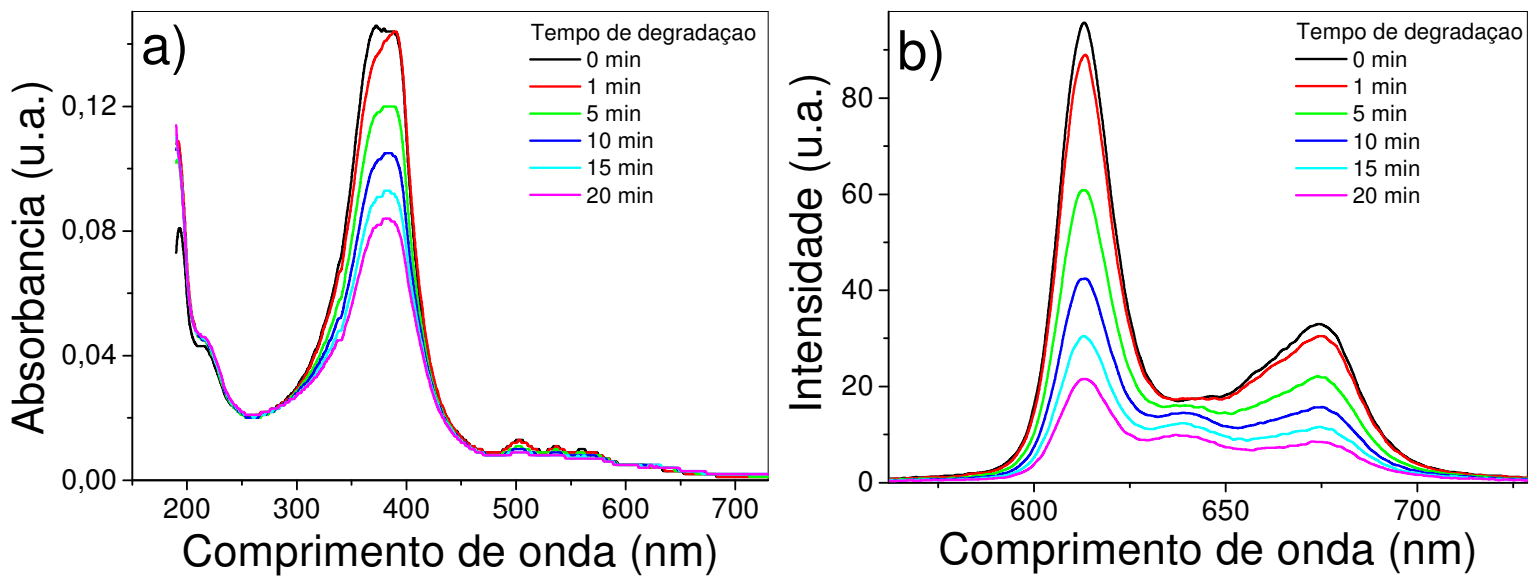

Figura 32 - a) Espectros de absorção e PL referentes à degradação do PG em pH 7. b) Espectros de PL para o mesmo caso da figura a) 

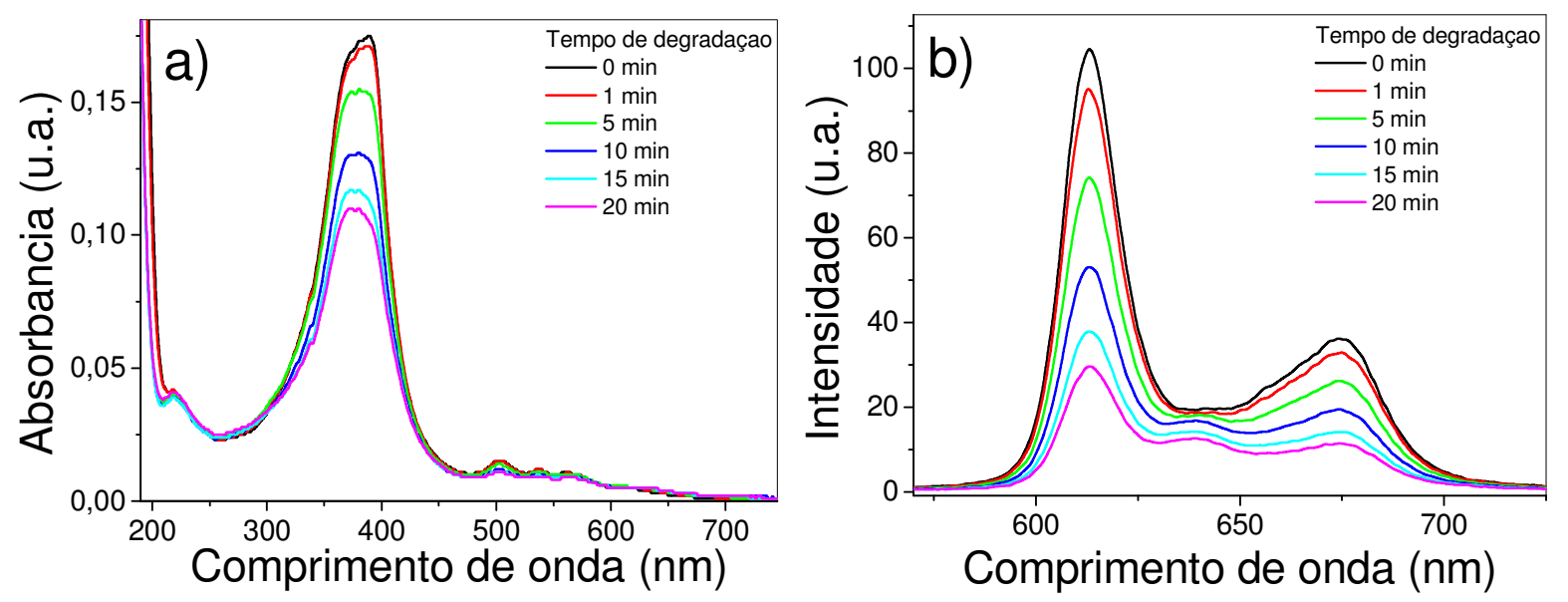

Figura 33 - a)Espectros de absorção e PL referentes à degradação do PG em pH 10. b) Espectros de PL para o mesmo caso da figura a)

As figuras 31, 32 e 33 comparam espectros de absorbância (coluna à esquerda) e de PL (coluna à direita) medidos durante a fotodegradação do PG no intervalo de tempo de 0 a 20 minutos para valores de $\mathrm{pH}$ 4, 7 e 10 respectivamente. O comprimento de onda da luz de excitação foi de $395 \mathrm{~nm}$ (Banda de Soret) e a intensidade luminosa de $30 \mathrm{~mW} / \mathrm{cm}^{2}$. A concentração de PG utilizada foi de $2 \times 10^{-6} \mathrm{M}$.

Pode-se ver que a taxa de degradação depende da metodologia (absorbância e PL) e também do pH. A absorbância diminui muito mais em intensidade do que em deslocamento espectral. A queda no valor da absorbância em um dado comprimento de onda está associada mais fundamentalmente com a seção de choque de absorção que é o produto da densidade de estados (depende do número da espécie absorvedora, por exemplo) e da força de oscilador, ou seja, da probabilidade da transição óptica. A separação do efeito de cada fator é muito difícil em um experimento de degradação, pois tanto a espécie (número) quanto a força de oscilador (momento de dipolo induzido, por exemplo) pode estar alterando ao mesmo tempo. Estudos minuciosos de fotodegradação em porfirinas já foram realizados $3,5,10,12,13$.

Já é bem conhecido que a interação do anel conjugado com o fóton durante a iluminação do monômero ou de agregados pode gerar a fotocatálise com a abertura do anel, fotoprodutos oxidados provindos da auto oxidação através da geração de oxigênio singleto e dependendo do grau da fotodegradação pode formar subprodutos como clorina e bilirrubina ${ }^{12}$. Nos níveis e tempos de excitação utilizados no presente trabalho e pelas pequenas modificações espectrais observadas, acreditamos que espécies oxidadas do PG são os subprodutos mais frequentes. Por exemplo, o valor da absorbância cai mais eficientemente na banda de Soret no comprimento de onda de excitação em $395 \mathrm{~nm}$. Este resultado pode indicar 
que, das diferentes estruturas espectrais não resolvidas nessa região espectral da banda de Soret associadas a espécies distintas (dímeros, agregados, etc), apenas a espécie excitada nesse comprimento de onda pode estar sofrendo degradação preferencial. Outras regiões espectrais aumentam em intensidade com o processo de fotodegradação, como aquelas associadas a transições ópticas de anéis aromáticos em $200 \mathrm{~nm}$. Esse aumento pode estar associado a fotoresíduos ${ }^{13,31}$.

A PL também altera pouco em termos espectrais, mas decai mais eficientemente do que a absorbância para $\mathrm{pH} \geq 7$ no tempo de degradação. Isso se deve ao fato da PL estar associada não só com a excitação, mas também com diferentes processos durante a relaxação do estado excitado. Uma banda de emissão aparece mais resolvida em torno de $640 \mathrm{~nm}$ com o decorrer do processo de degradação. A mesma banda apareceu como resíduo nos experimentos de centrifugação acima como espécie que não interagia com a $\mathrm{NP}$ de $\mathrm{TiO}_{2}$. Assim, acreditamos que essa espécie aparece não como um aumento de fotoprodutos, mas pela a supressão gradativa das emissões associadas às bandas em 613 e $675 \mathrm{~nm}$.

As figuras 34 a) e b) compara o decaimento temporal das intensidades da PL normalizadas para a absorbância (medida em 395 nm) e da PL (medida em 613 nm) para o PG em solução aquosa com diferentes pHs. As figuras também mostram os ajustes dos decaimentos por uma exponencial simples. A partir desse ajuste foi possível estimar as velocidades de degradação k (ver tabela 3).
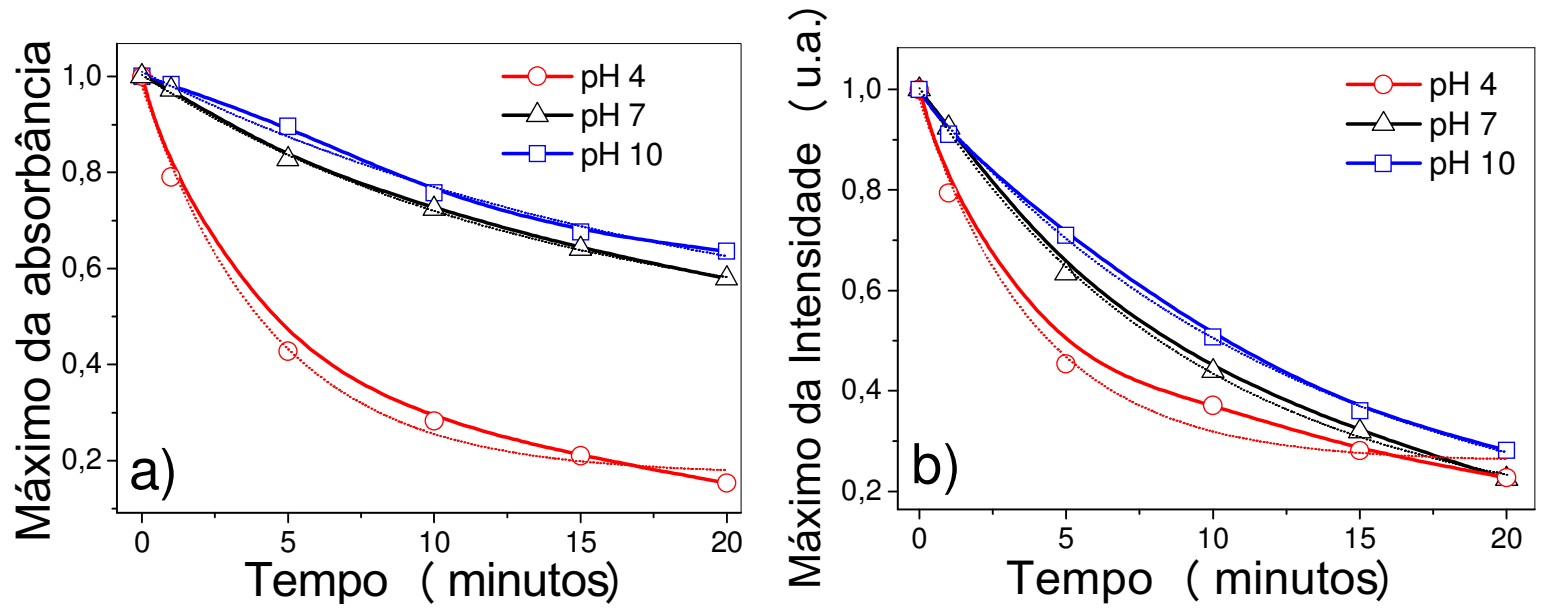

Figura 34 - a) Taxas dos espectros de absorção para a degradação do $P G$ em pH 4, 7, 10. b) Taxas dos espectros de PL para a degradação do $\mathrm{PG}$ em pH 4, 7, 10

Segundo a equação (7), quanto maior for o valor de k mais forte será a queda da exponencial. Portanto, analisando a tabela 3 vemos que se obtém uma degradação mais eficaz para $\mathrm{pH} 4$, principalmente para a absorbância, e menos eficaz para $\mathrm{pH}$ 10. A absorbância cai 
pouco para valores de $\mathrm{pH}$ acima de 7, já o decaimento da PL é mais eficaz para todos os $\mathrm{pHs,}$ o que pode estar relacionado a processos não radiativos diversos que passam a atuar com a fotodegradação.

Tabela 3 - Valores das constantes de velocidade de degradação $k\left(\right.$ min $\left.^{-1}\right)$ para os espectros da figura 34

\begin{tabular}{ccc}
\hline $\mathrm{pH}$ & absorção & $\mathrm{PL}$ \\
\hline 4 & 0,132 & 0,103 \\
7 & 0,029 & 0,079 \\
10 & 0,024 & 0,067 \\
\hline
\end{tabular}

$\mathrm{O}$ forte decaimento da absorbância para $\mathrm{pH}$ ácido se deve à formação de agregados moleculares. Como vimos anteriormente, para pH ácido ocorre protonação das moléculas de PG resultando em uma maior agregação destas moléculas. Para pH básico ocorre desprotonação e desagregação das moléculas, prevalecendo a sua forma monomérica ${ }^{29,30}$. Portanto, a estrutura das moléculas de PG são fortemente influenciadas pelo $\mathrm{pH}$ do meio.de tal modo que elas podem se comportar como agentes redutores ou agentes oxidantes ${ }^{8}$. Em soluções ácidas, devido à aglomeração de moléculas de PG, cria-se condições anaeróbicas, pois o oxigênio molecular presente na água encontra resistência para penetrar por difusão no interior dos agregados ${ }^{31}$. Assim, o processo de redução entre as moléculas é inibido e o processo de oxidação é favorecido.

$\mathrm{Na}$ introdução desta dissertação, descrevemos os dois processos (tipo I, tipo II) simultâneos envolvidos na fotodegradação do PG. Tais processos levam à formação de espécies reativas de oxigênio (EROs). No experimento com a solução ácida (figura 34 a), b)) predomina a degradação do tipo I via radicais hidroxila $(\cdot \mathrm{OH})$ e superóxido $\left(\mathrm{O}_{2}^{-}\right)$. Como explicado anteriormente, devido ao baixo pH e a conseqüente aglomeração das moléculas, cria-se condições anaeróbicas dificultando a ocorrência da degradação do tipo II via transferência de energia através do oxigênio singleto. Em virtude da maior proximidade das moléculas nos aglomerados tem-se uma otimização do processo de degradação. Para $\mathrm{pH}=10$ tem-se os dois os tipos de degradação ocorrendo simultaneamente mas como as moléculas se encontram muito dispersas tem-se uma menor taxa de degradação, se comparada com a degradação em $\mathrm{pH}=7$. 


\subsection{Fotodegradação do PG adsorvido na superfície das partículas de $\mathrm{TiO}_{2}$}

$\mathrm{Na}$ seção anterior, vimos que quando moléculas de PG são excitadas em um determinado comprimento de onda inicia-se o processo de degradação das moléculas através de reações redox (tipo I) ou através de transferência de energia via oxigênio singleto (tipo II). Nesta seção descrevermos a fotodegradação de soluções contendo moléculas de PG adsorvidas sobre partículas de $\mathrm{TiO}_{2}$.

\subsubsection{Degradação em pH 7}

Neste experimento de fotodegradação, as partículas utilizadas foram aquelas que possuíam áreas superficiais próximas (A3, B2, C1 e D1). Com isso, estamos excluindo efeitos de área superficial, pois queremos estudar apenas o efeito da interação molecular e processos fotofísicos devido ao aglomeramento molecular na superfície do $\mathrm{TiO}_{2}$ no processo de fotodegradação. Nesta seção será considerado apenas soluções preparadas em $\mathrm{pH}=7$ e na condição de que as moléculas estejam adsorvidas na superfície da partícula (máxima adsorção superficial: $\left[\mathrm{TiO}_{2}\right]=0,3 \mathrm{mg} / \mathrm{mL}$ e $[\mathrm{PG}]=2 \times 10^{-6}$ M.) nesse $\mathrm{pH}$. As soluções foram irradiadas com $30 \mathrm{~mW} / \mathrm{cm}^{2}$ no comprimento de onda da banda de Soret (395 nm, um pouco abaixo da lacuna de energia do $\mathrm{TiO}_{2}$ ), ou seja, somente a porfirina é excitada. 


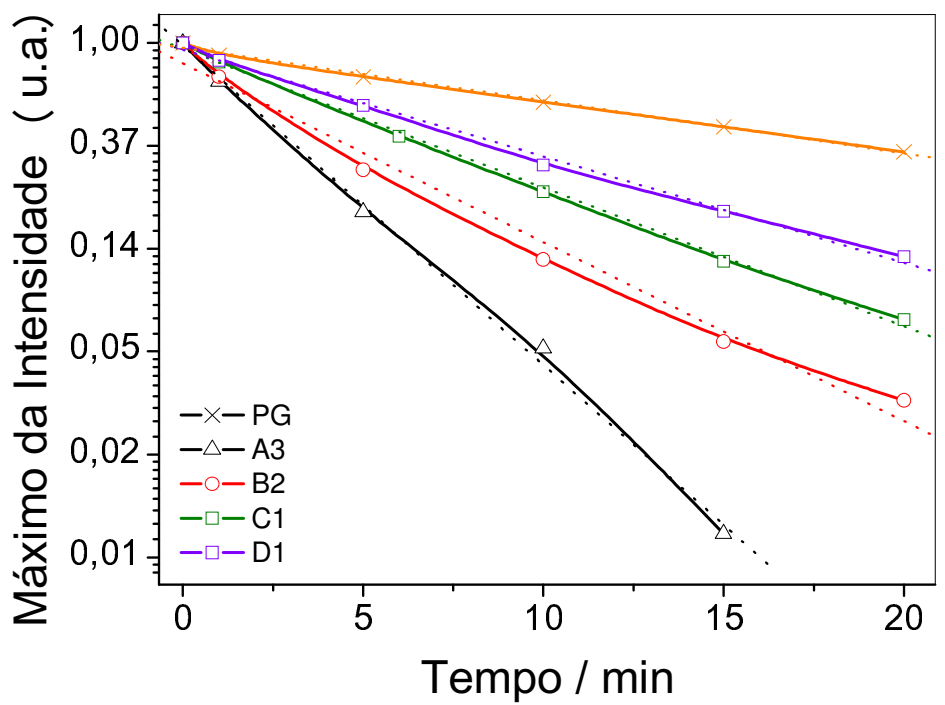

Figura 35 - Decaimento da PL no experimento de fotodegradação das moléculas de PG adsorvidas na superfície de diferentes partículas de $\mathrm{TiO}_{2}$

A figura 35 compara a dependência temporal da intensidade normalizada da PL para o PG em solução com as NPs de $\mathrm{TiO}_{2}$ A3, B2, C1 e D1 com o decaimento da PL somente do PG. Analogamente aos casos da seção anterior, o processo de degradação também segue uma cinética próxima da de primeira ordem. Na figura 35 as linhas pontilhadas correspondem ao ajuste exponencial para cada tipo de partícula. Tal ajuste é descrito pela equação (7) e apresenta a forma de uma reta na escala vertical logarítmica. Através do ajuste, podemos encontrar os valores das taxas de degradação k para o PG isolado ou adsorvido em cada partícula.

Tabela 4 - Constantes de velocidade de degradação referentes à figura 35

\begin{tabular}{cc}
\hline & $k\left(\min ^{-1}\right)$ \\
\hline A3 & 0,31071 \\
B2 & 0,17398 \\
C1 & 0,13492 \\
D1 & 0,10363 \\
PG & 0,05132 \\
\hline
\end{tabular}

Analisando a figura 35 e a tabela 4 notamos primeiramente que todas as soluções com partículas de $\mathrm{TiO}_{2}$ apresentam uma melhor eficiência de degradação se comparadas com a 
solução contendo somente PG. Vemos também que a eficiência de degradação é maior para partículas sintetizadas com uma quantidade menor de precursor de titânio na razão Ti:AC:EG (vide tabela 1), pois como vemos na tabela 4 a eficiência aumenta de D1 (1:2:8) para A3 (1:16:64). A quantidade da fase anatase na composição das partículas também aumenta de D1 (94\%) para A3 (98,5\%). Portanto, segundo nossos experimentos, a presença de anatase é determinante na velocidade de degradação e quanto maior for a sua presença mais eficiente será a degradação. Embora o uso de $\mathrm{TiO}_{2}$ na fase anatase pura ou quase pura seja comum para degradação fotocatalítica, há uma grande variedade de estudos disponíveis na literatura ${ }^{32}$ sobre o aumento de eficiência fotocatalítica através do uso de produtos comerciais de composição híbrida como o Degussa P- $25^{\circledR}$ que possui $80 \%$ anatase e $20 \%$ rutilo.

Os dados de fotodegradação do presente trabalho indicam que aglomerados moleculares são responsáveis pelo aumento da taxa de degradação do PG. Vimos também que a adsorção molecular aumenta com a porcentagem da fase anatase. Assim, o experimento da figura 35 mostra que partículas contendo maior adsorção molecular (maior agregação) possuem taxas de degradação maiores. É interessante notar que os processos fotofísicos que induzem a degradação competem com a transferência de carga de forma extremamente rápida para a NP. Apesar do $\mathrm{TiO}_{2}$ não ser excitado pela luz no comprimento de onda de $395 \mathrm{~nm}$, pode ser que a transferência de carga do PG excitado para a NP favoreça processos de fotocatalise através desse elétron extra na banda de condução. Porfirinas tem sido utilizadas para aumentar a ação fotocatalítica do $\mathrm{TiO}_{2}$ através da absorção de luz na faixa do visível e sua consequente injeção de elétron ${ }^{56,57,58,59}$. A eficiência desse processo estaria fortemente relacionada com a interação e adsorção dessas porfirinas nas superfícies desses materiais semicondutores.

\subsubsection{Degradação do $\mathrm{PG}$ sobre $\mathrm{TiO}_{2}$ : efeito de $\mathrm{pH}$}

$\mathrm{Na}$ seção 3.3.1 vimos que a eficiência da fotodegradação das moléculas de PG depende do $\mathrm{pH}$. Se o pH do meio for ácido tem-se maior agregação das moléculas. Se o pH for básico as moléculas estão mais dispersas e menos agregadas. O efeito de $\mathrm{pH}$ é evidenciado nos espectros através de mudança de intensidade e de forma de linha. Nesta seção, devido à 
importância que o pH do meio exerce sobre a eficiência de fotodegradação, descreveremos os resultados obtidos em experimentos de fotodegradação de moléculas de PG adsorvidas sobre a superfície das partículas do tipo A3, que apresentou maior efeito de adsorção e degradação para três valores distintos de $\mathrm{pH}(4,7$ e 10). Estamos interessados aqui no efeito da degradação e não nos processos fotofísicos envolvidos e por isso vamos apresentar medidas de absorbância, que independe desses processos. As condições utilizadas no presente experimento são as mesmas que as da seção anterior.

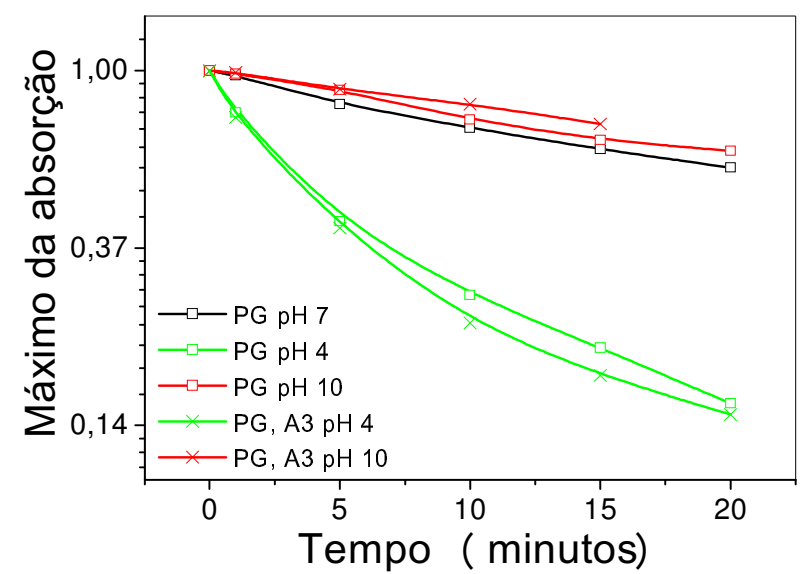

Figura 36 - Decaimento da absorbância do PG em função do tempo de excitação para PG adsorvido em A3 para pH 4,7 e 10

A figura 36 mostra medidas de absorbância em função do tempo de exposição contínua à excitação CW. Podemos ver que a fotodegradação para solução do PG com a NP apresenta basicamente o mesmo comportamento da solução contendo somente PG para os diferentes pHs. É interessante notar que, para $\mathrm{pH}=4$, o $\mathrm{PG}$ está adsorvido totalmente sobre a NP e para $\mathrm{pH}=10$ ele está totalmente disperso na solução aquosa. Este resultado é muito interessante, pois reforça a hipótese de que a formação de agregados, seja ele em solução ou na superfície da NP, tem grande influência na degradação do PG. Estudos mais detalhados devem ser realizados futuramente para verificar se essa hipótese se aplica a outras porfirinas. Determinar o grau de recobrimento superficial da porfirina, otimizar a transferência de carga para o $\mathrm{TiO}_{2}$ e, ao mesmo tempo, reduzir os processos de fotodegradação são procedimentos de fundamental importância para a utilização deste sistema de materiais em células fotovoltaicas e fotocatalíticas no futuro. 


\section{CONCLUSÕES}

Neste trabalho obtivemos uma melhor compreensão dos processos físicos envolvidos na interação de moléculas de PG com NPs de $\mathrm{TiO}_{2}$. Através do método que desenvolvemos, ao qual chamamos de método de arraste, foi possível quantificar essas interações. Tal método consiste na centrifugação das NPs juntamente com as moléculas adsorvidas e uma posterior analise óptica da solução sobrenadante com o intuito de estudar a adsorção das porfirinas na superfície do $\mathrm{TiO}_{2}$. A centrifugação tem a finalidade de retirar as NPs contendo PG inativos oticamente depositados sobre a superfície eliminando processos de espalhamento. Observamos que NPs de $\mathrm{TiO}_{2}$ com predominância da fase anatase em sua estrutura possui maior interação e, consequentemente, maior adsorção molecular, enquanto a fase rutilo possui baixa adsorção molecular por ser extremamente estável.

A afinidade e interação entre porfirina e partículas de $\mathrm{TiO}_{2}$ em solução foram analisadas para diferentes valores de $\mathrm{pH}$. Este estudo permitiu determinar o valor do $\mathrm{pKa} 3,5$ do PG e do ponto isoelétrico (PZZP) no valor de $\mathrm{pH} \sim 6$ do $\mathrm{TiO}_{2}$. Para NPs com fase anatase, a adsorção molecular aumenta com a redução do $\mathrm{pH}$ de 6 para 3,5 devido à atração Coulombiana. Para valores de $\mathrm{pH}$ menores que o pKa e maior que o ponto PZZP a dessorção é favorável pela repulsão de cargas.

Com relação às técnicas espectroscópicas utilizadas, foi observado em nossos experimentos que a PL é muito mais sensível à interação do PG com a NP de $\mathrm{TiO}_{2}$ do que a absorção e que a queda da luminescência com a concentração dessa partícula sem a centrifugação se deve à adsorção superficial completa dessas moléculas quando em solução. Também foram estudados efeitos da agregação e da cobertura molecular nos processos de fotodegradação e de transferência lateral de energia entre moléculas adsorvidas.

O método de arraste, desenvolvido neste trabalho, teve como princípio básico o fenômeno da adsorção química. Grupos carboxílicos presentes nas moléculas de PG garantem uma eficiente adsorção molecular e um excelente acoplamento eletrônico entre os níveis doadores do cromóforo excitado e os níveis aceitadores do $\mathrm{TiO}_{2}$. Através deste método, moléculas de PG adsorvem sobre a superfície das partículas de $\mathrm{TiO}_{2}$ e, para cada tipo de partícula, obtivemos propriedades diferenciadas. Tais propriedades se refletem em nossos 
experimentos como a quantidade de sítios ativos disponíveis para interação molecular. Por meio dos experimentos de arraste obtivemos os pontos onde ocorre máxima adsorção das moléculas. Esta condição de arraste também estabeleceu uma melhor condição de degradação, pois nessa condição temos máxima interação entre as moléculas e as $\mathrm{NPs}$ de $\mathrm{TiO}_{2}$. Observamos que NPs de $\mathrm{TiO}_{2}$ com predominância da fase anatase apresentam maior fotodegradação. Isso se deve à formação de agregados moleculares sobre essas superfícies, favorecendo processos de transferência de energia concorrentes com os processos de transferência de carga. 


\section{TRABALHOS FUTUROS}

- Obter melhor caracterização das partículas de $\mathrm{TiO}_{2}$ através de microscopia confocal e medidas de potencial zeta.

- Estender a metodologia empregada para outros sistemas moleculares.

- Estudar e quantificar os processos de transferência de cargas na superfície das partículas.

- Aplicar o conhecimento adquirido em áreas como biofísica e dispositivos. 


\section{REFERÊNCIAS}

1 DOLPHIN, D. The porphyrins. New York: Academic Press, 1978. v.1.

2 SMITH, K. M. General features of the structure and chemistry of porphyrin compounds. In: SMITH, K. M. (Ed.)Porphyrins and metalloporphyrins,Amsterdam:Oxford Elsevier, 1975. v.3

3 CARVALHO, V. C. M. Estudo dos efeitos de duas porfirinas hidrofílicas em células tumorais Hep-2 visando aplicação em terapia fotodinâmica do câncer. 2001. 91 f. Disseração (Mestrado em Quimica Analítica) - Instituto de Química de São Carlos, Universidade de São Paulo, São Carlos, 2001.

4 IVANOV, A. V.; RESHETNICKOV, A. V.; PONAMAREV, G. V. One more PDT application of chlorin $\mathrm{e}_{6}$. Optical Methods for Tumor Treatment and Detection: mechanisms and techniques in photodynamic therapy IX, v. 1, n. 3, p. 131-137,2000.

5 MENEZES, P. F. C. D. Estudos espectroscópicos e citotóxicos do PHOTOGEM ${ }^{\circledR}$ fotodegradado e dos fotoprodutos formados pela irradiação com laser. 2006. 155 f. Tese (Doutorado) - Instituto de Química de São Carlos, Universidade de São Paulo, São Carlos, 2006.

6 MIRONOV, A. F.; NIZHNIK, A. N.; NOCKEL, A. Y. Hematoporphyrin derivatives - an oligomeric composition study.Journal of Photochemistry and Photobiology B-biology, v. 4, n. 3, p. 297-306,1990.

7 COLUSSI, V. C.;NICOLA, E. M.; NICOLA, J.H. Phototherapy, photochemotherapy and various photosensitizers. Revista da Associação Medica Brasileira, v. 42, n. 4, p. 229236,1996 .

8 BRAULT, D. Physical-chemistry of porphyrins and their interactions with membranes - the importance of $\mathrm{pH}$. Journal of Photochemistry and Photobiology B- biology, v. 6, n. 1-2, p. 79-86,1990. 
9 REDMOND, R. W.; KOCHEVAR, I. E. Spatially resolved cellular responses to singlet oxygen. Photochemistry and Photobiology, v. 82, n. 5, p. 1178-1186,2006.

10 STRAUSS, W. S. L.; SAILER, R.; GSCHWEND, M. H.; EMMER, H.; STEINER, R.; SCHNECKENBURGER, H. Selective examination of plasma membrane-associated photosensitizers using total internal reflection fluorescence spectroscopy: correlation between photobleaching end photodynamic efficacy of protoporphyrin IX. Photochemistry and Photobiology, v. 67, n. 3, p. 363-369,1998.

11 MACDONALD, I. J.; DOUGHERTY, T. J. Basic principles of photodynamic therapy. Journal of Porphyrins and Phthalocyanines, v. 5, n. 2, p. 105-129,2001.

12 BONNETT, R.; MARTINEZ, G. Photobleaching of sensitisers used in photodynamic therapy. Tetrahedron, v. 57, n. 47, p. 9513-9547,2001.

13 ROTOMSKIS, R.; STRECKYTE, G.; BAGDONAS, S. Phototransformations of sensitizers .2. photoproducts formed in aqueous solutions of porphyrins. Journal of Photochemistry and Photobiology B-biology, v. 39, n. 2, p. 172-175,1997.

14 SKOOG, D. A.; HOLLER, F. J.; CROUCH, S. R. Princípios de análise instrumental. $6^{\text {a }}$ ed .Porto Alegre: Bookman, 2009.

15 LAKOWICZ, J. R. Principles of fluorescence spectroscopy.3rded. New York: Springer, 2006.

16 DIEBOLD, U. Structure and properties of $\mathrm{TiO}_{2}$ surfaces: a brief review. Applied Physics A-materials science \& processing,v. 76, n. 5, p. 681-687,2003.

17 DIEBOLD, Y.; CALONGE, M. Applications of nanoparticles in ophthalmology. Progress in Retinal and Eye Research, v. 29, n. 6, p. 596-609,2010.

18 JANES, R.; EDGE, M.; RIGBY, J.; MOURELATOU, D.; ALLEN, N. S. The effect of sample treatment and composition on the photoluminescence of anatase pigments. Dyes and Pigments, v. 48, n. 1, p. 29-34,2001. 
19 ATIK, M.; LIMA NETO, P.; AVACA, L. A.; AEGERTER, M. A. Sol-gel thin-films for corrosion protection.Ceramics International, v. 21, n. 6, p. 403-406,1995.

20 FOX, M. A.; DULAY, M. T. Heterogeneous photocatalysis. Chemical Reviews, v. 93, n. 1, p. 341-357,1993.

21 KAY, A.; GRATZEL, M. Low cost photovoltaic modules based on dye sensitized nanocrystalline titanium dioxide and carbon powder. Solar Energy Materials and Solar Cells, v. 44, n. 1, p. 99-117,1996.

22 GERFIN, T.; GRATZEL, M.; WALDER, L. Molecular and supramolecular surface modification of nanocrystalline $\mathrm{TiO}_{2}$ films: charge-separating and charge-injecting devices. Molecular Level Artificial Photosynthetic Materials, v. 44, p. 345-393,1997.

23 HOFFMANN, M. R.;MARTIN, S. T.; CHOI, W.; BAHNEMANNT, D. W. Environmental applications of semiconductor photocatalysis. Chemical Reviews, v. 95, n. 1, p. 69-96,1995.

24 DUNFORD, R.;SALINARO, A.; CAI, L.; SERPONE, N.; HORIKOSHI, S.; HIDAKA, H.; KNOWLAND, J. Chemical oxidation and DNA damage catalysed by inorganic sunscreen ingredients. FEBS Letters, v. 418, n. 1-2, p. 87-90,1997.

25 RONCONI, C. M.; PEREIRA, E. C. Electrocatalytic properties of $\mathrm{Ti} / \mathrm{TiO}_{2}$ electrodes prepared by the Pechini method. Journal of Applied Electrochemistry, v. 31, n. 3, p. 319323,2001 .

26 MENEZES, P. F. C.; IMASATO, H.; BAGNATO, V. S.; SIBATA, CL. H.; PERUSSI, J.R. Influence of $\mathrm{pH}$ on the phototransformation process of Photogem ${ }^{\circledR}$. Laser Physics, v. 19, n. 7, p. 1457-1462,2009.

27 LI, W.; GANDRA, N.; ELLIS, E.D.; COURTNEY, S.; LI, S.; BUTLER, E.; GAO, R. pHresponsive, $\mathrm{TiO}_{2}$-attached porphyrin for singlet oxygen production in an aqueous solution. Acs Applied Materials \& Interfaces, v. 1, n. 8, p. 1778-1784,2009. 
28 ATKINS, P. W.; DE PAULA, J. Physical chemistry. 7th. ed. New York: Oxford University Press, 2002.

29 MENEZES, P. F. C.; IMASATO, H.; FERREIRA, J.; BAGNATO, V.S.; SIBATA, C.H.; PERUSSI, J.R. Aggregation susceptibility on phototransformation of hematoporphyrin derivatives. Laser Physics Letters, v. 5, n. 3, p. 227-235,2008.

30 FRIBERG, E. G.; CUNDERLÍKOVÁ, B.; PETTERSEN, E.O.; MOAN, J.pH effects on the cellular uptake of four photosensitizing drugs evaluated for use in photodynamic therapy of cancer. Cancer Letters, v. 195, n. 1, p. 73-80,2003.

31 ROTOMSKIS, R.; BAGDONAS, S.; STRECKYTE, G. Spectroscopic studies of photobleaching and photoproduct formation of porphyrins used in tumour therapy. Journal of Photochemistry and Photobiology B-biology, v. 33, n. 1, p. 61-67,1996.

32 THEVENET, F.; GUAITELLA, O.; HERRMANN, J.M.; ROUSSEAU, A.; GUILLARD, C. Photocatalytic degradation of acetylene over various titanium dioxide-based photocatalysts. Applied Catalysis B-environmental, v. 61, n. 1-2, p. 58-68,2005.

33KADISH, K.M.; SMITH, K.M.; GUILLARD, R. The porphyrin handbook,New York: Academic Press, 2000. v.6, cap. 41.

34 QUAN, V.A.Degradation of the solar cell dye sensitizer N719 - Preliminary building of dye-sensitized solar cell.2006. 51 f. Tese (Mestrado) -Department of Life Sciences and Chemistry,Roskilde University, Dinamarca, 2006.

35 HAGFEldT, A.; BOSCHLOO, G.; SUN, L.; KLOO, L.; PETTERSSON, H. Dyesensitized solar cells. Chemical Reviews, v. 110, n. 11, p. 6595-6663, 2010. 
37 STOCKWELL, D.; YANG, Y.; HUANG, J.; ANFUSO, C.;HUANG, Z.; LIAN, T. Comparison of electron -transfer dynamics from coumarin 343 to $\mathrm{TiO}_{2}, \mathrm{SnO}_{2}$ and $\mathrm{ZnO}$ nanocrystalline thin films: role of interface-bound charge-separated pais. The Journal of Physical Chemistry C, v.114, n.14, p.6560-6566, 2010.

38 TACHIBANA, Y.; HAQUE, S.A.; MERCER, I.P.; MOSER, J.E.; KLUG, D.R.; DURRANT, J.R. Modulation of the rate of electron injection in dye-sensitized zanocrystalline $\mathrm{TiO}_{2}$ films by externally applied bias. The Journal of Physical Chemistry B, v.105, n.31, p.7424-7431, 2001.

39 HAINS, A.W.; LIANG, Z.; WOODHOUSE, M.A.; GREGG, B.A. Molecular semiconductors in organic photovoltaic cells. Chemical Reviews, v.110, n.11, p.6689-6735, 2010.

40 CLARKE, T.M; DURRANT, J.R. Charge photogeneration in organic solar cells. Chemical Reviews, v.110, n.11, p.6736-6767, 2010.

41 CAMPBELL, W.M.; BURRELL, A.K.; OFFICER, D.L., JOLLEY, K.W. Porphyrins as light harvesters in the dye-sensitised $\mathrm{TiO}_{2}$ solar cell. Coordination Chemistry Reviews, v. 248, n. 13-14, p. 1363-1379, 2004.

42 PARK, H.; BAE, E.; LEE, J.J.; PARK, J.; CHOI, W. Effect of the anchoring group in rubipyridyl sensitizers on the photoelectrochemical behavior of dye-sensitized $\mathrm{TiO}_{2}$ electrodes: carboxylate versus phosphonate linkages. The Journal of Physical Chemistry B, v.110, n.17, p.8740-8749, 2006.

43 WIBERG, J.; MARINADO, T.; HAGBERG, D.P.; SUN, L; HAGFELDT, A.; ALBINSSON, B. Distance and driving force dependencies of electron injection and recombination dynamics in organic dye-sensitized solar cells. The Journal of Physical Chemistry B, v.114, n.45, p.14358-14363, 2010.

44 FARZAD, F; THOMPSON, D.W.; KELLY, C.A.; MEYER, G.J. Competitive intermolecular energy transfer and electron injection at sensitized semiconductor interfaces. Journal of the American Chemical Society, v.121, n.23, p.5577-5578, 1999.

45 JIN, S.; SNOEBERGER III, R.C.; ISSAC, A.; STOCKWELL, D.; BATISTA, V.S.; LIAN, T. Single-molecule interfacial electron transfer in donor-bridge-nanoparticle acceptor complexes. The Journal of Physical Chemistry B, v. 114, n. 45, p. 14309-14319, 2010. 
46 PARK, J.; YI, J.; TACHIKAWA, T.; MAJIMA, T.; CHOI, W. Guanidiniumenhanced production of hydrogen on nafion-coated dye/ $/ \mathrm{TiO}_{2}$ under visible light. The Journal of Physical Chemistry Letters, v. 1, n. 9, p.1351-1355, 2010.

47 DURRANT, J.R.; HAQUE, S.A.; PALOMARES, E. Towards optimisation of electron transfer processes in dye sensitised solar cells. Coordination Chemistry Reviews, v. 248, n. 13-14, p. 1247-1257, 2004.

48 FILLINGER, A.; PARKINSON, B.A. The adsorption behavior of a ruthenium-based sensitizing dye to nanocrystalline $\mathrm{TiO}_{2}$ coverage effects on the external and internal sensitization quantum yields. Journal of The Electrochemical Society, v. 146, n. 12, p. 4559-4564, 1999.

49 LU, H.P.; TSAI, C.Y.; YEN, W.N.; HSIEH, C.P.; LEE, C.W.; YEH, C.Y.; DIAU, E.W.G. Control of dye aggregation and electron injection for highly efficient porphyrinsensitizers adsorbed on semiconductor films with varying ratios of coadsorbate. The Journal of Physical Chemistry C, v. 113, n. 49, p. 20990-20997, 2009.

50 IMAHORI, H.; MATSUBARA, Y.; IIJIMA, H.; UMEYAMA, T.; MATANO, Y.; ITO, S.; NIEMI, M.; TKACHENKO, N.V.; LEMMETYINEN, H. Effects of meso-diarylamino group of porphyrins as sensitizers in dye-sensitized solarcells on optical, electrochemical, and photovoltaic properties. The Journal of Physical Chemistry C, v. 114, n. 23, p. 1065610665, 2010.

51 SCHAAP, A.P.; THAYER, A.L.; BLOSSEY, E.C.; NECKERS, D.C.Polymer-based sensitizers for photooxidations.Journal of the American Chemical Society, v. 97, n. 13, p. 3741-3745, 1975.

52 ZEBGER, I.; POULSEN, L.; GAO, Z.; ANDERSEN, K.L.; OGILBY, P.R.Singlet oxygen images of heterogeneous samples: examining the effect of singlet oxygen diffusion across the interfacial boundary in phase-separated liquids and polymers. Langmuir, v. 19, n. 21, p. 8927-8933, 2003.

53 DIEBOLD, U. The surface science of titanium dioxide. Surface Science Reports, v. 48, n. 5-8, p. 53-229, 2003.

54 CHEN, X.; SHEN, A.; GUO, L.; MAO, S.S. Semiconductor-based photocatalytic hydrogen generation. Chemical Reviews, v.110, n. 11, p. 6503-6570, 2010. 
$55 \mathrm{CHOI}, \mathrm{W}$.; PARK, $\mathrm{H}$. Photocatalytic reactivities of nafion-coated $\mathrm{TiO}_{2}$ for the degradation of charged organic compounds under uv or visible light. The Journal of Physical Chemistry B, v. 109, n. 23, p. 11667-11674, 2005.

56 ZHAO, D.; CHEN, C.; WANG, Y.; JI, H.; MA, W.; ZANG, L.; ZHAO, J. Surface modification of $\mathrm{TiO}_{2}$ by phosphate: effect on photocatalytic activity and mechanism implication. The Journal of Physical Chemistry C, v. 112, n. 15, p. 5993-6001, 2008.

57 CHANG, M.Y.; HSIEH, Y.H.; CHENG, T.C.; YAO, K.S.; WEI, M.C.; CHANG, C.Y. Photocatalytic degradation of 2,4-dichlorophenol wastewater using porphyrin/ $/ \mathrm{TiO}_{2}$ complexes activated by visible light. Thin Solid Films,v. 517, n. 14, p. 3888-3891, 2009.

58 YU, J.; DAI, G.; CHENG, B. Effect of crystallization methods on morphology and photocatalytic activity of anodized $\mathrm{TiO}_{2}$ nanotube array films. The Journal of Physical Chemistry C, v. 114, n. 45, p. 19378-19385, 2010.

59 CHANG, M.Y.; CHANG, C.Y.; HSIEH, Y.H.; YAO, K.S.; CHENG, T.C.; HO, C.T. Photocatalytic degradation of methylene blue using porphyrin/ $/ \mathrm{TiO}_{2}$ complexes activated by visible light. Advanced Materials Research, v. 47-50, p. 471-474, 2008. 